\title{
WestVirginiaUniversity
}

THE RESEARCH REPOSITORY @ WVU

Graduate Theses, Dissertations, and Problem Reports

2006

\section{Selection of pilot buses for VAR support and voltage stability risk analysis}

\author{
Talpasai Lakkaraju \\ West Virginia University
}

Follow this and additional works at: https://researchrepository.wvu.edu/etd

\section{Recommended Citation}

Lakkaraju, Talpasai, "Selection of pilot buses for VAR support and voltage stability risk analysis" (2006). Graduate Theses, Dissertations, and Problem Reports. 1776.

https://researchrepository.wvu.edu/etd/1776

This Thesis is protected by copyright and/or related rights. It has been brought to you by the The Research Repository @ WVU with permission from the rights-holder(s). You are free to use this Thesis in any way that is permitted by the copyright and related rights legislation that applies to your use. For other uses you must obtain permission from the rights-holder(s) directly, unless additional rights are indicated by a Creative Commons license in the record and/ or on the work itself. This Thesis has been accepted for inclusion in WVU Graduate Theses, Dissertations, and Problem Reports collection by an authorized administrator of The Research Repository @ WVU. For more information, please contact researchrepository@mail.wvu.edu. 


\title{
Selection of Pilot Buses for VAR Support and Voltage Stability Risk Analysis
}

\author{
by \\ Talpasai Lakkaraju \\ Thesis submitted to the \\ College of Engineering and Mineral Resources \\ at West Virginia University \\ in partial fulfillment of the requirements \\ for the degree of \\ Master of Science \\ in
}

Electrical Engineering

Professor Muhammad Akram Choudhry, Ph.D.

Professor Karl Schoder, Ph.D.

Professor Ali Feliachi, Ph.D., Chair

Lane Department of Computer Science and Electrical Engineering

Morgantown, West Virginia
2006

Keywords: Voltage stability, Loading margin, Pilot bus, VAR support, SVC location, Risk analysis, Security cost, Voltage collapse 


\author{
Abstract \\ Selection of Pilot Buses for VAR Support \\ and \\ Voltage Stability Risk Analysis \\ by \\ Talpasai Lakkaraju \\ Master of Science in Electrical Engineering \\ West Virginia University \\ Professor Ali Feliachi, Ph.D., Chair
}

The primary objective of this thesis is to develop an index for the placement of reactive power support devices to ensure reliable operation of power systems. It is especially aimed at improving the load voltage profile and system security when loading is increased. Maintaining a good system voltage profile and security is an important aspect in voltage stability studies, especially with the ever increasing power consumption and system disturbances or contingencies. A new VAR support placement algorithm is developed using a standard continuation power flow and N-1 contingency criterion to pinpoint the best locations for the placement of VAR devices. The objective formulation takes into account the worst case voltage deviations at all load buses and at the same time maximizes the loading margin under different contingencies and loading levels. The algorithm has been tested on three standard benchmark test systems and demonstrates that the proposed algorithm improves considerably when compared to an existing method, for locating a suitable site for VAR support.

The secondary objective of this research focuses on the important aspect of estimating and quantifying the voltage collapse risk with and without the VAR support. It is motivated by the perception that VAR support guarantees additional security for the current system and is economically justifiable. A decision tree based model is designed for estimating the risk, which accounts for both the future system uncertainties and the consequences associated with violation of limits and voltage collapse. A case study on the standard IEEE 24 bus reliability test system investigates the different scenarios and evaluates the risk. The results prove that in spite of high installation costs, an SVC can make the system more reliable and ensure cost savings. 


\title{
Dedicated To
}

\author{
My Eternal Grandfather, \\ His Divine Grace A.C. Bhaktivedanta Swami Srila Prabhupada \\ and
}

All the Great Devotees of Lord Sri Gauranga Mahaprabhu, who are compared to sharks in the great ocean of love of God and who do not care for the various rivers of liberation. 


\section{Acknowledgement}

First of all, I would like to thank the Transcendental Lord Sri Krsna who is beyond mundane sense perception, for giving me strength and intelligence to complete this work. I would like to thank and extend my sincere gratitude to my advisor Dr. Ali Feliachi for his constant support, guidance throughout this work. I would also like to thank Dr. Karl Schoder for his immense support, suggestions and the time he spent in correcting this document to make it presentable.

I am also thankful to my committee member Dr. Muhammad Choudhry for his support throughout my graduate education. I would also like to thank Dr. John Saymansky for his constant support, time and invaluable suggestions and feedback.

My family, though not present here, have always been my source for inspiration. I am greatful to my father, mother, and brother for encouraging and supporting me all the time. I am greatful to all the my morgantown and moundsville friends and APERC lab colleagues who encouraged me and helped me complete my thesis. 


\section{Contents}

$\begin{array}{ll}\text { Abstract } & \text { ii }\end{array}$

Acknowledgement iv

List of Figures $\quad$ viii

List of Tables $\quad$ x

Notation and Acronyms xii

1 Introduction $\quad 1$

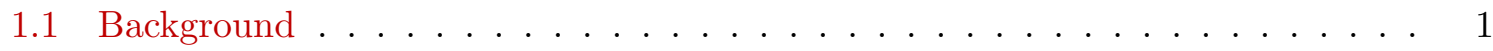

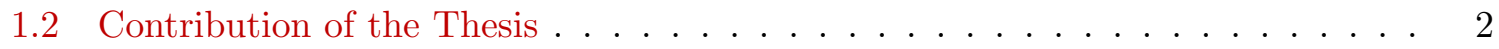

1.3 Outline of the Thesis . . . . . . . . . . . . . . . 3

2 Literature Survey $\quad 4$

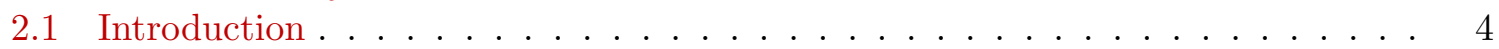

2.2 Review of Basics of Voltage Stability . . . . . . . . . . . . . . . 5

2.2.1 Bifurcations in Power Systems . . . . . . . . . . . . . 5

2.3 Voltage and Reactive Power Control . . . . . . . . . . . . . . . . 7

2.3.1 Voltage Control and Pilot Bus Determination Techniques . . . . . . . 7

2.3.2 Location of VAR support Devices and Pilot Bus Control . . . . . . . . . 9

2.4 Risk Analysis of Voltage Collapse . . . . . . . . . . . . . . . . . . . . . 10

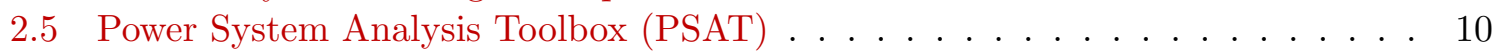

2.5.1 Models and Routines in PSAT . . . . . . . . . . . . . . 11

2.6 Palisade Decision Tools for Risk Analysis . . . . . . . . . . . . . . 13

3 Voltage Stability Indices $\quad 14$

3.1 Introduction . . . . . . . . . . . . . . . . . . . . . . 14

3.2 Singular Values and Eigenvalues . . . . . . . . . . . . . . 15

3.2 .1 Minimum Singular Value . . . . . . . . . . . . . . . 15

3.2 .2 Eigenvalues . . . . . . . . . . . . . . . . . . 17

3.3 Loading Margin . . . . . . . . . . . . . . . . . . . . . . . . . . . . . . . . . . . . . . .

3.3 .1 Direct Method . . . . . . . . . . . . . . . . . . 19

3.3 .2 Continuation Method . . . . . . . . . . . . . 20

3.4 Sensitivity Factors . . . . . . . . . . . . . . . . . . . . 24 
3.5 Other Indices . . . . . . . . . . . . . . . . . . . . 25

3.5.1 Test Functions . . . . . . . . . . . . . . . . 25

3.5 .2 Tangent Vector Index $(\mathrm{TVI}) \quad \ldots \ldots \ldots \ldots$

4 Pilot Bus Selection $\quad 29$

4.1 Introduction . . . . . . . . . . . . . . . . . . . . . . . 29

4.2 System Model . . . . . . . . . . . . . . . . . . . . . . . . . 29

4.3 Pilot Bus Selection Procedure . . . . . . . . . . . . . . . . 30

5 Risk Analysis of Voltage Collapse $\quad \mathbf{3 5}$

5.1 Introduction to Risk Analysis . . . . . . . . . . . . . . . . . . . 35

5.2 Risk Analysis and Voltage Stability . . . . . . . . . . . . . 37

5.3 Evaluation of Voltage Stability Risk . . . . . . . . . . . . . . . 39

5.3.1 Evaluating the Probability of Voltage Collapse . . . . . . . . . . . . . 39

5.3 .2 Decision Tree Model . . . . . . . . . . . . . . . . . . . . . . . 41

5.4 SVC Investment Costs . . . . . . . . . . . . . . . . . . . 45

5.4.1 Equipment Costs and Infrastructure Costs . . . . . . . . . . . 46

6 Case Studies and Discussion $\quad 49$

6.1 PART I : Evaluation of Critical Buses For VAR Support ～. . . . . . . . . . 49

6.1 Test Systems Description _. . . . . . . . . . . . . 49

6.1.2 Results and Discussion . . . . . . . . . . . . . . . . 50

6.2 PART II : Voltage Stability Risk Analysis . . . . . . . . . . . . . . . . 62

6.2 .1 Without SVC . . . . . . . . . . . . . . . . . 64

6.2 .2 With SVC . . . . . . . . . . . . . . . . 65

7 Conclusion and Future Work $\quad 72$

7.1 Conclusion . . . . . . . . . . . . . . . . . . . 72

7.2 Future Work . . . . . . . . . . . . . . . . . 73

$\begin{array}{ll}\text { APPENDIX } & \mathbf{7 4}\end{array}$

$\begin{array}{lll}\text { A APPENDIX A } & \mathbf{7 4}\end{array}$

A.1 Test System Data . . . . . . . . . . . . . . . . . . . . . 74

A.1.1 PSAT Data Format . . . . . . . . . . . . . . . 74

A.1.2 WSCC 3-Machine 9 Bus System . . . . . . . . . . . . . 78

A.1.3 IEEE 14 Bus System . . . . . . . . . . . . . . . . . . . . . . . . . . . . . . . . . . . . .

A.1.4 IEEE 30 Bus System . . . . . . . . . . . . . . . . . . 80

A.1.5 IEEE 24 Bus Reliability Test System . . . . . . . . . . . . 83

$\begin{array}{llr}\text { B } & \text { APPENDIX B } & \mathbf{8 8}\end{array}$

B.1 Locational Marginal Prices . . . . . . . . . . . . . . . . 88

B.2 Hourly Peak Load in Percent of Daily Peak . . . . . . . . . . . . . . . . . 89

$\begin{array}{ll}\text { References } & 90\end{array}$ 


\section{List of Figures}

2.1 Traditional P-V Curve . . . . . . . . . . . . . . . . . . . . 6

3.1 One Step of the Continuation method . . . . . . . . . . . . . . . . 21

3.2 Predictor and Corrector Steps in Continuation power flow . . . . . . . . . . . . 24

4.1 Flow Chart for determining pilot buses using CPF and N-1 Contingency Analysis 31

5.1 LBNL (Lawrence Berkeley National Laboratory) estimate of power interruptions according to customer class $[28] \ldots \ldots \ldots \ldots$

5.2 Decision Tree Model for Risk Analysis . . . . . . . . . . . . . . . . . . . . 42

5.3 SVC Investment costs . . . . . . . . . . . . . . . . . . . 46

5.4 Typical Investemnt Costs for SVC / STATCOM [24] . . . . . . . . . . . . . 47

6.1 Western System Coordinating Council (WSCC) 3-Machines 9-Bus system . . . 50

6.2 Loading Margin Vs SVC Capacity for 3-Machines 9-Bus system . . . . . . . . . 51

6.3 Nose curves at Bus \#7 with and without SVC for 3-machine 9-bus system . . 52

6.4 Nose curves without SVC for 3-machine 9 bus system . . . . . . . . . . . 53

6.5 Nose curves with SVC at Bus \#9, for 3-machine 9 bus system . . . . . . . . . 53

6.6 Single line diagram of the IEEE 14 Bus System [42] . . . . . . . . . . . . . . 54

6.7 Nose curves with SVC at Bus \#14 (Modal analysis) . . . . . . . . . . . . . 56

6.8 Nose curves with SVC at Bus \#4 (Proposed approach . . . . . . . . . . . . 56

6.9 Nose curves at Bus \#14 for different contingencies without SVC . . . . . . . . 57

6.10 Nose curves at Bus \#14 for different contingencies with SVC at Bus \#4 . . . . 57

6.11 Comparision of voltages for two SVC locations at critical loading condition of system with SVC at bus \#14 . . . . . . . . . . . . . . . 58

6.12 Nose curve at Bus \#14 with Capacitor bank and SVC . . . . . . . . . . . . . 59

6.13 Single line diagram of the IEEE 30 Bus Test System [42] . . . . . . . . . . . 60

6.14 Plot of Maximum Loadability vs Number of SVCs . . . . . . . . . . . . . . 61

6.15 IEEE Single Area 24 Bus Reliability Test System - 96 [42] . . . . . . . . . . . 63

6.16 Probability of Voltage Collapse without SVC . . . . . . . . . . . . 66

6.17 Determining the Rating of SVC at Bus\# 9 for IEEE 24 bus Reliability Test System . . . . . . . . . . . . . . . . 66

6.18 Comparison of Probability of Collapse with and without SVC for IEEE 24 bus Reliability Test System . . . . . . . . . . . . . . . . . 67

6.19 Impact of voltage collapse with and without SVC for IEEE 24 bus RTS. . . . . 69 6.20 Impact of No voltage collapse with and without SVC for IEEE 24 bus RTS. . . 70 
6.21 Value at Risk with and without SVC . . . . . . . . . . . . . . 71 


\section{List of Tables}

2.1 Comparison of MATLAB-based packages for power system analysis [38] . . . 11

3.1 Comparison of Indices $[7] \ldots \ldots \ldots \ldots \ldots$

5.1 Table of major bulk power system outages (NERC, [41] ) . . . . . . . . 37

6.1 Critical buses ranking for 3-machine 9-bus system using proposed technique . . 51

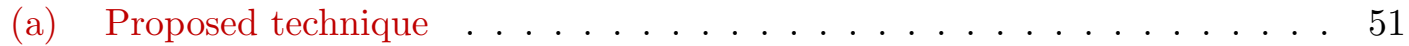

(b) Modal Analysis . . . . . . . . . . . . . . . . . . 51

6.2 Critical buses ranking for VAR support for IEEE 14 bus system . . . . . . . . . 55

6.3 Comparison of Loading Margins with SVC at Bus \#14 and Bus \#4 for different

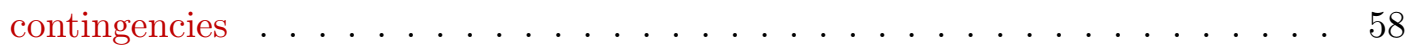

6.4 Ranking of buses for VAR support for IEEE 30 bus system using proposed and modal analysis . . . . . . . . . . . . . . . . . 6 61

6.5 Comparison of SVC Vs Maximum Loadability for Proposed approach and Modal Analysis . . . . . . . . . . . . . . . . . . . 62

6.6 Critical Contingencies for IEEE 24 bus system . . . . . . . . . . . . . 63

6.7 Loadability under various contingency conditions with their respective occurrence probabilities . . . . . . . . . . . . . . . . 64

6.8 Expected Load and standard deviation . . . . . . . . . . . . . . . 65

6.9 Loading Margin Randomness and Probability of Collapse Given a Contingency 65

6.10 Loadability under various contingency conditions . . . . . . . . . . . . 67

6.11 Loading Margin Randomness and Probability of Collapse with SVC . . . . . . 68

6.12 Value at risk with and without SVC . . . . . . . . . . . . . 69

6.13 Value at Risk with and without SVC with no decrease in Security Costs . . . . 70

A.1 Bus Data Format (Bus.con) . . . . . . . . . . . . . . . 74

A.2 PQ Data Format (PQ.con) . . . . . . . . . . . . . . 75

A.3 PV Data Format (PV.con) . . . . . . . . . . . . . . 75

A.4 Shunt Data Format (Shunt.con) . . . . . . . . . . . . . 75

A.5 SW Data Format (SW.con) . . . . . . . . . . . . . 76

A.6 Line Data Format (Line.con) . . . . . . . . . . . . . . . 76

A.7 Demand Data Format (Demand.con) . . . . . . . . . . . . . . 77

A.8 Supply Data Format (Supply.con) . . . . . . . . . . . . . 77

B.1 LMPs with and without SVC for IEEE 24 Bus System (Load level : 3870 MW) 88 
B.2 Hourly Peak Load in Percent of Daily Peak $([43]) \ldots . . . . . . .89$ 


\section{Notation and Acronyms}

Notation

\section{Acronyms}

$\begin{aligned} \text { AEP } & \text { American Electric Power } \\ \text { CPF } & \text { Continuation Power Flow } \\ \text { FACTS } & \text { Flexible Alternating Current Transmission Systems } \\ \text { LBNL } & \text { Lawrence Berkeley National Laboratory } \\ \text { LM } & \text { Loading Margin } \\ \text { NERC } & \text { North American Electric Reliability Council } \\ \text { PF } & \text { Power Flow } \\ \text { PSAT } & \text { Power Systems Analysis Toolbox } \\ \text { RTS } & \text { Reliability Test System } \\ \text { STATCOM } & \text { STATic synchronous COMpensator } \\ \text { SVC } & \text { Static Var Compensator } \\ \text { SVD } & \text { Singular Value Decomposition } \\ \text { TVI } & \text { Tangent Vector Index } \\ \text { VS } & \text { Voltage Stability } \\ \text { WSCC } & \text { Western System Coordinating Council (now WECC) } \\ \text { WECC } & \text { Western Electricity Coordinating Council }\end{aligned}$




\section{CHAPter}

\section{1}

\section{Introduction}

\section{$1.1 \quad$ Background}

In the power system operation and planning, voltage stability is one of the main issues, because it essentially deals with system reliability and security. In the current open access environment, because of the uncertain system conditions, the power transfer often results in high degree of vulnerability with respect to voltage stability. In the literature [1], there has been considerable degree of research in this area and to develop various tools and indices in order to perform the security assessment required for the safe operation of power systems. There has also been a vast literature concerning the problems due to voltage stabilities, and the need for effective actions for the secure operation of overall power systems.

According to IEEE definition Voltage stability refers to the ability of a power system to maintain steady voltages at all buses in the system after being subjected to a disturbance from a given initial operating conditions

Because of constant change in power demand, stress and contingencies, the problem of voltage stability has in the past often resulted in most severe blackouts and with the demand for the load ever increasing, the future aiming at a reliable power system, remains a great 
challenge for the planning personnel, and researchers. In the initial stages of the voltage stability problem, the system voltage decreases gradually but in later stages the decrease is rapid and results in complete or partial blackout. The following factors [35] can be cited as few among the several factors leading to such problems :

- Stressed power system scenario (high active and reactive power loading in the system)

- Inadequate reactive power resources

- Load characteristics at low voltage magnitudes

- Tap changers response to the voltage magnitude decrease at the load buses

- Unexpected or unwanted relay operations

Apart from these there are some other factors like reactive limits on generators and outages which directly or indirectly influence the system and result in voltage instability. To overcome these effects of instability, in the past there has been research to effectively control the voltage using pilot buses and provide additional reactive power support. The suitable location for reactive power support is a key area of research, also its an important study both in terms of improving system performance and its economic relevance in modern power systems.

\subsection{Contribution of the Thesis}

The objective of the research is to develop an index for the placement of the reactive power support devices, so as to improve the voltage level and the security of the power system. In this work, a new approach is proposed for identifying these buses, which are termed as pilot buses or critical load buses or weak buses, so that the voltage stability of the system is improved alongside added security. To implement the same a continuation power flow based N-1 contingency analysis is performed, to evaluate the proposed objective for different contingencies and loading levels.

This research also focuses on probabilistic voltage collapse risk analysis, the objective of which is to evaluate the risk of voltage collapse by assessing the potential of an Static Var Compensator installation at the pilot bus locations and to determine if there use is economically justified. This analysis takes into consideration the future uncertainties in and consequences associated with voltage collapse and violation of limits. Different scenarios including risk plots and results are presented in detail to discuss the above mentioned objectives. 


\subsection{Outline of the Thesis}

This section gives an outline of the remaining chapters presented in this thesis:

In chapter 2, literature review is presented. A brief description of pilot bus determination techniques and related techniques for location of FACTS devices or reactive power support is discussed. Also, risk analysis and its applications to voltage stability is reviewed.

In chapter 3, important voltage stability indices, which are currently used in practice, are discussed in detail. Each index and its advantage and disadvantage are discussed. Also, the advantage of loading margin as voltage stability index is discussed. Finally, a table of comparison of indices is presented.

In chapter 4, the approach for selection of pilot buses using the proposed technique is mentioned. Also a brief description of system model and loading margin is discussed. Finally, a brief description of Power System Analysis Toolbox (PSAT) is presented.

In chapter 5, a brief introduction to risk analysis and its approach to voltage collapse with and without SVC is discussed. A decision tree based model is implemented to evaluate the risk. Also a model for SVC cost is discussed.

In chapter 6 , the results of the proposed implementation of pilot bus selection and risk analysis are presented.

In chapter 7, summary of the work done in this thesis is given (Section 7.1) and the possible directions for future work discussed. 


\section{CHAPter}

2

\section{Literature Survey}

\section{$2.1 \quad$ Introduction}

In view of the worldwide restructuring of the electricity industry, it is becoming very essential for the power systems to operate securely, under different operating conditions and especially, during contingencies. Voltage stability is one of the important phenomenons and in view of voltage collapses in recent past, lot of work has been especially devoted to it. Voltage stability is mainly concerned with maintaining acceptable voltage profile under all operating conditions. In this chapter a brief outline on the problem of maintaining this voltage profile and some previous work in this area is discussed. The main objective of all the work is to find the critical buses or pilot buses, which when maintained at constant voltage ensure acceptable voltage levels at all the buses in the network. The evaluation of critical or pilot buses give us an insight for the location of reactive power support or VAR support devices in the power system. 


\subsection{Review of Basics of Voltage Stability}

The power transfer between the generation and load centers is accompanied by voltage drops through the transmission network. These voltage drops are in the order of few percent during normal operating conditions, but under heavy loaded or stressed conditions, there might be a substantial change in the voltage drop which would affect the quality and reliability of the power supply. The important challenge for power system planners and operators is to maintain the voltage always within acceptable levels.

\subsubsection{Bifurcations in Power Systems}

" The qualitative structure of the flow can change as parameters are varied. In particular, fixed points can be created or destroyed, or their stability can change. These qualitative changes in the dynamics are called bifurcations, and the parameter values at which they occur are called bifurcation points [50]".

In static voltage stability the slow changes in the power system eventually lead the system into instability situations with declining voltage and shortage of reactive power. This can be observed from the P-V curve analysis shown in Fig. 2.1, wherein it shows the variation of load voltage magnitude with the loading p. As seen from the Fig. 2.1, for low loading values there are two equilibrium points or solutions, one with high voltage and one with low voltage. The high voltage solution has low current and low voltage solution has high current. Now, as the loading slowly increases, these two equilibrium points approach each other and coalesce at the critical point $\mathrm{p}^{*}$. Any loading past $\mathrm{p}^{*}$ has no equilibrium solution. This nose point or bifurcation point corresponds to the maximum limit beyond which the system collapses because of lack of enough reactive support to maintain the voltage profile. This is a typical example of a saddle-node bifurcation in which fixed points are created and destroyed. As the loading parameter is varied, two fixed points move toward each other, collide, and mutually annihilate [50].

With the increase of voltage collapse situations, voltage stability is being recognized as one of the major challenge for system operation. Also with deregulation in practice, and with open transmission line policy, utilities are encouraged to operate transmission lines to their limits foreseeing economic incentive. 


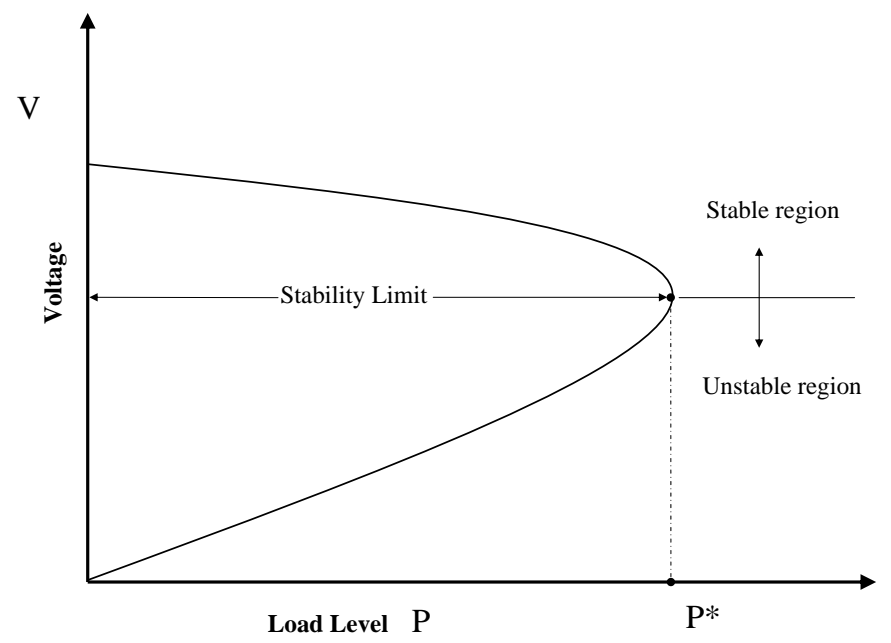

Figure 2.1: Traditional $P-V$ Curve

In view of regular voltage collapse incidents, there has been a significant research effort by power community to discuss the problem in detail. This section provides a brief outline and few references on this topic, keeping in mind the vast literature published [1] in the past.

Voltage stability is defined as [30] " the ability of power system to maintain acceptable voltage at all buses in the system after being subjected to a disturbance from a given initial operating condition ". Though initially voltage instability is a local phenomenon, its consequences are wide spread. Voltage collapse is the situation which arises when a sequences of events accompanied by voltage instability result in the total or partial breakdown of power system. It is the process by which the sequence of events accompanying voltage instability leads to a blackout or abnormally low voltages in a significant part of the power system [29], [52]. In [57], the phenomenon of voltage instability including the past references on this topic has been thoroughly discussed.

A complete detail study of voltage collapse and indices has been reported in the IEEE voltage stability report [7] which discusses the ongoing research in this field worldwide. Voltage stability is inherently a dynamic problem. But, since time domain simulations are time consuming and also they do not readily provide the sensitivity information or the degree of stability [37]. For these reasons generally for bulk system studies the static analysis is preferred in order to provide more insight into the voltage and reactive power problem. 


\subsection{Voltage and Reactive Power Control}

Voltage control in a power system requires sufficient reactive power sources. Most of the voltage instability and collapse situations occur due to lack of enough reactive resources in the power system. With the ever increasing loading levels, and lack of enough resources to compensate the loading, power system is increasingly getting stressed. This results in instability problems and also violation of voltage limits, which is a concerning issue in the current deregulated scenario. One way to mitigate this problem is to reduce the load which is not always feasible, or add additional reactive support using capacitors or utilizing the dynamic nature of reactive support FACTS devices like SVC, STATCOM, etc.

The technique commonly displayed is to place an additional reactive power support at the critical bus of the system. There are few definitions described in the literature to define pilot buses and weak buses.

- According to Electricité de France and P. Lagonotte et al. [32]: Pilot bus is a bus chosen in a zone, such that its voltage variation may represent the voltage evolutions throughout the zone.

- According to A. Conejo et al. [17]: Secondary voltage control keeps voltage magnitude of certain load buses, known as pilot buses at their reference values by coordinated generator control actions, so that the voltage profile is achieved throughout the transmission network.

- According to P. Kundur et al. [21] in their Modal analysis: Weak or Critical buses are buses which contribute more to the voltage collapse based on participation factors evaluated from reduced Jacobian using modal analysis.

- In this work, pilot bus or weak bus is defined as the bus which, when supported, improves voltage profile at all the buses and also ensures additional security to the system, in terms of increased loading margin.

\subsubsection{Voltage Control and Pilot Bus Determination Techniques}

The problem of large-scale voltage control [32] can be divided or organized into the three hierarchical levels as described below 
- Primary voltage control.

- Secondary voltage control.

- Tertiary voltage control.

At the primary level the control devices aim to control the rapid and random voltage variations by maintaining the voltage at reference values. The secondary control level generally deals with slow and large voltage deviations such as hourly load changes. Through the secondary voltage control it is possible to keep a proper voltage profile throughout the transmission network [23], [17], [18], by determining the control actions necessary to maintain the reference voltage values at certain buses denominated as pilot buses.

This problem of secondary voltage control, which mainly deals with controlling voltage magnitudes and reactive power flows in the network, is a multi objective optimization problem. The secondary voltage control scheme is currently in practice in France [32] and other European countries [45].

The objective of tertiary control level is to achieve the secure and economic operation of the power system. This is large scale optimization problem such as an optimal power flow problem and is related to the coordination of the whole network for secure operation.

The pilot bus selection is a complex, large scale, non-linear problem [18]. In [49] the authors proposed a time consuming and complex approach for selecting the pilot buses called "simulated annealing", which is used to control the voltage deviations at the load buses. In [32] the concept of electrical distance is used to divide the network into areas, and to find the pilot bus in each control area. But the major drawback in this approach is it does not consider different operating conditions regarding different loading levels.

Approaches in [17] and [45] describe a more elaborate approach for selection of pilot buses considering different operating condition and different topologies. But the drawback of the approaches is its linearization of the load flow equations. It is important that the pilot bus selection aspect and the necessary control be valid under all conditions especially in deregulated scenario where the system is operated close to the transmission capacity limit. In such conditions, the linearized model approach may not be optimal.

In [19],[18], various heuristic approaches and a Greedy search technique for nonlinear selection of pilot buses is implemented by solving an extended load flow problem designating few 
buses as pilot buses (PQV) and few other buses as generator buses (P) controlling the voltage magnitude at the pilot buses. Though the approach improves on the previous approaches, it does not consider different contingency conditions except for load level increase. Also the index proposed is the square of the average value of voltage magnitude deviations, which may be not be the accurate index in determining the pilot bus sensitivity.

\subsubsection{Location of VAR support Devices and Pilot Bus Control}

There has also been significant research in the past to find the locations for placing FACTS devices or capacitors for reactive power support. In [21], [37], [62] the authors presents modal analysis using eigenvalues of the reduced Jacobian and participation factors to locate the weak buses of the system. But the disadvantage of this approach is that it fails to predict accurately these buses under different contingency cases and does not consider the complete nonlinear system.

Different voltage stability indices have been proposed in the past [7], [1], which are useful tools in the problem of critical bus evaluation. Eigenvalues, approximately give us the information about the proximity of system to voltage collapse, and eigenvalue information has been used in [37] to evaluate participation factors and subsequently weak buses. Also, the eigenvalues or singular values are not good indicators at predicting voltage collapse point because of their high non-linear behavior near the collapse point as discussed in [9].

In [4] the authors use tangent vector index, readily available from continuation power flow solution to find possible locations of critical buses for reactive power support. As discussed in [9], this index might not useful in predicting the critical bus because the behavior of the index changes when reactive limits and other limits are considered, though it exhibits a linear behavior in the case of without limits.

In [16], [62] the authors use singular values and corresponding vectors and also present an index called "Voltage Collapse Proximity index", for critical bus identification using simulated annealing technique for placement of reactive power sources, which is a very laborious and time consuming and selects too many buses for reactive support which might not be ideal when FACTS devices are to be used. Also, it considers linearized power flow equations to evaluate the index, which might not be an ideal approach considering the nonlinear nature of the system. In [27], [53], a voltage stability index is defined to evaluate the critical buses of the 
system, but the index does not give information regarding the system margin to bifurcation and does not consider the contingency situations or reactive power limits.

In this work voltage stability problem is considered more as reactive power problem than a voltage control scheme, and an approach is developed to find the optimal location for the placement of reactive power support device. This approach considers N-1 contingency criterion with generator reactive limits and different loading conditions with loading margin determined from continuation power flow solution [2].

\subsection{Risk Analysis of Voltage Collapse}

This thesis also investigates on a new approach to risk analysis of voltage collapse, which is performed to evaluate and assess the effectiveness of installing a Static Var Compensator (SVC) in the system. This approach is based on decision tree analysis [55], wherein the two possibilities of the system response to uncertainty are discussed, one which results in voltage collapse and other in no collapse but possible limit violation, resulting in additional security costs. The analysis is carried on with and without reactive power support device to address the economic feasibility or effectiveness of having it installed in the system. In this work, an SVC has been chosen as the reactive support device, though capacitors and other sources can be used as reactive power support devices. The main idea is to investigate the risk at value with and without the device.

The two types of uncertainties discussed are contingency and load forecast uncertainty as discussed in [26]. Loading margin is used as an index to evaluate the respective probabilities of collapse for each outage or contingency. A continuation power flow technique is employed to evaluate the maximum value of the loading parameter. Also a risk analysis tool " @ Risk" developed by Palisade corporation Palisade Decision tools is used to perform this analysis.

\subsection{Power System Analysis Toolbox (PSAT)}

The power system analysis toolbox (PSAT) [38] is a MATLAB based toolbox for static and dynamic analysis of electric power systems. PSAT includes power flow, continuation power flow, optimal power flow, small signal stability analysis and time domain simulation. All functions can be accessed by means of graphical user interfaces (GUIs) and a Simulink-based 


\begin{tabular}{c|c|c|c|c|c|c}
\hline Package & PF & CPF & OPF & SSSA & TDS & GUI \\
\hline \hline EST [59] & $\sqrt{ }$ & & & $\sqrt{ }$ & $\sqrt{ }$ & \\
\hline MatEMTP [36] & & & & & $\sqrt{ }$ & $\sqrt{ }$ \\
\hline Matpower [63] & $\sqrt{ }$ & & $\sqrt{ }$ & & & \\
\hline PAT [48] & $\sqrt{ }$ & & $\sqrt{ }$ & $\sqrt{ }$ & $\sqrt{ }$ & \\
\hline PSAT [38] & $\sqrt{ }$ & $\sqrt{ }$ & $\sqrt{ }$ & $\sqrt{ }$ & $\sqrt{ }$ & $\sqrt{ }$ \\
\hline PST [14] & $\sqrt{ }$ & & & $\sqrt{ }$ & $\sqrt{ }$ & \\
\hline SPS [51] & $\sqrt{ }$ & & & $\sqrt{ }$ & $\sqrt{ }$ & $\sqrt{ }$ \\
\hline VST [15] & $\sqrt{ }$ & $\sqrt{ }$ & & $\sqrt{ }$ & $\sqrt{ }$ & $\sqrt{ }$ \\
\hline
\end{tabular}

Table 2.1: Comparison of MATLAB-based packages for power system analysis [38]

library which provides an user friendly tool for network design.

Table (2.1) depicts a brief comparison of the existing MATLAB-based packages for power system analysis. The features illustrated in the table are power flow $(\mathrm{PF})$, continuation power flow (CPF), optimal power flow (OPF), small signal stability analysis (SSSA), time domain simulation (TDS) along with features such as graphical user interface (GUI).

\subsubsection{Models and Routines in PSAT}

\section{A. Power System Model}

The power system model is based on non-linear differential algebraic equations and can be represented by:

$$
\begin{aligned}
\dot{z} & =f(z, y, p) \\
0 & =g(z, y, p)
\end{aligned}
$$

where $z$ represents the state variables, $y$ represents the algebraic variables and p represents independent variables. Vector function $f$ represents the differential equations and $g$ represents the algebraic equations.

PSAT used model in equation (2.1) for all the algorithms like power flow, continuation power flow, optimal power flow, time domain simulation and small signal stability studies. In this section only power flow and continuation power flow are discussed, for more routines of PSAT one can refer to [38]. 


\section{B. Power Flow}

PSAT power flow includes the standard Newton-Raphson method, fast decoupled power flow, and a power flow with both single slack bus and distributed slack bus models. The power flow problem is formulated as follows based on equation (2.1).

$$
\begin{aligned}
& f(z, y, p)=0 \\
& g(z, y, p)=0
\end{aligned}
$$

The distributed slack bus model is based on a generalized power center concept and consists in distributing losses among all the chosen generators as slack buses. This is obtained by rewriting active powers $P_{G}$ of slack and $\mathrm{PV}$ generators as

$$
P_{G}=\left(1+k_{G} \gamma\right) P_{G 0}
$$

where $P_{G 0}$ are the desired generator active powers, $k_{G}$ is the scalar variable which distributed the losses among the generators and $\gamma$ represents the participation factors of generator to distribute the losses.

\section{Continuation Power Flow}

The CPF algorithm consists in a predictor step which computes a normalized tangent vector and a corrector step that can be obtained either by means of a local parametrization or a perpendicular intersection. A more detail step by step process of continuation power flow will be discussed in Chapter 3. The Continuation power flow problem is defined as follows based on equation (2.1)

$$
\begin{aligned}
& f(z, y, p)=0 \\
& g(z, y, p)=0
\end{aligned}
$$

where $\lambda \in \Re$ is the loading parameter, which is used to vary the base case generator and load powers, $P_{G 0}, P_{L 0}$, and $Q_{L 0}$ as follows:

$$
\begin{aligned}
P_{G} & =P_{G 0}+\left(\lambda+\gamma k_{G}\right) P_{G D} \\
P_{D} & =P_{D 0}+\lambda P_{L D} \\
Q_{D} & =Q_{D 0}+\lambda Q_{L D}
\end{aligned}
$$


where $P_{G D}, P_{L D}$ and $Q_{L D}$, represent generator and load power directions. If these data are undefined, then the base case powers are used as the load power directions i.e.,.

$$
\begin{aligned}
P_{G} & =\left(\lambda+\gamma k_{G}\right) P_{G 0} \\
P_{D} & =\lambda P_{D 0} \\
Q_{D} & =\lambda Q_{D 0}
\end{aligned}
$$

where $k_{G}$ represents distribution slack bus variable, and $\gamma$ represents generation participation coefficients.

\subsection{Palisade Decision Tools for Risk Analysis}

In this study the MS Excel based software @RISK developed by Palisade Decision Tools [44] has been used to compute the required distributions and probabilities. @RISK is a industry standard software for risk analysis and is useful in decision making subject to uncertainty. @RISK extends the analytical capabilities of Microsoft Excel to include risk analysis and simulation. @RISK uses Monte Carlo simulation for risk analysis. With this technique, uncertain input values in a spreadsheet are specified with probability distributions. A more detail information regarding the package and all the funtions can be obtained at [44]. 


\section{Chapter}

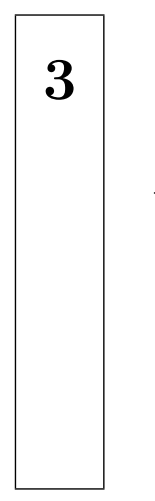

\section{Voltage Stability Indices}

A considerable amount of research has been undertaken [7] to determine indices for detecting the proximity of voltage collapse of power systems. This chapter discusses some of the indices, their advantages, disadvantages, and finally presents them in a tabular format for ease of comparison [7].

\subsection{Introduction}

Performance indices to predict voltage collapse proximity are very useful, as these indices can be effectively used to carry out off-line or on-line studies to evaluate how close the system is to instability. The next step after evaluating the indices is to search for ideal location for remedial control and VAR devices [54]. Ultimately, this effort will yield an improved system that can sustain potential damage due to different contingencies and loading conditions.

In this discussion of voltage stability indices, the standard power flow model is used, where the variations of active and reactive powers are assumed to be the the main parameters that drive the system to the bifurcation or singularity. The typical power flow vector nonlinear equation defining active and reactive power mismatches can be expressed as follows [7], [38]. 


$$
\left[\begin{array}{l}
\Delta P(x, \lambda) \\
\Delta Q(x, \lambda)
\end{array}\right]=f(x, \lambda)=0
$$

where $x$ is a state vector of power flow problem and typically represents $\mathrm{V}$ and $\delta$, i.e., the bus voltages and angles and can also be used to compute other system variables like generator reactive power injections $\mathrm{Q}$.

The variable $\lambda$ represents a scalar parameter or loading factor used to simulate the load changes that drive the system to the collapse point.

$$
\begin{aligned}
P_{D} & =\lambda P_{D 0} \\
Q_{D} & =\lambda Q_{D 0} \\
P_{G} & =\left(\lambda+\gamma k_{G}\right) P_{G 0}
\end{aligned}
$$

In this case the parameter $\lambda$ represents the net MVA change in the total system load. The variables $P_{D 0}, Q_{D 0}$, and $P_{G 0}$ represent the base case powers.

\subsection{Singular Values and Eigenvalues}

In this section two performance indices based on singular values and eigenvalues for voltage collapse proximity are discussed.

\subsubsection{Minimum Singular Value}

Singular values have been employed in the power systems because of their useful orthonormal decomposition of the Jacobian matrices. For a real square matrix $A$ of dimension $n \times n$, we have

$$
A=X \Sigma Y^{T}=\sum_{i=1}^{n} x_{i} \sigma_{i} y_{i}^{T}
$$

where the singular vectors $x_{i}$ and $y_{i}$ are the $i^{\text {th }}$ columns of unitary matrices $\mathrm{X}$ and $\mathrm{Y}$, and $\Sigma$ is a diagonal matrix of positive real singular values $\sigma_{i}$, such that $\sigma_{1} \geq \sigma_{2} \geq \ldots . \geq \sigma_{n}$. The diagonal entries of $\Sigma^{2}$ correspond to the eigenvalues of matrix $A A^{T}$. The singular value 
decomposition is typically used to determine the rank of a matrix, which is equal to the number of non zero singular values of A. The application of singular value decomposition (SVD) in static voltage collapse focuses on observing the minimum singular value, which becomes close to zero at the point of collapse [34].

For power system analysis, the matrix A represents the power flow Jacobian J, which contains the first derivatives of active and reactive power mismatch equations, $\Delta P$ and $\Delta Q$, with respect to voltage magnitude $\mathrm{V}$ and angles $\delta$.

$$
J=\left[\begin{array}{ll}
\frac{\partial P}{\partial \delta} & \frac{\partial P}{\partial V} \\
\frac{\partial Q}{\partial \delta} & \frac{\partial Q}{\partial V}
\end{array}\right]
$$

As discussed in [54], [7], the minimum singular value of the power flow Jacobian can be used as a possible index to characterize the proximity of the system to voltage collapse. For a real $n \times n$ square Jacobian matrix $J$

$$
J=U \Sigma V^{T}=\sum_{i=1}^{n} u_{i} \sigma_{i} v_{i}^{T}
$$

where the singular vectors $u_{i}, v_{i}$ are the $i^{\text {th }}$ columns of the unitary matrices $U$ and $V$, and $\Sigma$ is a diagonal matrix of positive real singular values $\sigma_{i}$, such that $\sigma_{1} \geq \sigma_{2} \geq \ldots . \geq \sigma_{n}$

Using the power flow model discussed in equation (3.1), the linearized equations can be expressed as follows

$$
\left[\begin{array}{c}
\Delta P \\
\Delta Q
\end{array}\right]=J\left[\begin{array}{c}
\Delta \delta \\
\Delta V
\end{array}\right]
$$

Equation (3.6), can be rewritten as

$$
\left[\begin{array}{c}
\Delta \delta \\
\Delta V
\end{array}\right]=V \Sigma^{-1} U^{T}\left[\begin{array}{c}
\Delta P \\
\Delta Q
\end{array}\right]=\sum_{i=1}^{n} \sigma_{i}^{-1} v_{i} u_{i}^{T}\left[\begin{array}{c}
\Delta P \\
\Delta Q
\end{array}\right]
$$

The minimum singular value is a relative measure of how close the Jacobian is to singularity and, therefore, the system to the proximity of voltage collapse or to bifurcation point. 
Equation (3.7), can be rewritten as

$$
\left[\begin{array}{c}
\Delta \delta \\
\Delta V
\end{array}\right]=\sigma_{n}^{-1} v_{n} u_{n}^{T}\left[\begin{array}{c}
\Delta P \\
\Delta Q
\end{array}\right]
$$

We can derive the following information from the left and right singular vectors [9]:

1. The maximum entries in $v_{n}$ indicate the most sensitive voltage magnitudes and angles (critical buses)

2. The maximum entries in $u_{n}$ correspond to the most sensitive direction of changes in active and reactive power injections.

In [58], the author proposed a simplified approach by using a reduced power flow Jacobian, by assuming no active power variation, i.e., $\Delta P=0$,Thus,

$$
\Delta Q=\left(J_{4}-J_{3} J_{1}^{-1} J_{2}\right) \Delta V=J_{Q V} \Delta V
$$

where,

$$
J=\left[\begin{array}{cc}
\frac{\partial P}{\partial \delta} & \frac{\partial P}{\partial V} \\
\frac{\partial Q}{\partial \delta} & \frac{\partial Q}{\partial V}
\end{array}\right]=\left[\begin{array}{cc}
J_{1} & J_{2} \\
J_{3} & J_{4}
\end{array}\right], \quad \operatorname{det} J_{Q V}=\frac{\operatorname{det} J}{\operatorname{det} J_{1}}
$$

The singular values of the reduced Jacobian matrix can be used to determine the proximity to voltage collapse similar to the standard Jacobian J [34].

\subsubsection{Eigenvalues}

Eigenvalues, which are similar to singular values, can be used to determine the proximity to voltage collapse point or bifurcation point. The eigenvalue decomposition of the standard load flow Jacobian matrix $\mathrm{J}$ can be written as

$$
J=W \Lambda U^{T}=\sum_{i=1}^{n} w_{i} \mu_{i} u_{i}^{T}
$$


where $W$ represents a matrix of right eigenvectors $w_{i}$, U represents the matrix of left eigenvectors $u_{i}$, and $\Lambda$ is a diagonal matrix of eigenvalues $\mu_{i}$

The Jacobian defined in equation (3.9) can be directly used for decomposition [7], as this matrix is diagonalizable. The magnitude of eigenvalues provides a relative measure of proximity to instability. The corresponding eigenvectors provide information about the mechanism of loss of voltage stability. The system is considered voltage unstable if at least one of the eigenvalues is negative. A zero eigenvalue of $J_{Q V}$ means that the system is on the verge of voltage instability. Furthermore, small eigenvalues of $J_{Q V}$ determine the proximity of the system to being voltage unstable. The corresponding eigenvectors have same interpretation as the singular vectors, i.e., the maximum entries in the right eigenvector correspond to the critical buses and the maximum entries in the left eigenvectors defines the most sensitive direction for changes of power injection.

The disadvantage of the eigenvalue and singular values is their highly nonlinear behavior near the collapse point with generation limits in place as discussed in [9]. The indices show a sudden large drop when close to bifurcation point, making them inadequate for detecting the proximity to the collapse point.

\subsection{Loading Margin}

Loading margin is the most widely accepted index for proximity of voltage collapse. With respect to a particular operating point, the amount of additional load in the specific direction of load increase that would cause a voltage collapse is called the loading margin to voltage collapse. In simple terms, it is the distance between the current operating point and the maximum loading point of which voltage collapse occurs.

In most of the cases of saddle node bifurcations in power systems, the system load is chosen as the parameter which tends to drive the system from a current stable equilibrium point to the voltage collapse or bifurcation point.

The advantages of the loading margin as a voltage collapse index are [7]:

- The loading margin is simple to compute, well accepted, and easily understood.

- The loading margin is not based on a particular system model, it only requires a static power system model. It can be used with dynamic system models, but it does not depend 
on the details of the dynamics.

- The loading margin is an accurate index, that takes full account of power system nonlinearity and limits such as reactive power control limits encountered as the loading is increased.

- Once the loading margin is computed, it is easy to compute its sensitivity with respect to any power system parameters.

Some disadvantages of Loading margin as voltage collapse index, are :

- The loading margin is computationally more expensive when compared to other indices because it requires computation at point away from the current operating point.

- The loading margin requires the assumption of direction of load increase, which may not be readily available.

The loading margin can be calculated by starting at the current operating condition and by making small increments in loading and recomputing the load flows at each increment till the breakdown point or bifurcation point is reached.

In practice, direct method or point of collapse method and continuation method are used to evaluate the loading margin and are explained in the following sections.

\subsubsection{Direct Method}

Directs methods, also known as point of collapse methods [47] were developed to directly determine the singular bifurcation points of nonlinear systems. It can be used to determine [8] the loading margin to collapse $\Delta \lambda=\lambda^{*}-\lambda$, at any given operating point $\lambda$.

The method consists of solving the following equations to directly compute the collapse point $\left(x^{*}, \lambda^{*}\right)$.

$$
\begin{aligned}
f(x, \lambda) & =0 \\
D_{x} f(x, \lambda)^{T} w & =0 \\
\|w\|_{\infty} & =1
\end{aligned}
$$




$$
\begin{aligned}
f(x, \lambda) & =0 \\
D_{x} f(x, \lambda) v & =0 \\
\|v\|_{\infty} & =1
\end{aligned}
$$

where

- $f(x, \lambda)=0$ represents bifurcation manifold ${ }^{1}$

- $D_{x} f(x, \lambda) v=0$ or $D_{x} f(x, \lambda)^{T} w=0$ is the singularity condition of the jacobian $D_{x} f(x, \lambda)$

- $\|w\|$ and $\|v\|$ are non-zero left and right eigenvectors norm respectively of the power flow jacobian.

The nonsingular equations (3.11) and (3.12) correspond to the system's steady state equations, the singularity condition at collapse point and nonzero eigenvector requirement for any given system. Since $J$ is singular at bifurcation point, a nonsingular eigenvector $v$ or $w$ must be guaranteed. The loading margin has been observed to exhibit a linear and smooth behavior $[7]$.

The disadvantage of this approach is the high computational cost as the number of equations doubles with respect to the steady state equations. The other disadvantage of the direct method as discussed in [8] and [40] is its inadequateness in predicting the collapse point when limits such as generator reactive power limits may come into effect and henceforth. Also, the requirement of good initial conditions for the eigenvectors, and the convergence problems as the system approaches the collapse point due to significant change in eigenvalues and eigenvectors. Another major disadvantage of direct method is its limitation of only detecting system singularities (bifurcation). The continuation methods overcome these difficulties as explained in the following section.

\subsubsection{Continuation Method}

The Continuation method is used to find the bifurcations of the nonlinear equations similar to the direct methods. The advantage of this method is its ability to not only find the bifurcation

\footnotetext{
${ }^{1}$ In this part and rest of the document, $\mathrm{f}$ represents a column vector.
} 
point but also to trace the bifurcation manifold accurately. Consequently the voltage behavior at all the system buses can be determined. Since, voltage profiles or PV nose curves are used in some utilities to determine the proximity to voltage collapse, tracing their behavior over different loading levels is an important observation.

The basic idea behind the continuation power flow technique is to use successive power flow solutions to compute the voltage profile up to and beyond the collapse point. But, continuation methods overcome the difficulties of successive power flow solution methods as they are based on an augmented system model through parameterization. This allows to trace complete voltage profile or bifurcation manifold without any problem, as parameter $\lambda$ is varied.

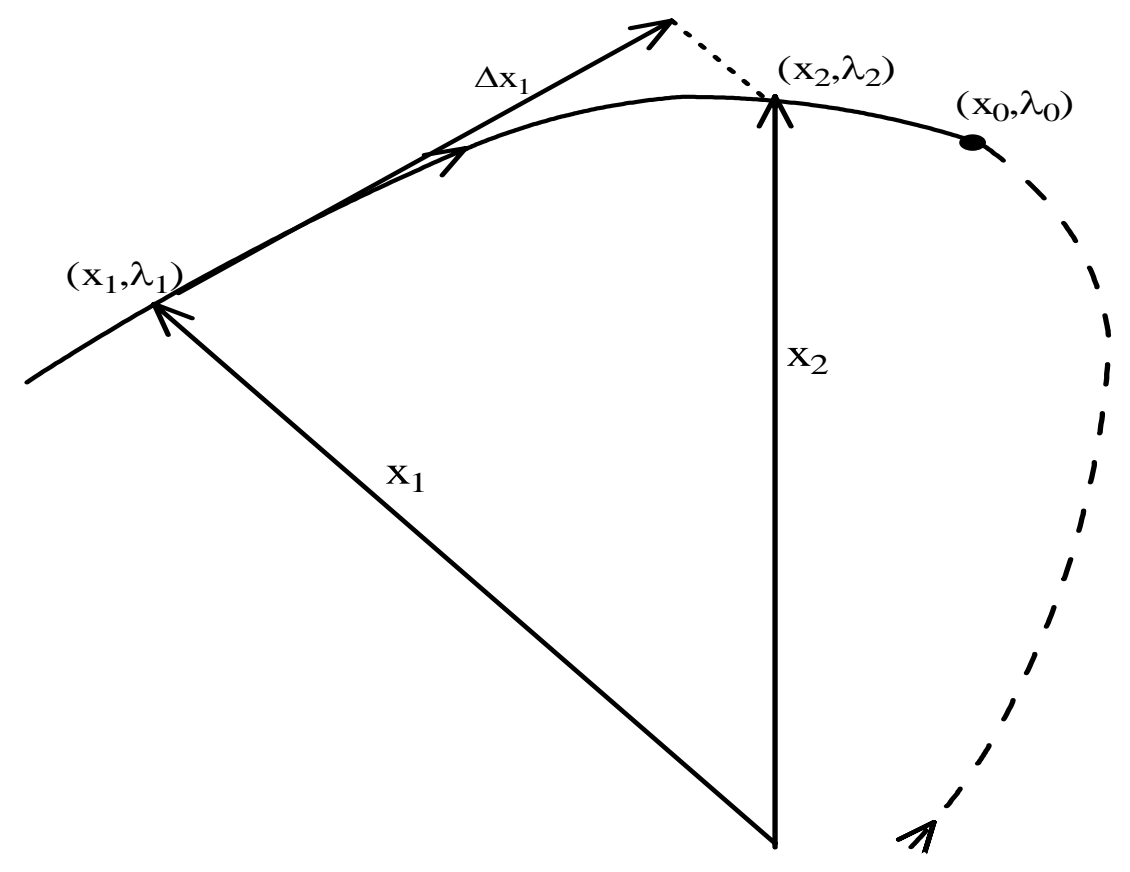

Figure 3.1: One Step of the Continuation method

The technique implemented in the continuation is illustrated in Fig. 3.1, where a given equilibrium point $\left(x_{1}, \lambda_{1}\right)$ is used to compute the direction vector $\Delta x_{1}$ and the change in parameter $\Delta \lambda$ of the system. There are two steps involved in the process 
1. Predictor and Parameterization : This step is known as the predictor, since it generates an initial guess $\left(x_{1}+\Delta x_{1}, \lambda_{1}+\Delta \lambda_{1}\right)$, which is then used to compute the new equilibrium point $\left(x_{2}, \lambda_{2}\right)$ in the corrector step.

Assuming the initial operating point $\left(x_{1}, \lambda_{1}\right)$ is known and

$$
f\left(x_{1}, \lambda_{1}\right)=0
$$

holds, taking partial derivatives yields,

$$
\left.\frac{d f}{d \lambda}\right|_{\left(x_{1}, \lambda_{1}\right)}=\left.D_{x} f\left(x_{1}, \lambda_{1}\right) \frac{d x}{d \lambda}\right|_{x=x_{1}}+\left.\frac{\partial f(x, \lambda)}{\partial \lambda}\right|_{x=x_{1}}=0 .
$$

The tangent vector at that point is given by

$$
\tau=\left.\frac{d x}{d \lambda}\right|_{x=x_{1}}=-\left.D_{x}^{-1} f\left(x_{1}, \lambda_{1}\right) \frac{\partial f(x, \lambda)}{\partial \lambda}\right|_{x=x_{1}}
$$

where $D_{x} f\left(x_{1}, \lambda_{1}\right)$ represents power flow Jacobian.

As the system approaches the bifurcation or collapse point, the system Jacobian becomes ill-conditioned and at the bifurcation the Jacobian is singular, and hence in order to ensure that the tangent vector $\tau$ and numerical solution of the equations is well defined we need parameterization of the predictor and corrector steps.

\section{A. Step Length Control}

The parameter step and the direction vector are found from the normalization of the tangent vector found in the equation (3.14). The step generated by the predictor is given by

$$
\frac{\Delta x_{1}}{\Delta \lambda_{1}}=t_{1}
$$

Hence, one can choose

$$
\begin{aligned}
\Delta \lambda_{1} & =\frac{k}{\left\|t_{1}\right\|} \\
\Delta x_{1} & =k \frac{t}{\left\|t_{1}\right\|}
\end{aligned}
$$


where $k$ is a scalar positive constant that controls the size of the predictor step. This normalization results in the reduction of the step size as the system approaches the bifurcation point since the magnitude of tangent vector increases as the system gets closer to this point. Therefore, steeper the curve, smaller is the step length. The optimal values of step size $k$ have been investigated by using the tangent vectors [11], [20].

\section{B. Parameterization}

One of the simple technique used in [2], [8] is local parameterization, which consists of interchanging the parameter $\lambda$ with the system variable $x_{i} \in x$ that has the largest normalized entry in the tangent vector, so that $\lambda$ becomes part of the equations, whereas $x_{i}$ becomes the new parameter $\mathrm{p}$, i.e.,

$$
p=\max _{i}\left\{\left|\frac{\Delta x_{i}}{x_{i}}\right|,\left|\frac{\Delta \lambda}{\lambda}\right|\right\}
$$

Detailed information regarding the predictors and parameterization techniques is given in $[7]$.

2. Corrector Step : The corrector step finds the actual point of solution $\left(x_{2}, \lambda_{2}\right)$, generated from the predictor step point $\left(x_{1}+\Delta x_{1}, \lambda_{1}+\Delta \lambda_{1}\right)$ with or without parameterization. This solution can be obtained by solving the following set of equations for $x$ and $\lambda$

$$
\begin{aligned}
& f(x, \lambda)=0 \\
& \rho(x, \lambda)=0
\end{aligned}
$$

From the Fig. 3.2, using a vector perpendicular to the tangent vector, we have

$$
\rho(x, \lambda)=\left[\begin{array}{c}
\Delta x_{1} \\
\Delta \lambda_{1}
\end{array}\right]^{T}\left[\begin{array}{c}
x_{2}-x_{1}-\Delta x_{1} \\
\lambda_{2}-\lambda_{1}-\Delta \lambda_{1}
\end{array}\right]=0
$$

which can be written as, 


$$
\rho(x, \lambda)=\Delta x_{1}^{T}\left(x_{2}-x_{1}-\Delta x_{1}\right)+\Delta \lambda_{1}\left(\lambda_{2}-\lambda_{2}-\Delta \lambda_{1}\right)=0
$$

As shown in the Fig.(3.2), starting from point $\left(x_{1}, \lambda_{1}\right)$ the above equations converge to solution $\left(x_{2}, \lambda_{2}\right)$

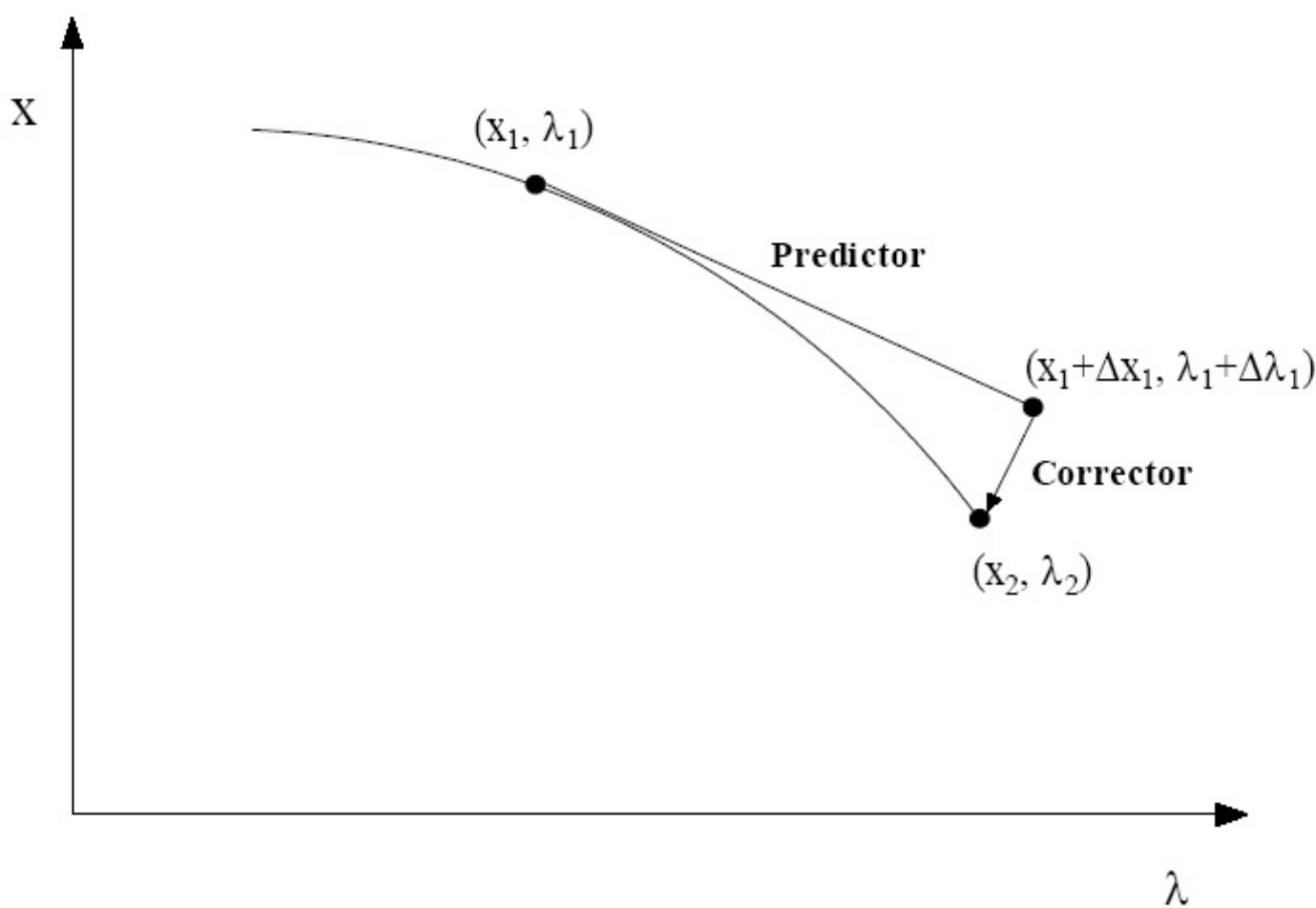

Figure 3.2: Predictor and Corrector Steps in Continuation power flow

\subsection{Sensitivity Factors}

Sensitivity factors are some of the well known indices used to detect voltage stability problems. These indices [7] were used to predict voltage control problems in generator QV curves and they may be defined as

$$
V S F_{i}=\max _{i}\left\{\frac{d V_{i}}{d Q_{i}}\right\}
$$


where, VSF stands for voltage sensitivity factor. As the generator $i$ approaches the bottom of its QV curve, the $V S F_{i}$ value increases and changes its sign, indicating an unstable voltage condition. Based on the above definition, more indices called Sensitivity Factors, have been proposed to evaluate the system wide performance. For a system represented by equation 3.1), the sensitivity factor may be defined as :

$$
S F=\left\|\frac{d x}{d \lambda}\right\|
$$

When the value of $\mathrm{SF}^{2}$ becomes large, the system becomes unstable and collapses eventually, as the value of $\Delta \lambda \rightarrow 0$ as the system approaches the maximum loadability point or bifurcation point. If only system voltages are monitored then, the same SF can be defined as

$$
V S F=\left\|\frac{d V}{d \lambda}\right\|
$$

\subsection{Other Indices}

\subsubsection{Test Functions}

Voltage stability index, independent of the system model has been proposed in [47] and defined as

$$
t_{l k}=\left|e_{l}^{T} J J_{l k}^{-1} e_{l}\right|
$$

where, $J$ represents the system Jacobian, $e_{l}$ is the $l^{\text {th }}$ unit vector, i.e., a vector with all entries zero except the $l^{\text {th }}$ row, also

$$
J_{l k}=\left(I-e_{l} e_{l}^{T}\right) J+e_{l} e_{k}^{T}
$$

where, $I$ represents the identity matrix. Equation (3.26) can be understood simply as a modified Jacobian matrix with $l^{\text {th }}$ row removed and replaced by row $e_{k}^{T}$. The normal load

\footnotetext{
${ }^{2}$ In linear algebra, a norm is a function that assigns a positive length or size to all vectors in a vector space, other than the zero vector. Though, by definition all norms are in a sense equivalent, here the infinity norm was found to yield better results.
} 
flow Jacobian equation is singular at bifurcation point, but this modified Jacobian matrix $J_{l k}$ is guaranteed non-singular if the $l^{\text {th }}$ and $k^{\text {th }}$ are chosen so that they correspond to non zero entries in the zero eigenvectors $\mathrm{v}$ and $\mathrm{w}$ associated with the zero eigenvalue of $J$. Furthermore, if $l=k=c$, where $c$ corresponds to the maximum entry in $\mathrm{v}$, the test function become the critical test function

$$
t_{c c}=\left|e_{c}^{T} J J_{c c}^{-1} e_{c}\right|
$$

The Jacobian matrices and test function family are functions of system variables and parameters, i.e., $J=J(x, \lambda), J_{l k}=J_{l k}(x, \lambda)$, and $t_{l k}=t_{l k}(x, \lambda)$. As the parameter $\lambda$ changes and approaches the collapse point, the system variables change and as a result the critical test function $t_{c c}$ displays a quadratic shape as a function of loading margin. Hence

$$
\Delta \lambda \approx a t_{c c}^{2}
$$

where $a$ is a scalar constant. This behavior allows the use of $t_{c c}$ for determining the system proximity to voltage collapse. The problem with using $t_{c c}$ is the difficulty of determining the critical buses $c$ [7].

\subsubsection{Tangent Vector Index (TVI)}

The tangent vector defined in (3.14) may be used as an index to detect proximity to voltage collapse. The computation of tangent vector according to (3.14)is easy and inexpensive as it can be done in one additional Newton-Raphson iteration. This vector also gives information regarding how the system variables are affected by changing $\lambda$. Also from equation (3.14) it can be shown that the tangent vector converges to "zero" right eigenvector at the collapse point. The TVI is defined as

$$
T V I_{i}=\left|\frac{d V_{i}}{d \lambda}\right|^{-1}
$$

where, $d V_{i} / d \lambda$ is an entry in the tangent vector $d x / d \lambda$ corresponding to voltage magnitude $V_{i}$ for bus i. Now, as the system approaches the collapse point, $d V_{i} / d \lambda \rightarrow \infty$ and, hence, $T V I_{i} \rightarrow 0$.

There are several other indices like energy functions, reduced determinant, etc., available, and detailed information including their performance is available in [7]. Table (3.1) summarizes all aspects discussed here. Since all the indices have their advantages and disadvantages, it 
is not practical to recommend a particular index as the only one to use. Depending on the study (on-line or off-line) and accuracy needed, one can choose the indices as needed. In this work, loading margin determination using a continuation power flow technique has been chosen because of its high accuracy and reliability and also because of the need of more accurate evaluation of voltage collapse situations when incorporating additional reactive power support. 


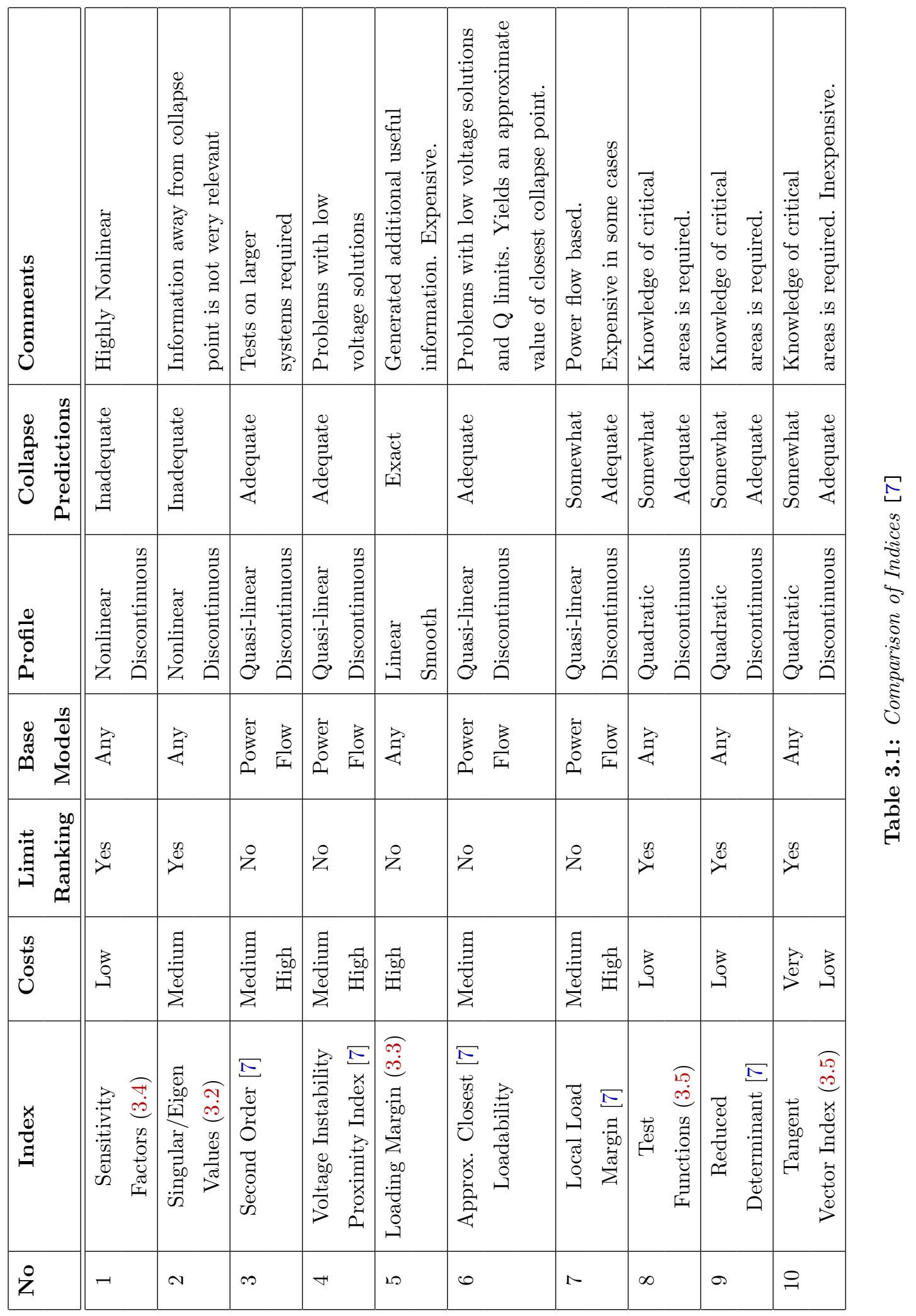




\section{Chapter}

4

\section{Pilot Bus Selection}

\subsection{Introduction}

This chapter discusses the approach used for the selection of the pilot buses for reactive power support. As discussed and stated earlier, the term pilot bus reflects the most sensitive bus affecting the system both in terms of maintaining good voltage profile and additional stability support to the system.

\subsection{System Model}

The quasi-steady-state description of a power system applicable to voltage stability analysis described in equation (2.1), is given by the differential-algebraic equations

$$
\begin{aligned}
\dot{z} & =f(z, y, \lambda) \\
0 & =g(z, y, \lambda)
\end{aligned}
$$

where $z$ corresponds to system state variables and y represents the algebraic variables. The variable $\lambda$ represents a single parameter or set of parameters that "slowly" change in time as the system moves from one stable equilibrium point to another equilibrium point till it reaches the collapse or bifurcation point. 
Rewriting equation (4.1) as

$$
\left[\begin{array}{c}
\dot{z} \\
0
\end{array}\right]=f(z, y, \lambda)
$$

The system can be represented in another way by defining $x=[z, y]^{T}$, so that the equations (4.1) and (4.2) can be rewritten as

$$
\left[\begin{array}{c}
\dot{z} \\
0
\end{array}\right]=f(x, \lambda)
$$

The system model in equation (3.1) of Chapter 3 is a subset of the model presented in equation (4.3) where $f(x, \lambda)$ represents the active and reactive power mismatches. Assuming that the system moves from one stable equilibrium point to another as the load is slowly changed till it reaches the bifurcation point, it is possible to use static analysis to obtain adequate information regarding system stability.

\subsection{Pilot Bus Selection Procedure}

The main idea of this selection process is to find the optimal location based on the voltage constraints of the system and the loading margin corresponding to it. The flowchart depicting the pilot bus selection analysis is illustrated in Fig. 4.1. A description of the flowchart and the selection analysis is discussed in this section.

As shown in Fig. 4.1, the system data (bus data and line data) is used to run a continuation power flow solution to perform a contingency screening. Although one could perform the analysis for each outage, this would result in a lengthy process for realistic size networks. Since the characteristics of the system change with different contingency conditions, the screening of the contingency is done by selecting lines that are heavily loaded near the collapse point based on the solution obtained from continuation power flow.

The loading margin of the selected contingencies is evaluated and used for computing the loading margin index. The N-1 analysis and continuation power flow are run with reactive support device at each load bus ${ }^{1}$ for selected contingencies and the loading margin is evaluated

\footnotetext{
${ }^{1}$ In some test systems (For example 24 bus single area IEEE Reliability Test System -96), the buses that do not possess any load or generating capability but just act as connecting nodes are also considered for possible location of VAR support.
} 


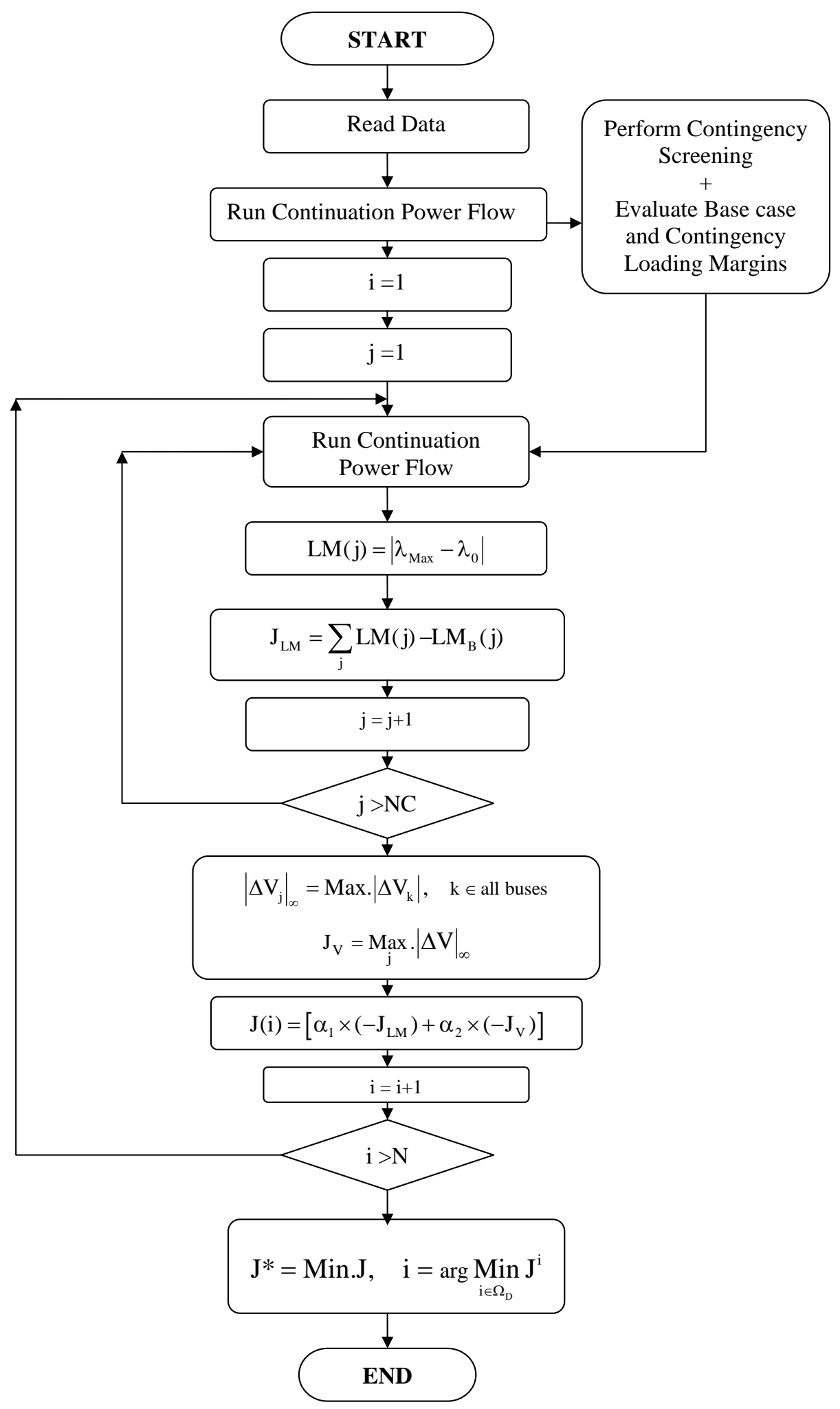

Figure 4.1: Flow Chart for determining pilot buses using CPF and N-1 Contingency Analysis 
when the voltage limit is violated. The important point here is to understand that the ideal location for the VAR support, with reactive limits considered, would be the location which enhances the voltage level at all the buses and ensure an adequate increase in the loading margin when compared to the base case and other possible locations.

The objective function for the bus selection for VAR support can be mathematically formulated as

$$
J^{*}=\min _{i \in \Omega_{D}} J^{i}=\min _{i \in \Omega_{D}} \alpha_{1} \widehat{J}_{1}^{i}+\alpha_{2} \widehat{J}_{2}^{i}
$$

subject to

$$
\begin{array}{cl}
V_{\min } \leq V \leq V_{\max } & \text { at all buses } \\
Q_{G \min } \leq Q_{G} \leq Q_{G \max } & \text { at VAR generating buses } \\
\lambda_{\min } \leq \lambda \leq \lambda_{\max } &
\end{array}
$$

where the following are evaluated for each choice of pilot bus location $i$

$$
\begin{aligned}
L_{M}^{i} & =\left[\sum_{j \in \Omega_{C}}\left(L M_{j}-L M_{j}^{B}\right)\right] \\
J_{1}^{i} & =-L_{M}^{i} \\
J_{2}^{i} & =\max _{j \in \Omega_{C}}\left\|\Delta V_{j}\right\|_{\infty} \\
\left\|\Delta V_{j}\right\|_{\infty} & =\max _{k \in \text { all buses }}\left|\Delta V_{k}\right|
\end{aligned}
$$


and

$$
\begin{aligned}
\Omega_{C} & =\text { Selected contingencies } \\
\Omega_{D} & =\text { All load buses } \\
L M_{j} & =\text { Loading margin of } \mathrm{j}^{\text {th }} \text { contingency with VAR device } \\
L M_{j}^{B} & =\text { Base case loading margin of } \mathrm{j}^{\text {th }} \text { contingency } \\
\widehat{J}_{1}^{i} & =\text { Normalized value of } \mathrm{J}_{1}^{\mathrm{i}} \\
\widehat{J}_{2}{ }^{i} & =\text { Normalized value of } \mathrm{J}_{2}{ }^{\mathrm{i}} \\
\Delta V_{k} & =\left|V_{k}-1.0\right| \\
\alpha_{1}+\alpha_{2} & =1
\end{aligned}
$$

The $L M$ in the equation (4.5) denotes loading margin. Loading margin, as discussed in Section 3.3 of Chapter 3, is defined as the distance between the current operating point and the maximum loading point or collapse point. It gives a measure of how much the system can be loaded or how far the system is currently operating from the verge of instability.

In the equation (4.4), $\alpha_{1}$ and $\alpha_{2}$ represent weights for the multi-objective index. In equation (4.5) difference between the loading margins of the base case and that with VAR device for all the selected contingencies is evaluated. This forms the first part of the objective function represented in equation (4.4). Then, the infinity norm or the worst case voltage magnitude deviations is evaluated at all the buses for each selected contingency as represented in the equations (4.7) and (4.8). The final step is to compute the overall value of the objective represented in (4.4), combined with the normalized weights. These weights are chosen (equal in this case) that voltage magnitude deviations and loading margins will have equal weightage in the evaluation of overall objective. This is important because planning reactive power support should provide additional security in terms of increased loading margin, which guarantees improved system stability and decreased voltage magnitude deviations. The voltage deviations are evaluated with respect to 1 p.u. Since both of these factors are important and have to be addressed, they are given equal priority in the overall objective formulation. As the procedure takes into consideration the N-1 criterion, which guarantees a thorough analysis, the outcome of the pilot bus location is related to the optimal location under different network conditions. The vectors $J_{1}{ }^{i}$ and $J_{2}{ }^{i}$ are normalized values obtained by dividing the value with the maximum entry obtained during SVC placement at different locations. This is to ensure 
the resultant value is scaled between 0 and 1 . 


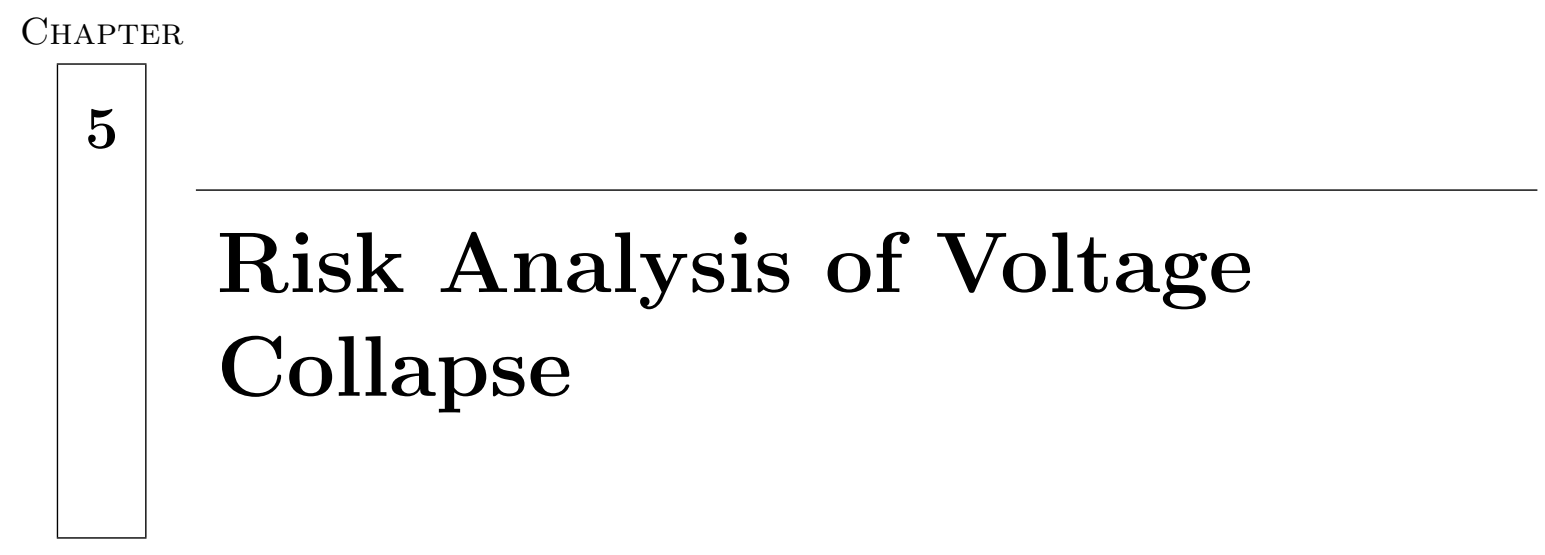

\subsection{Introduction to Risk Analysis}

Risk is defined in the IEEE standard dictionary [25] as the product of the probability and consequence of associated events. Risk can also be understood as:

1. Expected financial loss per unit time

2. Expression of combined severity and probability of loss

3. Long-term rate of loss

Risk derives from the inability to see into the future and indicates a degree of uncertainty. Depending on the situation, risk can be either objective or subjective [44]. For example, flipping a coin is an objective risk because the odds are well known. Even though the outcome is uncertain, an objective risk can be described precisely based on theory and experiment. Describing the odds for rain next week is not so clear and represents a subjective risk. Subjective risk can be always refined with new information. Most risks are subjective and this has important implications for anyone analyzing risk or making decisions based on risk analysis.

In a broader sense, risk analysis is any technique, qualitative and/or quantitative, for assessing the impact of uncertainty on decision making or situations. The goal of these methods 
is to help the decision maker choose a course of action, given a better understanding of the possible outcomes that may occur. A typical risk analysis method [44] would generally contain the following steps or stages in the process of risk quantification.

- Developing a Model: Defining the problem.

- Identifying Uncertainty: Identifying uncertain variables, specifying their possible values with probability distributions, and specifying assumptions regarding the distribution.

- Analyzing the Model through Simulation: Determining the range and probabilities of possible outcomes for the different scenarios chosen. Evaluating results and quantifying the risk.

- Making a Decision: Making a decision based on the results provided and personal preferences.

Due to the inherent probabilistic nature of power systems behavior, deterministic analysis provides only a weak assessment for such a complex system [61]. An important motivation for analyzing risk with respect to system enhancements is generally associated with enhancements of the power system. These improvements may be through installation of new equipment like FACTS devices, or transmission planning, etc. In order to determine the economic feasibility, the impact of decision making on risk reduction must be studied. Hence, a probabilistic economic analysis is required.

Financial risk reduction has gained greater importance in the deregulated power industry [61]. The competitive environment forces utilities to operate systems closer to stability limits and stressing the system close to its thermal and voltage capabilities. In such a stressed scenario, system operating conditions may deteriorate and reliability of the power system may be reduced. Evidence of this is provided by the number of power outage events and blackouts that have occurred recently. Table 5.1 as released by NERC [41], lists some of the major outages that have taken place in the recent past.

According to a recent study [28], the annual costs of power interruptions were estimated to be approximately $\$ 79$ billion per year as show in Fig. 5.1. These power outages provide us the insight that N-1 contingency criterion that is being used in the power industry for the reliability may not be sufficient to preserve the reliability of the system. However, at the same time, it is difficult to justify the cost of $\mathrm{N}-2$ and $\mathrm{N}-\mathrm{K}$ principle in power system planning. 


\begin{tabular}{|c|c|c|c|}
\hline DATE & $\begin{array}{c}\text { STATES } \\
\text { PROVINCES AFFECTED }\end{array}$ & $\begin{array}{l}\text { CUSTOMERS } \\
\text { AFFECTED }\end{array}$ & $\begin{array}{c}\text { OUTAGE } \\
\text { DURATION }\end{array}$ \\
\hline 9-Nov-65 & $\begin{array}{c}\text { Northeastern US, } \\
\text { Ontario }\end{array}$ & $\begin{array}{l}30,000,000 \text { people. Over } \\
20,000 \mathrm{MW} \text { of demand }\end{array}$ & Up to 13 hours \\
\hline 13-Jul-77 & New York City & $\begin{array}{l}9,000,000 \text { people. } \\
6,000 \text { MW of demand }\end{array}$ & Up to 26 hours \\
\hline 2-Jul-96 & Western US & $\begin{array}{c}2,000,000 \text { ( } 10 \% \text { of the } \\
\text { customers in the Western- } \\
\text { Interconnection). } 11,850 \mathrm{MW} \\
\text { of demand }\end{array}$ & $\begin{array}{l}\text { From a few minutes } \\
\text { to several hours }\end{array}$ \\
\hline 3-Jul-96 & Western US & $\begin{array}{l}\text { The disturbance from July } 2 \\
\text { reoccurred }\end{array}$ & $\begin{array}{l}\text { Operators interrupted } \\
\text { load to most of Idaho }\end{array}$ \\
\hline 10-Aug-96 & Western US & $\begin{array}{l}\text { 7,500,000 customers. } \\
28,000 \mathrm{MW} \text { of demand }\end{array}$ & Up to 9 hours \\
\hline 25-Jun-98 & $\begin{array}{l}\text { Midwestern US, } \\
\text { central Canada }\end{array}$ & $\begin{array}{l}152,000 \text { customers. } \\
950 \mathrm{MW} \text { of demand }\end{array}$ & 19 hours \\
\hline 14 Aug. 2003 & $\begin{array}{l}\text { Midwestern and Northeastern } \\
\text { US Southeastern, Canada }\end{array}$ & $\begin{array}{l}50,000,000 \text { customers } \\
\text { interrupted. Social costs } \\
\text { range from } \$ 6 \text { billion to } \$ 10 \text { billion }\end{array}$ & Many Hours \\
\hline 27 Sept. 2003 & Italy & $\begin{array}{l}57,000,000 \text { customers } \\
\text { interrupted }\end{array}$ & Many Hours \\
\hline
\end{tabular}

Table 5.1: Table of major bulk power system outages (NERC, [41])

So, the obvious alternative is to incorporate risk assessment and risk analysis in the practice of system planning, design, and operation in an attempt to reduce the risk to an acceptable level.

\subsection{Risk Analysis and Voltage Stability}

Voltage collapse typically occurs in heavily loaded power systems, weakened by transmission line outages and reactive power shortages. Most of the incidents also result from cascading failures due to overloading or natural disasters. But as we can see from Table 5.1 the outcome of such failures results in large monetary and significant opportunity cost to many segments of the economy. As far as power systems are concerned, its important to minimize the human and technical errors behind such failures. A deterministic approach in analyzing the potential of voltage collapse may not provide answers to the following questions [26]:

1. How safe or how risky are the current operating conditions?

2. How does risk change as the current operating condition changes or as the system is 


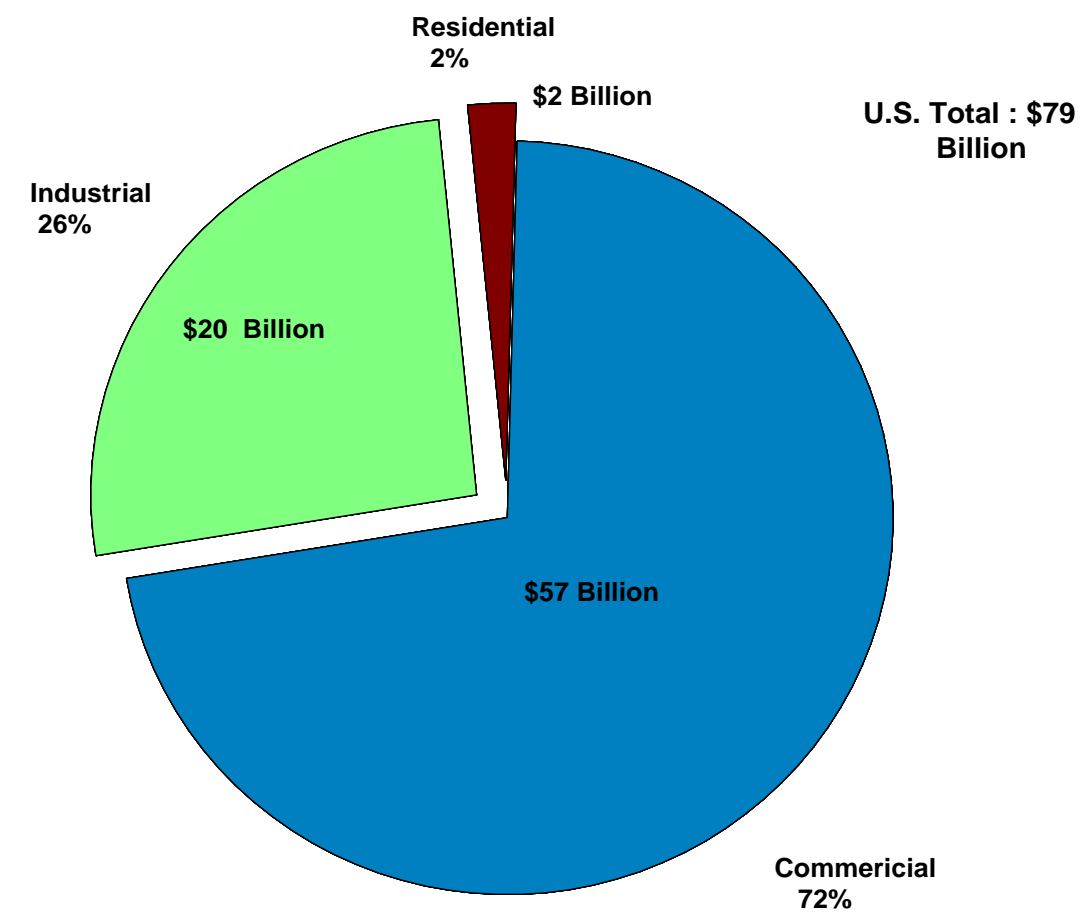

Figure 5.1: LBNL (Lawrence Berkeley National Laboratory) estimate of power interruptions according to customer class [28]

stressed or relieved?

3. How does risk change with the installation of additional transmission equipment?

Most of the voltage collapse problems are closely related to reactive power reserves and contingencies. The above three issues are directly or indirectly addressed in this work wherein the risk of voltage collapse or system failure without reactive compensation from static var compensator (SVC) is studied and quantified. Quantifying risk is important because system improvements require large capital investments. The basic idea is to provide a justification for installing reactive power support devices to reduce the risk of voltage collapse and estimate the associate savings through avoiding spreading blackouts, and hence improving transmission system reliability.

A risk based economic analysis of this capital investment is performed by examining the costs of the SVCs and the cost of outages to assess the economics of voltage collapse prevention through the use of these devices. The opportunity costs of reliability enhancement will be calculated and the economic feasibility of using SVC will be determined by accessing the improvement in reliability associated with their installation in the test system discussed in 
Section 6.2.

\subsection{Evaluation of Voltage Stability Risk}

Traditionally, deterministic performance indices have been used in many on-line and off-line studies for voltage security assessment. This project will focus on using loading margin as a stability index, because of its highly accurate prediction of collapse point and other advantages as discussed in section (3.3).

In this work, it is assumed that there are two distinct outcomes for the future performance of system voltages: collapse or no collapse. The bifurcation or collapse point on the PV curve provides the boundary between these two possible outcomes. Also, a system operating without a voltage collapse may undergo voltage limit violation and result in load interruption.

The main objective of this work is to asses the potential of SVC installation at specific locations to minimize the risk of voltage collapse and to determine if its use is economically justifiable. The location of the SVC is determined by the algorithm discussed in Section (4.3) of Chapter 4.

The voltage stability risk can be mathematically expressed by:

$$
\begin{aligned}
\operatorname{Risk}\left(X_{0}\right) & =P\left(\text { Collapse } \mid X_{0}\right) * \operatorname{Impact}(\text { Collapse })+ \\
& +\left(1-P\left(\text { Collapse } \mid X_{0}\right)\right) * \operatorname{Impact}(\text { No Collapse })
\end{aligned}
$$

where $X_{0}$ stands for the current operating conditions. The risk is dependent on the probability of voltage collapse at the given operating condition, as expressed by $P\left(\right.$ Collapse $\left.\mid X_{0}\right)$ term in equation (5.1) The impact of collapse and no collapse are evaluated based on the security costs and outage costs which will be discussed in the following sections of this chapter. For simplicity in deriving expressions, the notation of the given operating or loading condition $X_{0}$ will be dropped, but it is assumed that all the derivations are based on $X_{0}$, i.e., all the expressions are functions of $X_{0}$.

\subsubsection{Evaluating the Probability of Voltage Collapse}

Under the scope of short-term operating conditions, there can be many uncertainty factors associated with a voltage collapse such as: [26]. 
- Contingencies

- Short-term system load forecast

- Short-term parametric deviations (e.g., deviations of load sharing, generation dispatch, and other uncertainties.)

In this study, first two uncertainties are considered, i.e., contingencies and short-term load forecast.

\section{A. Contingency}

The occurrence of contingencies is calculated using the outage rate defined for each contingency. The probability of contingency is calculated as

$$
\text { probability }=\frac{\text { frequency } \times \text { duration }}{8760}
$$

where frequency is in number of outages per year and duration is in hours.

\section{B. Short-term system load}

Besides contingencies, short-term system load fluctuations are another type of uncertainty. A short-term load forecast gives an expectation of load $\mu_{L}$ and its standard deviation $\sigma_{L}$ which is assumed to be following a normal distribution

$$
L F=\operatorname{Normal}\left(\mu_{L}, \sigma_{L}\right)
$$

With the above two uncertainties considered the probability of voltage collapse is evaluated based on the loading margin index. The maximum loading margin $L M$ is evaluated based on the continuation power flow solution and the expected value of the current load level is calculated based on the equation (5.2) using hourly load demand data, see for example [43]. This hourly load demand is represented as the percentage of the peak demand value for both weekdays and weekends.

The probability of voltage collapse is the probability that the loading margin $M_{k}=L_{M k}-L_{k}$ is less than zero. This means that the current loading point is equal to or past the maximum loading point, for a given contingency $k$. Note that here $L_{k}$ is normally distributed as shown 
in equation (5.2). So, the resultant loading margin $M_{k}$ will also be a normal distribution with mean $\mu_{M k}$ and standard deviation $\sigma_{M k}$. We can express the probability of collapse mathematically through

$$
P\left(\text { collapse } \mid E_{k}\right)=P\left(M_{k} \leq 0 \mid E_{k}\right)
$$

By the Total Probability Theorem [31], the total probability of voltage collapse under a given contingency can be expressed as

$$
P(\text { collapse })=\sum_{E_{k}} P\left(\text { collapse } \mid E_{k}\right) * P\left(E_{k}\right)
$$

\subsubsection{Decision Tree Model}

The decision tree model for evaluating the voltage collapse risk is shown in Fig. 5.2. As discussed earlier, two main outcomes are assumed. One outcome represents voltage collapse and the other no collapse. The analysis is performed with and without using the reactive support device to see if the investments in it can be economically justified. The analysis discussed here may be applied for any system. In this work, IEEE 24 bus reliability test system is chosen as the test system because of its readily available data (especially outage rates and demand forecast etc.) and practical significance.

Using the information depicted in Fig. 5.2, the probabilities of events can be defined as follows: 


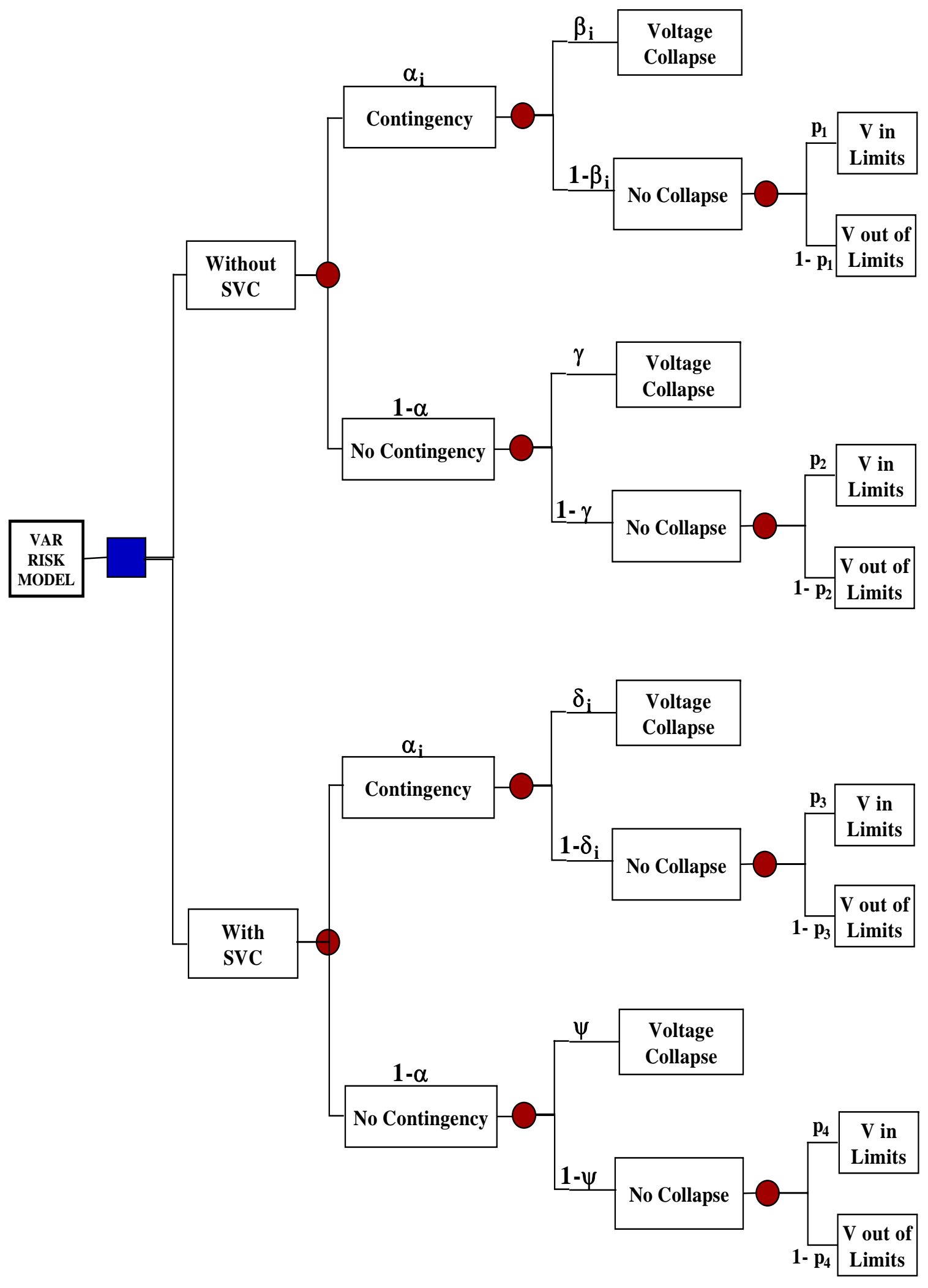

Figure 5.2: Decision Tree Model for Risk Analysis 


$$
\begin{aligned}
\alpha_{i} & =\text { Probability of contingency } i \text { (outage of a line } i \text { ) } \\
\beta_{i} & =\text { Probability of voltage collapse given a contingency } i \text { with no SVC } \\
1-\beta_{i} & =\text { Probability of no voltage collapse given a contingency } i \text { with no SVC } \\
\gamma & =\text { Probability of voltage collapse given no contingency with no SVC } \\
1-\gamma & =\text { Probability of no voltage collapse given no contingency with no SVC } \\
\delta_{i} & =\text { Probability of voltage collapse given a contingency } i \text { with SVC } \\
1-\delta_{i} & =\text { Probability of no voltage collapse given a contingency } i \text { with SVC } \\
\psi & =\text { Probability of voltage collapse given no contingency with SVC } \\
1-\psi & =\text { Probability of no voltage collapse given no contingency with SVC } \\
1-\alpha & =\text { Probability of no contingency. }
\end{aligned}
$$

where

$$
\alpha=\sum_{i=1}^{N} \alpha_{i}
$$

$N$ represents the number of selected contingencies or outages. Here it is assumed that the probability of contingencies remain the same with and without static var compensator in the system assuming random independent events are not influential by the presence of Static Var Compensator. These probabilities are calculated using equation (5.2) with outage rates of each line specified. Though including all the contingencies would be ideal, but in this study only critical contingencies or outages of lines are considered.

The expected impact of the outcomes of the above events can be defined as follows:

$$
\begin{aligned}
\operatorname{Im}(\text { Collapse }) & =\text { Impact of voltage collapse without SVC } \\
\text { Im }(\text { No Collapse }) & =\text { Impact of No voltage collapse without SVC } \\
\operatorname{Im}(\text { Collapse })_{S V C} & =\text { Impact of voltage collapse with SVC } \\
\operatorname{Im}\left(\text { No Collapse }_{S V C}\right. & =\text { Impact of No voltage collapse with SVC }
\end{aligned}
$$




\section{Case I : Without Static Var Compensator(SVC)}

$$
\begin{aligned}
P(\text { collapse }) & =\sum_{i=1}^{N} \alpha_{i} \cdot \beta_{i}+(1-\alpha) \cdot \gamma \\
P(\text { No Collapse }) & =\sum_{i=1}^{N} \alpha_{i} \cdot\left(1-\beta_{i}\right)+(1-\alpha) \cdot(1-\gamma)
\end{aligned}
$$

where $P($ collapse $)$ and $P(N o$ Collapse $)$ denote the probabilities of collapse and no collapse without SVC in the system. The expected impact can be expressed as:

$$
E[\operatorname{Im}(\text { Collapse })]=\left[\sum_{\text {bus }}\left(\text { Outage Cost }+S C_{\text {collapse }}\right) * P_{\text {Bus }}\right]
$$

Here, $S C_{\text {collapse }}$ denotes the security cost associated with voltage collapse and $P_{B u s}$ denotes the expected load at the bus. Outagecost is $\$ / M w h$ value of load not served because of collapse. Though it is possible to mitigate voltage collapse via restorative actions, the effectiveness of these actions are uncertain and it is assumed that voltage collapse results in total system blackout. Also, the service interruption at a bus is considered for the case of no voltage but the bus voltage violation. The formulation in this case can be expressed as follows

$$
E[\operatorname{Im}(\text { No Collapse })]=\left[\sum_{\text {bus }}\left(\left(L M P+S C_{V \text { cost }}\right) * P_{\text {Bus }}\right) * p\left(V_{\text {bus }}<V_{\text {Min }}\right)\right]
$$

Here, $S C_{V \text { cost }}$, denotes the security cost due to load interruption and $p\left(V_{\text {bus }}<V_{\text {Min }}\right)$ denotes the probability that the voltage violation occurs at the specific bus. Using the equations $(5.9,5.11)$, the risk expression for the case of no SVC, is given by

$$
\begin{gathered}
\operatorname{Risk}\left(X_{0}\right)=\left[\sum_{i=1}^{N} \alpha_{i} \cdot \beta_{i}+(1-\alpha) \cdot \gamma\right] *\left[\sum_{\text {bus }}\left(\text { Outage Cost }+S C_{\text {collapse }}\right) * P_{\text {Bus }}\right]+ \\
+\left[\sum_{i=1}^{N} \alpha_{i} \cdot\left(1-\beta_{i}\right)+(1-\alpha) \cdot(1-\gamma)\right] *\left[\sum_{\text {bus }}\left(\left(\text { LMP }+S C_{\text {Vcost }}\right) * P_{\text {Bus }}\right) * p\left(V_{\text {bus }}<V_{\text {Min }}\right)\right]
\end{gathered}
$$




\section{Case II : With Static Var Compensator(SVC)}

$$
\begin{aligned}
P(\text { Collapse })_{S V C} & =\sum_{i=1}^{N} \alpha_{i} \cdot \delta_{i}+(1-\alpha) \cdot \psi \\
P\left(\text { No Collapse }_{S V C}\right. & =\sum_{i=1}^{N} \alpha_{i} \cdot\left(1-\delta_{i}\right)+(1-\alpha) \cdot(1-\psi)
\end{aligned}
$$

where

$P(\text { collapse })_{S V C}$ and $P\left(N_{o} \text { Collapse }\right)_{S V C}$ denote the probabilities of collapse and no collapse with SVC in the system. The expected impact can be expressed as:

$$
\begin{aligned}
& E\left[\operatorname{Im}(\text { Collapse })_{S V C}\right]=\left[\sum_{\text {bus }}\left(\text { Outage } \text { Cost }^{S V C}+S C_{\text {collapse }}^{S V C}\right) * P_{\text {Bus }}\right] \\
& E\left[\operatorname{Im}\left(\text { No Collapse }_{S V C}\right]=\left[\sum_{\text {bus }}\left(\left(L M P^{S V C}+S C_{V \text { cost }}^{S V C}\right) * P_{\text {Bus }}\right) * p\left(V_{\text {bus }}<V_{M i n}\right)\right]\right.
\end{aligned}
$$

Similar to equation (5.11), $S C_{V \text { cost }}^{(S V C)}$, denotes the security cost due to load interruption and $p\left(V_{\text {bus }}<V_{\text {Min }}\right)$ denotes the probability that the voltage violation occurs at the specific bus with SVC in the system. The risk expression with SVC can be expressed as follows:

$$
\begin{aligned}
& \operatorname{Risk}\left(X_{0}\right)_{S V C}=\left[\sum_{i=1}^{N} \alpha_{i} \cdot \delta_{i}+(1-\alpha) \cdot \psi\right] *\left[\sum_{\text {bus }}\left(\text { Outage } \text { Cost }^{S V C}+S C_{\text {collapse }}^{\text {SVC }}\right) * P_{\text {Bus }}\right]+ \\
+ & {\left[\sum_{i=1}^{N} \alpha_{i}\left(1-\delta_{i}\right)+(1-\alpha)(1-\psi)\right] *\left[\sum_{\text {bus }}\left(\left(L M P^{S V C}+S C_{\text {Vcost }}^{S V C}\right) * P_{\text {Bus }}\right) * p\left(V_{\text {bus }}<V_{\text {Min }}\right)\right] } \\
+ & \quad \text { SVC Cost }
\end{aligned}
$$

\subsection{SVC Investment Costs}

The following total investment cost analysis for static var compensator is based on information from Siemens AG database [24]. According to the data given, costs can be approximated by

$$
C_{S V C}=0.0003 s^{2}-0.3051 s+127.38(\mathrm{US} \$ / \mathrm{kVar})
$$


where $C_{S V C}$ is in (US $\$ / \mathrm{kVar}$ ) and $\mathrm{s}$ is the operating range of the SVC in MVar. The plot of the cost function against operating range of 400 MVar is shown in Fig. 5.3.

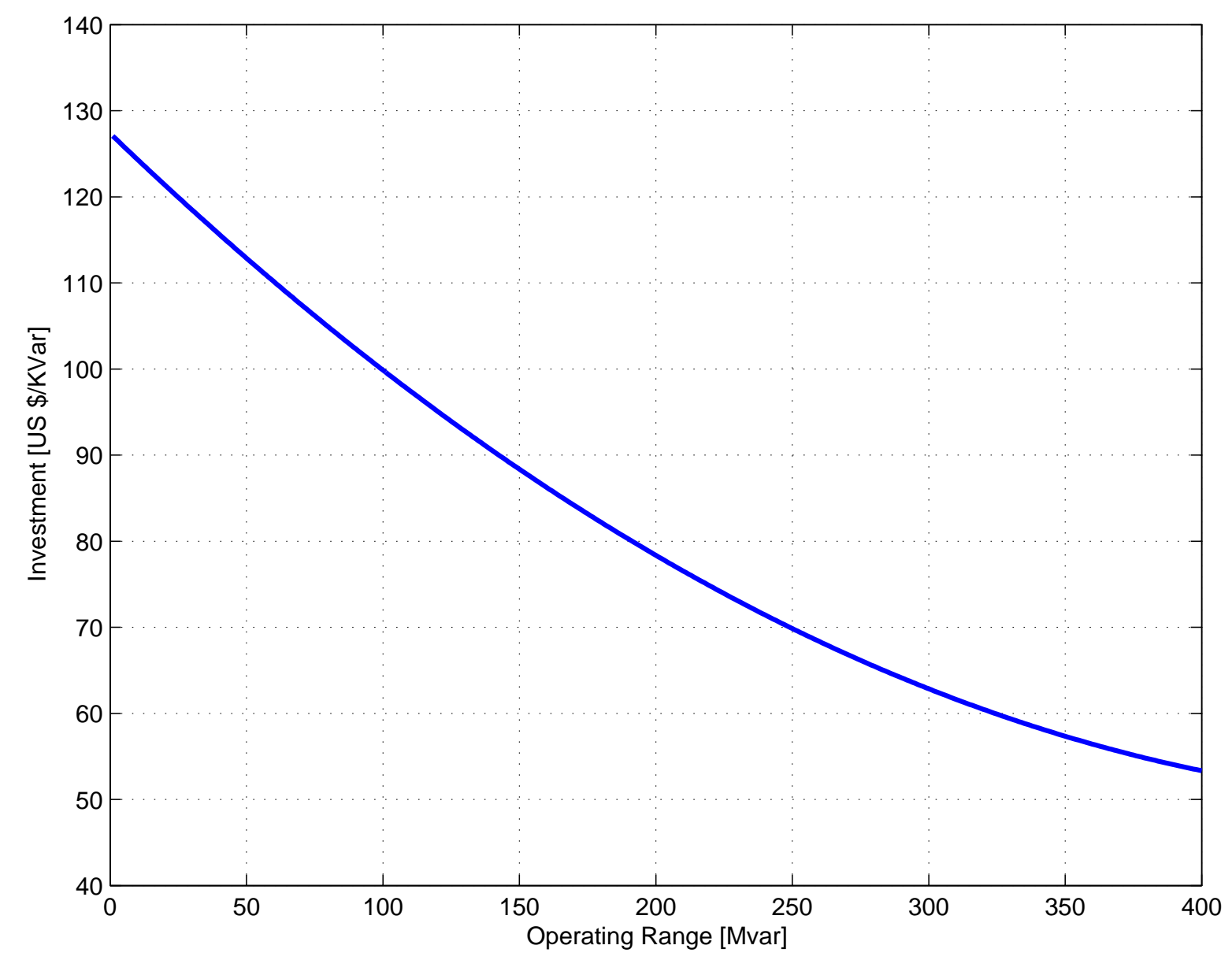

Figure 5.3: SVC Investment costs

\subsubsection{Equipment Costs and Infrastructure Costs}

As described in [24] the investment costs of FACTS devices can be split into two categories

1. Device equipment costs

2. Necessary Infrastructure costs

Equipment costs depend not only upon the installation rating but also upon special requirements such as: 
- Redundancy of the control and protection systems

- Seismic conditions

- Ambient conditions (e.g. temperature, pollution level), and

- Communication requirements with the substation control system or the regional or national control center.

Infrastructure costs depend on the device's and costs include

- Land acquisition, if there is insufficient space in the existing substation,

- Modifications to the existing substation,

- Construction of a building for indoor equipment,

- Yard civil works, and

- Communication infrastructure.

The typical range of investment costs is shown in Fig. 5.4, [24] with both the lower and upper limits of the cost areas. The lower limit of the cost area indicates the equipment costs and the upper limit indicates the total investment costs including the infrastructure costs. In this study, the total investment costs, corresponding to the upper limit of the Fig. 5.4 are used to take into consideration the worst case costs scenario. The operating costs of SVC are generally negligible when compared to the total investment costs and can be safely ignored.

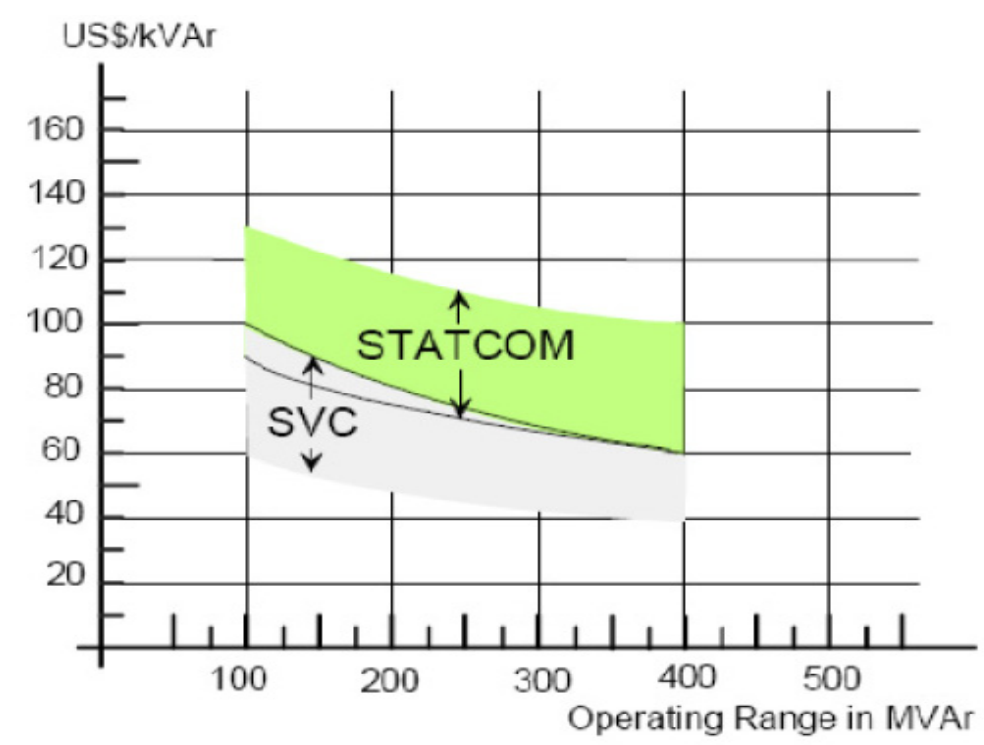

Figure 5.4: Typical Investemnt Costs for SVC / STATCOM [24] 
Most of the FACTS devices are in service for many years [24] and only a part of their life time is employed in regulation of power flow [6]. Since SVC procurement represents a significant capital expenditure, the decision must include returns the device will generate in the form of reductions in load load. In this study, the annualized cost of the device is calculated by assuming a uniform interest rate of $15 \%$ and 15 years of life expectancy. Hence, the annualized cost of the SVC as calculated from the model shown in Fig. 5.3 and from equation $(5.17)$ is

$$
\begin{aligned}
\text { Annual } C_{S V C} & =\frac{P \cdot r \cdot(1+r)^{N}}{(1+r)^{N}-1} \\
\text { Cost }_{S V C} & =\frac{\text { Annual } C_{S V C}}{8760}(U S \$ / h r)
\end{aligned}
$$

where $\mathrm{P}, \mathrm{r}$, and $\mathrm{N}$ denote principal value, interest rate per payment, and number of payments respectively. $C_{S V C}$ is the total investment costs of the SVC given from equation (5.17). 


\section{Chapter}

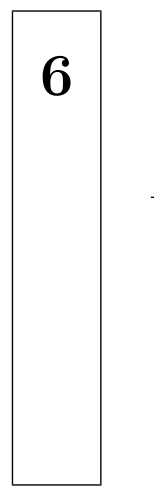

\section{Case Studies and Discussion}

This chapter describes two case studies, the first study focuses on examining critical buses for reactive power support, and the second on SVC risk analysis.

\subsection{PART I : Evaluation of Critical Buses For VAR Support}

The algorithm for the pilot or critical bus determination discussed in Chapter 4.3 is applied to different electric power systems. The nose curves and the voltages are displayed to monitor the voltage stability of the systems. A MATLAB based power system analysis tool [38] is used to compute the necessary values for the objective function.

\subsubsection{Test Systems Description}

Three test systems [42] have been analyzed and tested in this project to illustrate the proposed algorithm.

1. Western System Coordinating Council (WSCC) 3-Machines 9-Bus system as shown in Fig. 6.1.

2. The IEEE 14 bus test system, which represents a portion of the American Electric Power 
System (in the Midwestern US) as shown in Fig. 6.6.

3. The IEEE 30 bus test system, which represents a portion of the American Electric Power System (in the Midwestern US) as shown in Fig. 6.13.

\subsubsection{Results and Discussion}

Based on the index proposed in Chapter 4, the optimal location for VAR support is found for the above mentioned test systems.

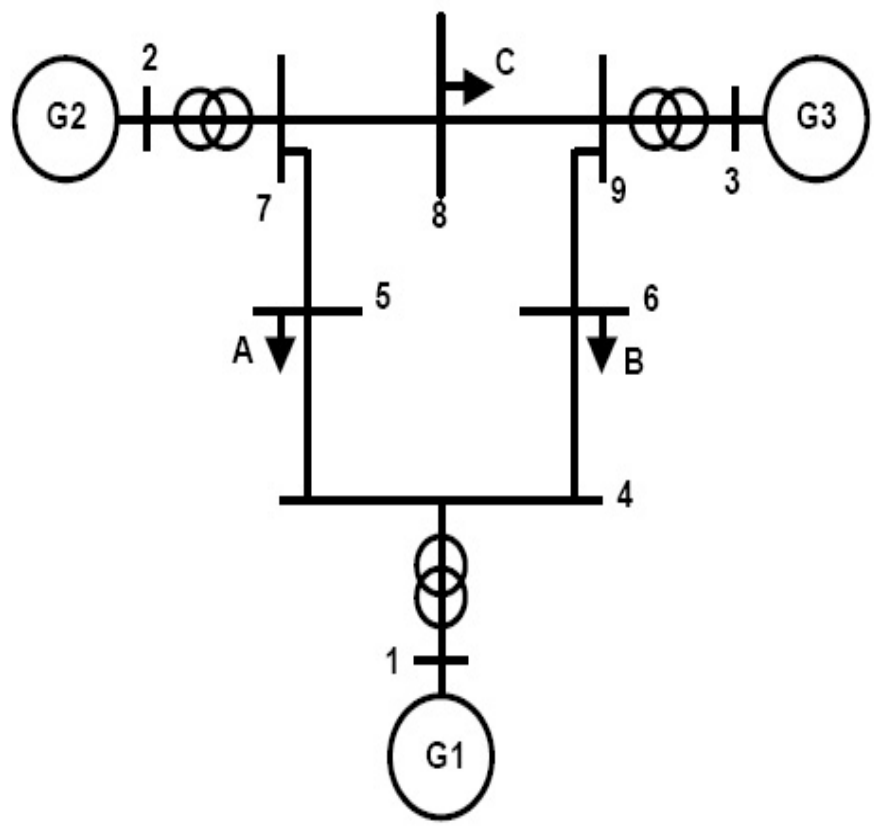

Figure 6.1: Western System Coordinating Council (WSCC) 3-Machines 9-Bus system

\section{Western System Coordinating Council (WSCC) 3-Machines 9-Bus system}

The critical bus ranking for VAR support for the 3-machine 9-bus system is shown in Table 6.1. Bus \#9 was found to be the pilot or critical bus suitable for the reactive power support. This result was found to be in accordance with the modal analysis ranking of critical buses which is shown in the Table 6.1 .

In order to estimate the most appropriate capacity of the VAR support, a relationship between the loading factor and the corresponding capacity of the device was found through 
(a) Proposed technique

\begin{tabular}{|c|c|}
\hline Bus No & J \\
\hline \hline $\mathbf{9}$ & $\mathbf{- 0 . 9 8 9}$ \\
\hline 5 & -0.4328 \\
\hline 6 & -0.3915 \\
\hline 8 & -0.3046 \\
\hline 7 & -0.2209 \\
\hline 4 & 0.4520 \\
\hline
\end{tabular}

(b) Modal Analysis

\begin{tabular}{|c|c|}
\hline Bus no & PF $^{1}$ \\
\hline \hline 9 & 0.3034 \\
\hline 5 & 0.2793 \\
\hline 7 & 0.1427 \\
\hline 4 & 0.1266 \\
\hline 8 & 0.0836 \\
\hline 6 & 0.0645 \\
\hline
\end{tabular}

Table 6.1: Critical buses ranking for 3-machine 9-bus system using proposed technique

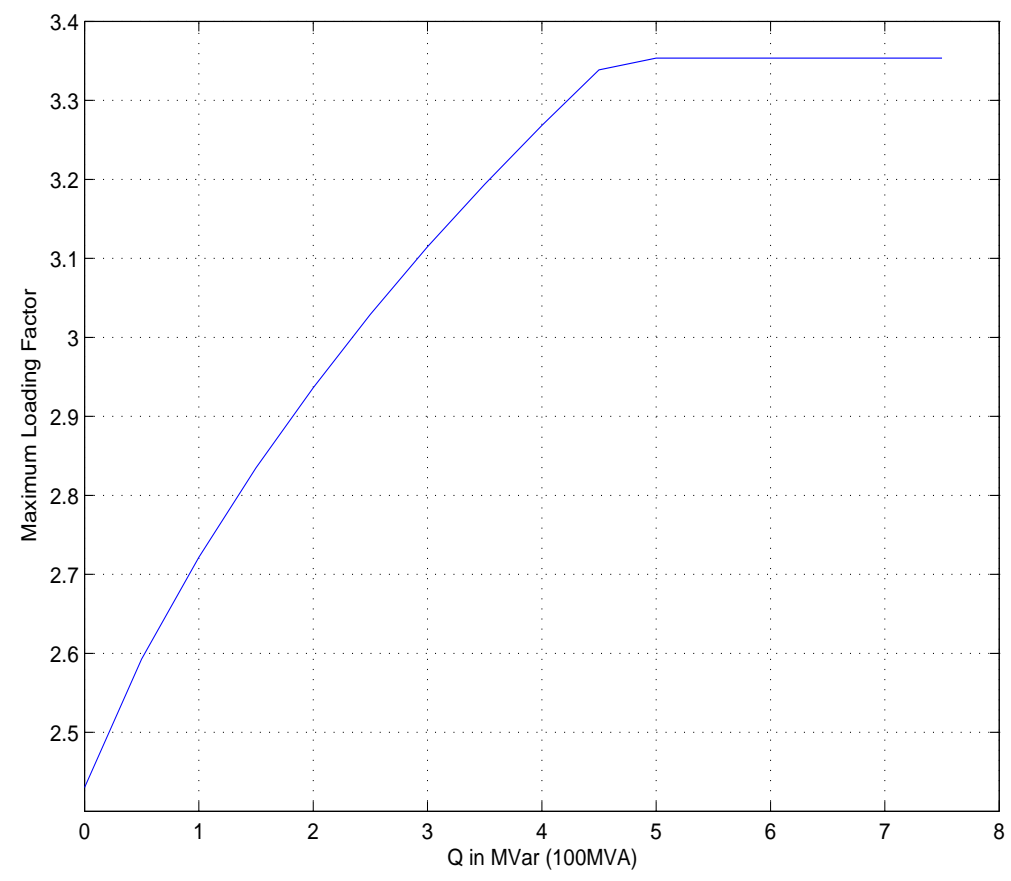

Figure 6.2: Loading Margin Vs SVC Capacity for 3-Machines 9-Bus system

evaluating information regarding how much support the device can provide against voltage collapse. The loading factor is the factor by which real and reactive power loads are increased to calculate the maximum loading point. This relationship is shown in the Fig. 6.2. Based on this relationship, the rating of the SVC was determined to be 500 MVar.

The effect of the placing an SVC with rating 500 MVar and using a constant bus voltage control scheme can be seen from the Fig. 6.3, Fig. 6.4 and 6.5. The loading margin of the 


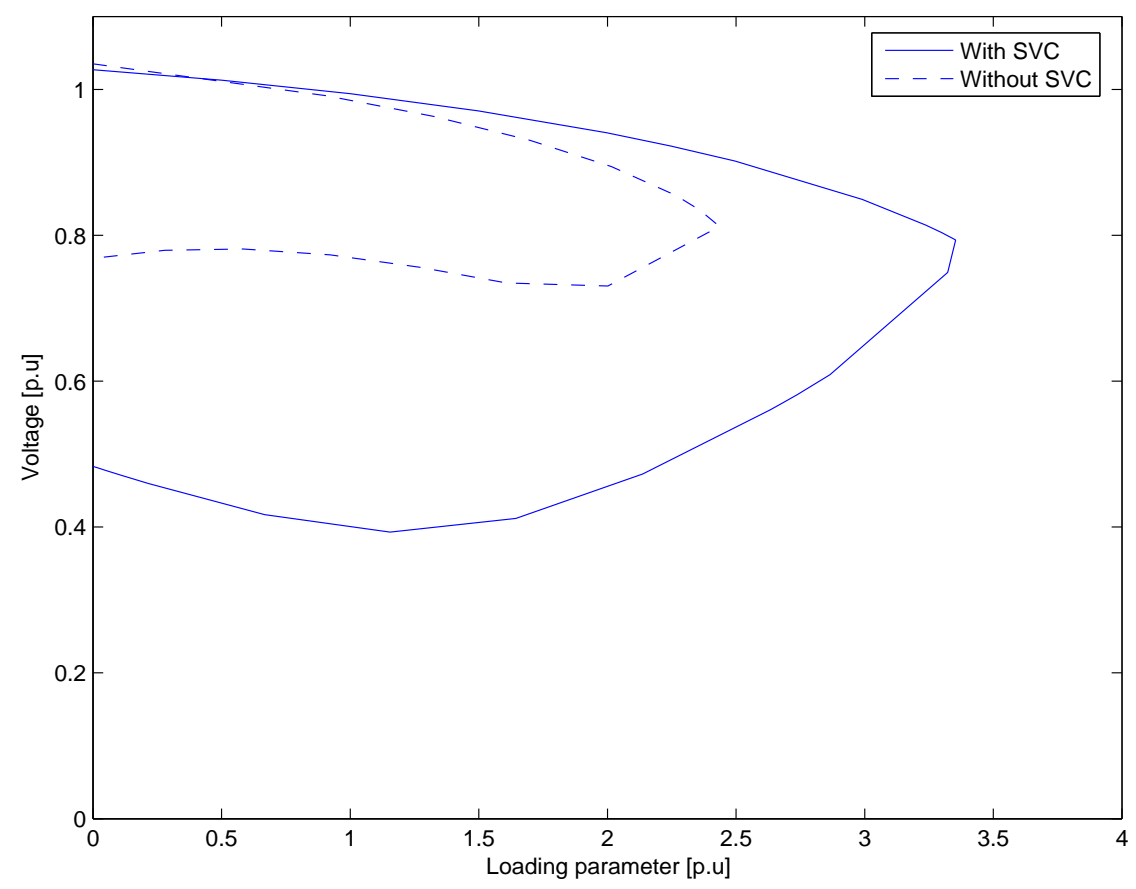

Figure 6.3: Nose curves at Bus \#'7 with and without SVC for 3-machine 9-bus system

system is increased from $2.45 \mathrm{p} . \mathrm{u}$ to $3.35 \mathrm{p} . \mathrm{u}$ (90 MVA), also the voltage profile of the system is vastly improved. Fig. 6.3 also shows the nose curve at a specific bus. The limit (point of voltage collapse) is reached when the additional VAR resources are depleted. Therefore, the resource margin can be used to predict operational resources.

\section{IEEE 14 Bus Test System}

The single line diagram of the IEEE 14 bus system is depicted in Fig. 6.6, which consists of two generators and three synchronous condensers located at buses $1,2,3,6$, and 8 , respectively. In this system, there are twenty branches and fourteen buses with eleven loads totaling “ $259 \mathrm{MW}$ " and "81.4 MVar" for the base case.

The ranking of the buses for critical bus identification based on both the proposed approach and Modal analysis [21] is shown in Table 6.2. The proposed approach selects bus \#4 as the best choice for the location of SVC. The weak bus determination approach using modal analysis, selects bus \#14. The effect of placing an SVC in the system for both the choices can be seen by observing the increase in the stability margin as shown in Fig. 6.7 and Fig. 6.8.

The approach used in this work selected bus \#4 as an ideal choice because majority of load 


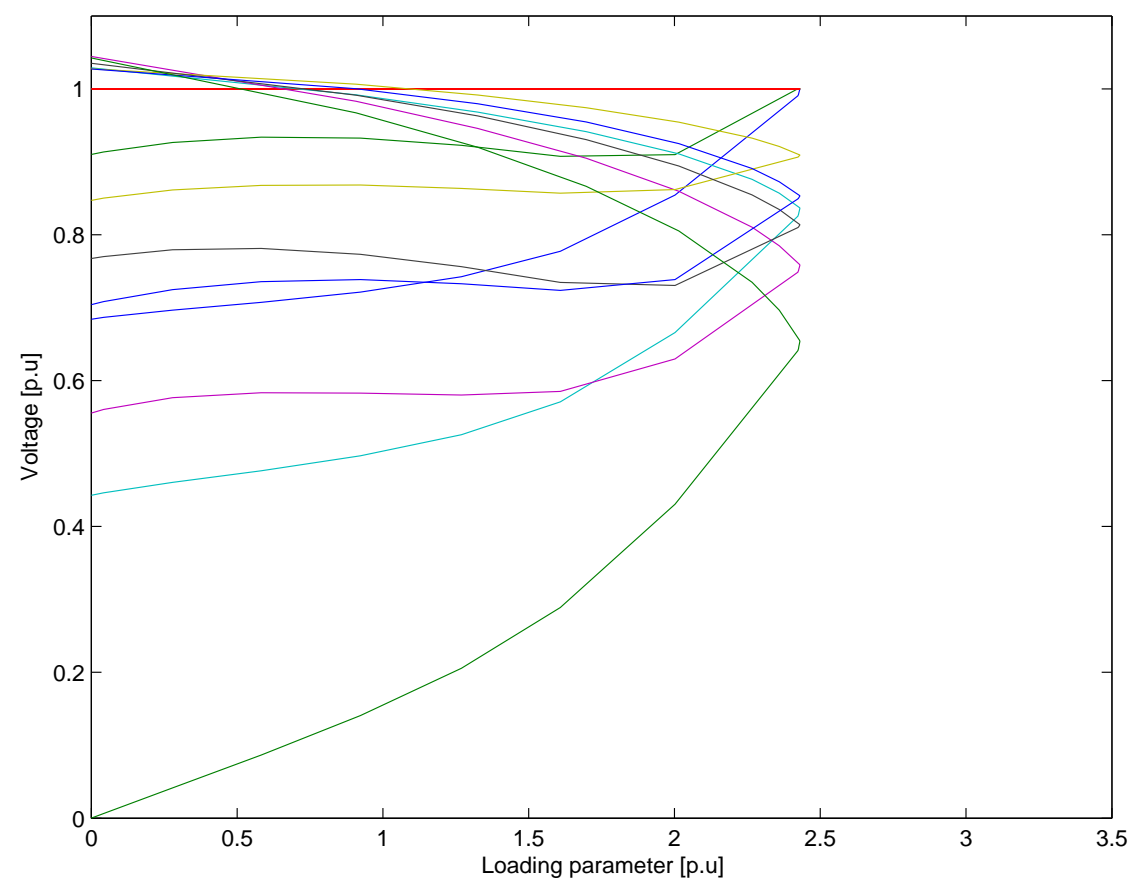

Figure 6.4: Nose curves without SVC for 3-machine 9 bus system

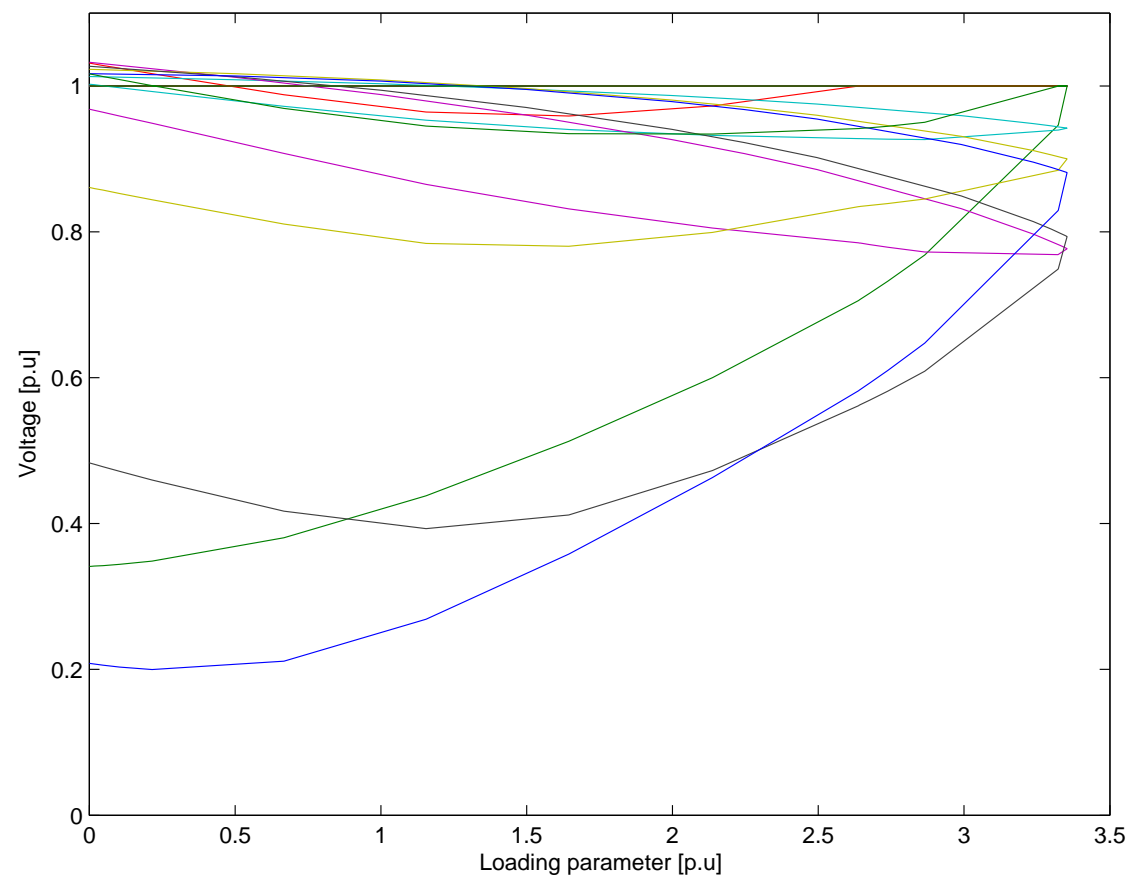

Figure 6.5: Nose curves with SVC at Bus \#9, for 3-machine 9 bus system 


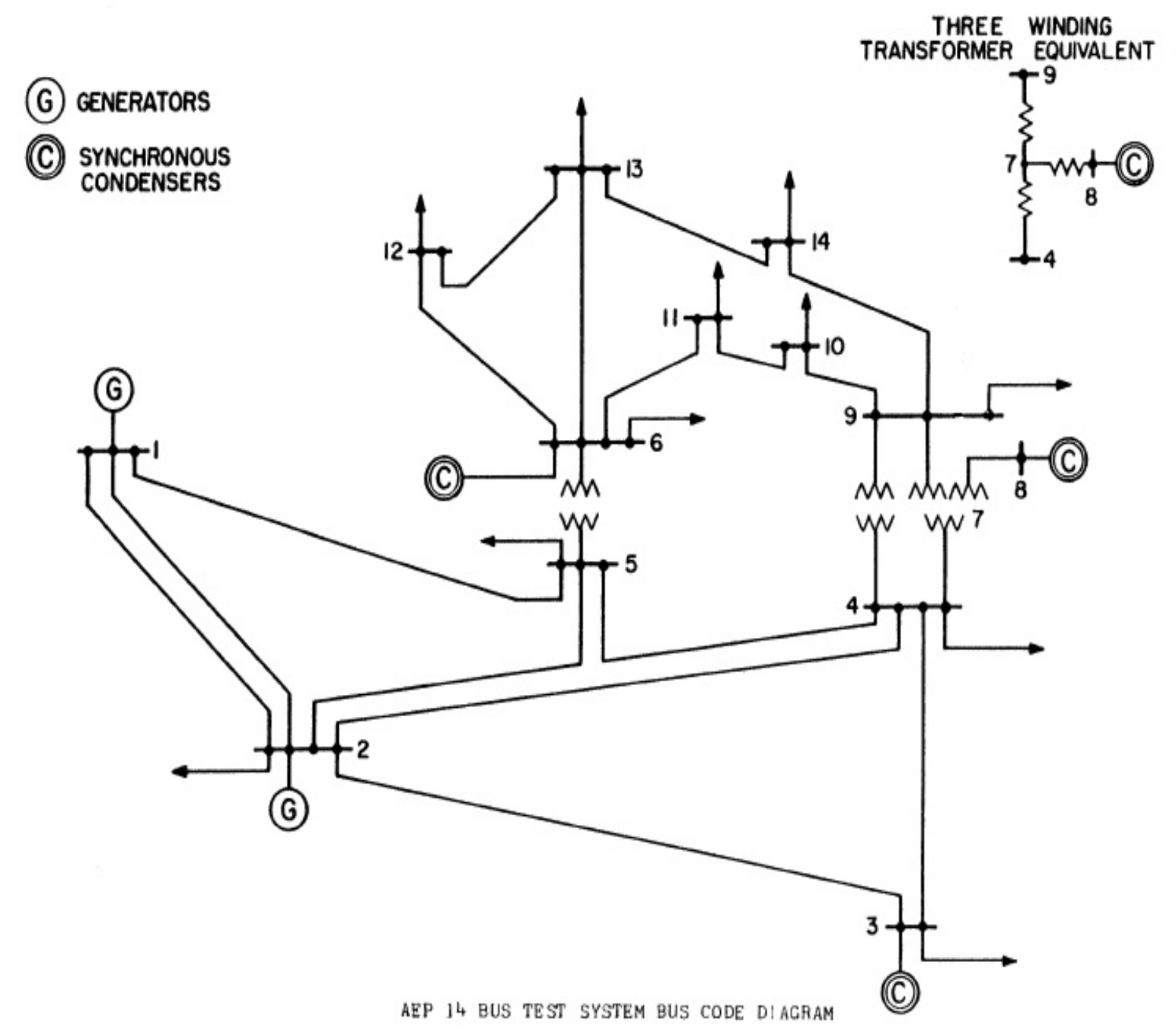

Figure 6.6: Single line diagram of the IEEE 14 Bus System [42] . 


\begin{tabular}{|c|c||c|c|}
\hline $\begin{array}{c}\text { Index Value } \\
\text { J }\end{array}$ & $\begin{array}{c}\text { Proposed } \\
\text { Bus \# }\end{array}$ & $\begin{array}{c}\text { Modal Analysis } \\
\text { Bus \# }\end{array}$ & PF \\
\hline \hline-0.3897 & 4 & 14 & 0.3190 \\
\hline-0.3120 & 5 & 10 & 0.2394 \\
\hline-0.2662 & 10 & 9 & 0.1988 \\
\hline-0.1361 & 9 & 11 & 0.1103 \\
\hline-0.1142 & 11 & 7 & 0.0691 \\
\hline-0.0686 & 14 & 13 & 0.0323 \\
\hline-0.0071 & 13 & 12 & 0.0189 \\
\hline 0.3193 & 7 & 4 & 0.0082 \\
\hline 0.4261 & 12 & 5 & 0.0040 \\
\hline
\end{tabular}

Table 6.2: Critical buses ranking for VAR support for IEEE 14 bus system

is constituted at bus number 3, 4, and 9. Also, the studies take into consideration the effect of generator reactive power limits. Any additional reactive power support must guarantee that these buses along with the rest of the buses in the network operate at a good voltage profile with remaining VAR resources under normal and contingency conditions. The effect of placing a reactive source of 300 MVA at bus \#4 for various contingencies can be seen by comparing Fig. 6.9 and Fig. 6.10.

Table 6.3 compares the loading margins for the selected contingencies. Note that these contingencies are ranked according to their severity. The performance of the system improves by placing an SVC at bus \#4 rather than bus \#14. Hence, bus \#4 is a better choice for the location of VAR support.

The effect of SVC at bus \#14 and bus \#4 on the loading margin is shown clearly in Fig. 6.7 and Fig. 6.8. Also, Fig. 6.11 shows the voltage magnitudes computed at the critical point, when SVC placed at bus \#14. As illustrated by placing SVC at bus \#4 we can actually maintain much better voltage level at a loading condition, which would result in the bifurcation or collapse of the system when SVC is placed at bus \#14. Similar to the case of the 3-machine 9-bus system, the rating of the SVC has been chosen based on the relationship between the MVar and the loading factor. In this case 300 MVar or 3 p.u has been chosen as the SVC rating. A case with shunt capacitor bank of total rating $1.5 \mathrm{p} . \mathrm{u}$ and $\mathrm{SVC}$ rating of 1.0 p.u 


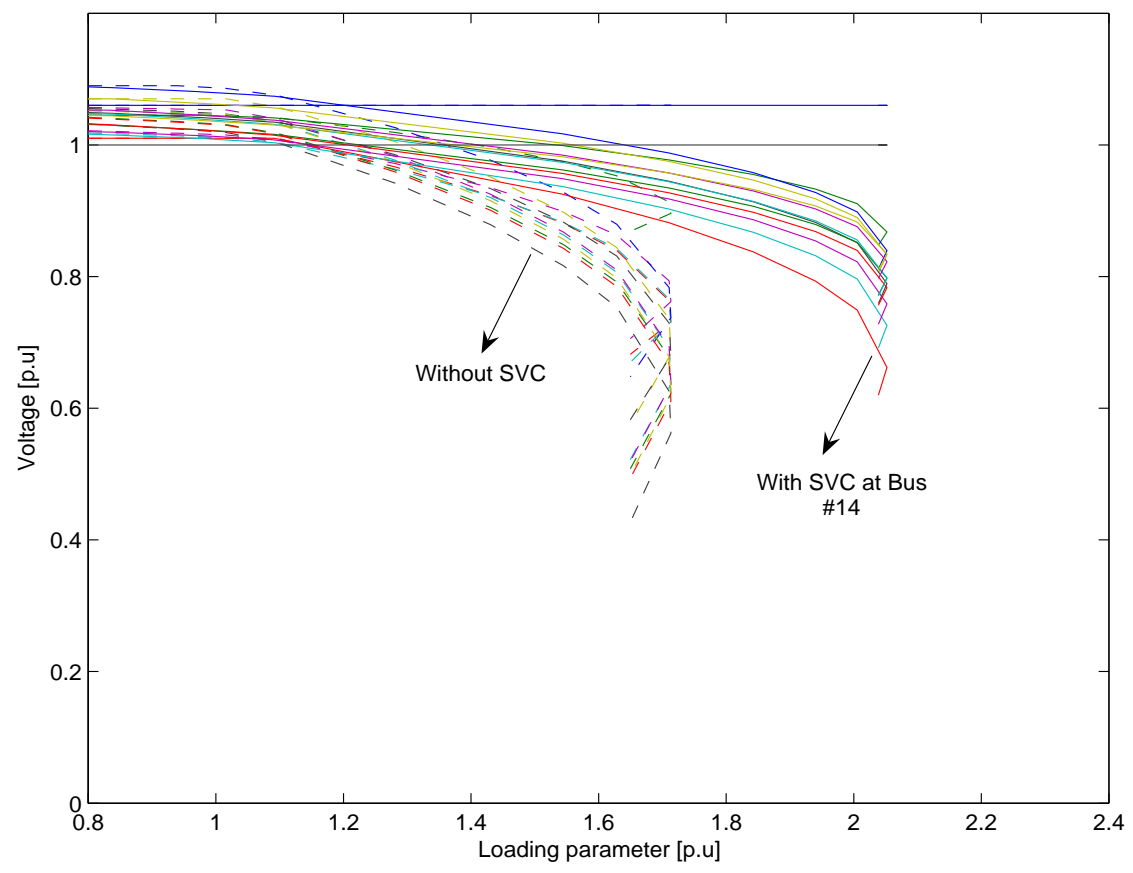

Figure 6.7: Nose curves with SVC at Bus \#14 (Modal analysis)

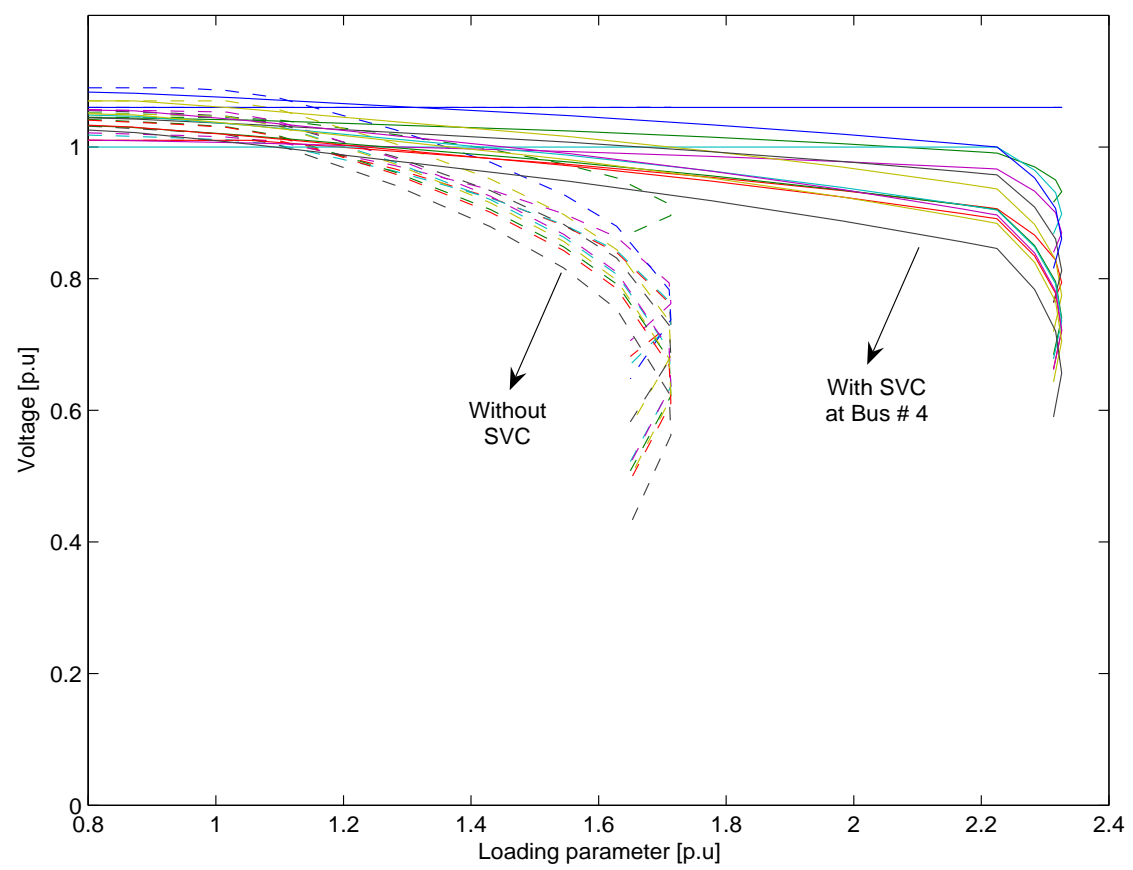

Figure 6.8: Nose curves with SVC at Bus \#4 (Proposed approach 


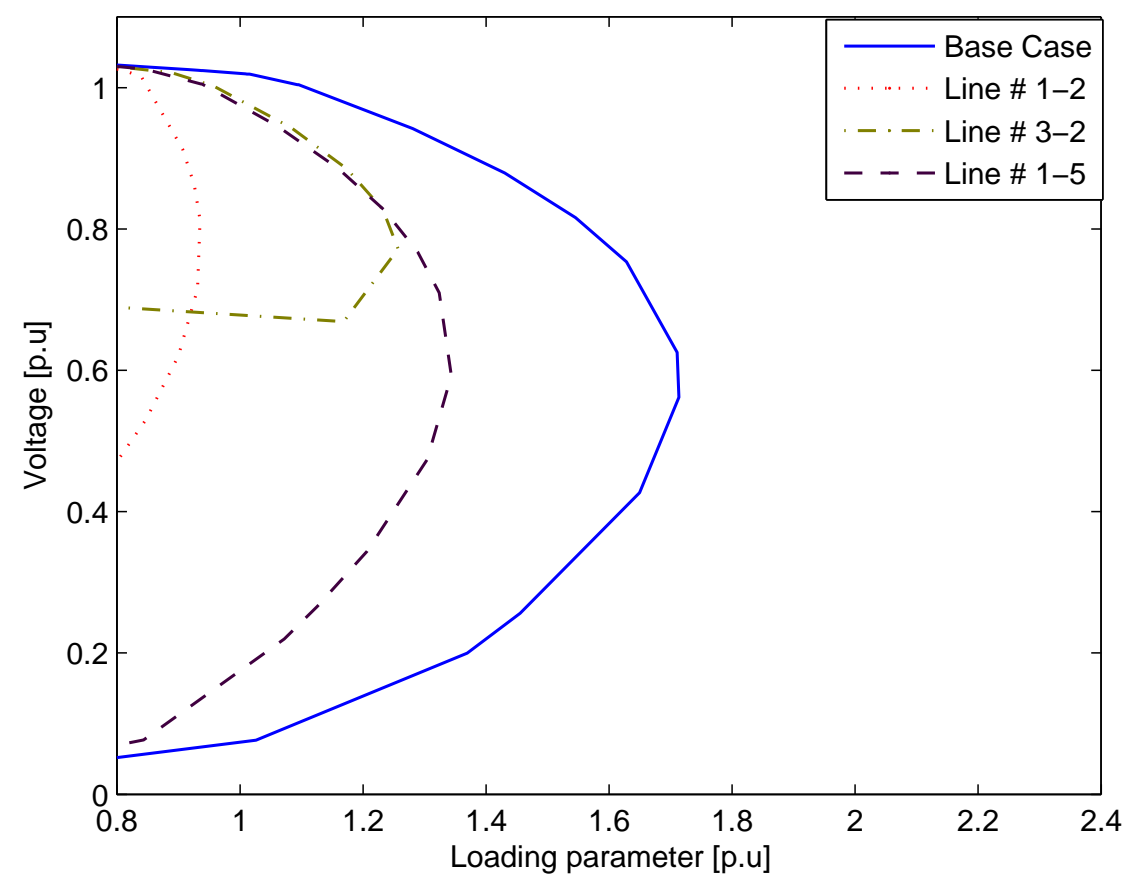

Figure 6.9: Nose curves at Bus \#14 for different contingencies without SVC

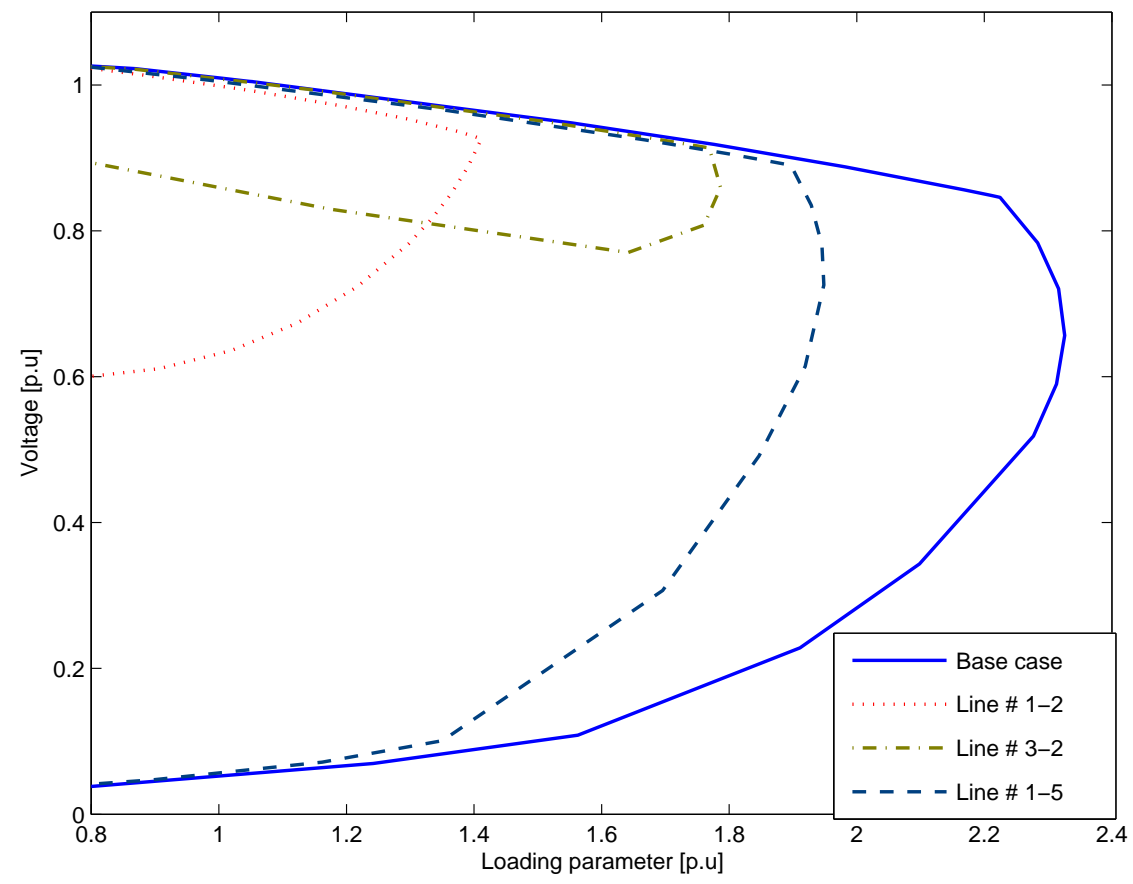

Figure 6.10: Nose curves at Bus \#14 for different contingencies with SVC at Bus \#4 


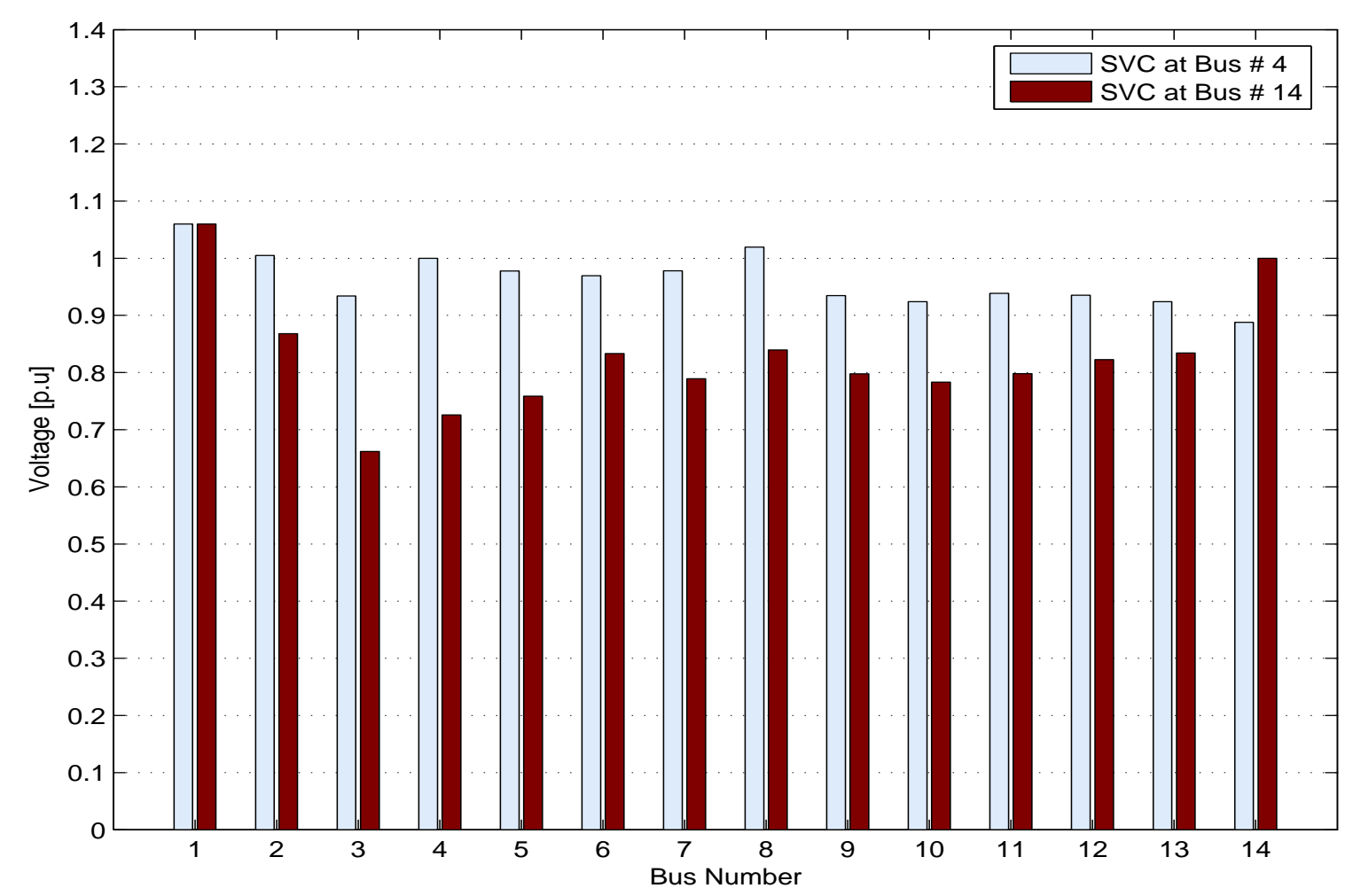

Figure 6.11: Comparision of voltages for two SVC locations at critical loading condition of system with $S V C$ at bus \#14

\begin{tabular}{|l||c|c|c|}
\hline $\begin{array}{c}\text { Outage } \\
\text { Line \# }\end{array}$ & Base case & $\begin{array}{c}\text { SVC } \\
\text { at Bus \#4 }\end{array}$ & $\begin{array}{c}\text { SVC } \\
\text { at Bus \#14 }\end{array}$ \\
\hline \hline $1-2$ & $\begin{array}{c}\text { No } \\
\text { Solution }\end{array}$ & 0.4378 & 0.0456 \\
\hline $3-2$ & 0.2059 & 0.4617 & 0.1671 \\
\hline $1-5$ & 0.1648 & 0.9194 & 0.4580 \\
\hline $2-4$ & 0.3628 & 0.8986 & 0.6747 \\
\hline $2-5$ & 0.4217 & 0.9679 & 0.7478 \\
\hline $5-6$ & 0.0807 & 0.1202 & 0.5410 \\
\hline $3-4$ & 0.4322 & 0.5889 & 0.5480 \\
\hline
\end{tabular}

Table 6.3: Comparison of Loading Margins with SVC at Bus \#14 and Bus \#4 for different contingencies 


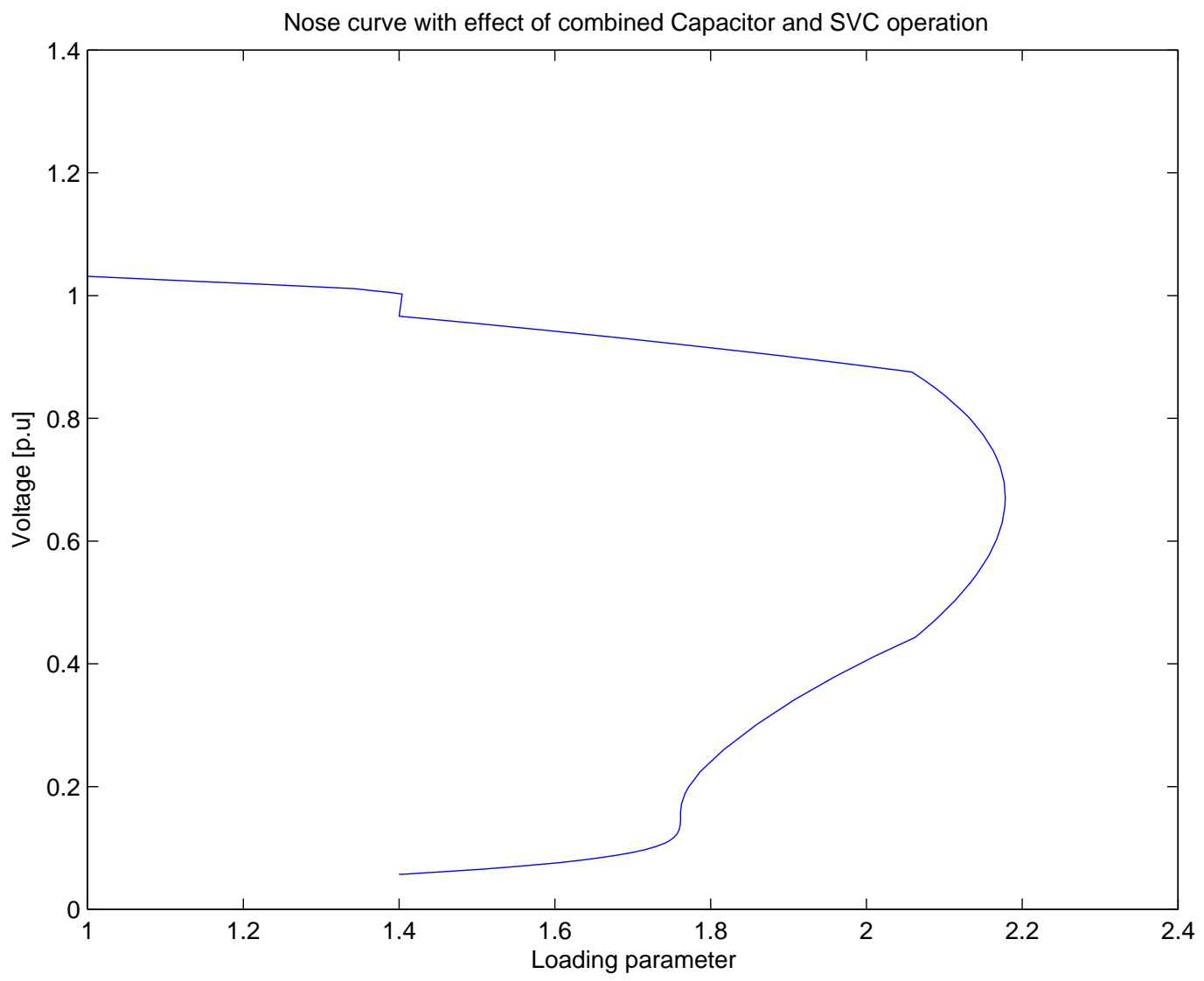

Figure 6.12: Nose curve at Bus \#14 with Capacitor bank and SVC

has been used to test the system. The rating of the SVC was chosen less than the capacitors to illustrate the point that cost of capacitors are cheap and an SVC of less rating can be used to control the voltage at the specific bus. It is assumed that at initial loading conditions, capacitor bank is activated and later SVC takes control. The main idea of this analysis is to show the benefits of low and alternative capacitor banks alongside SVCs. For the static analysis, the VAR support with SVC or Capacitor yields similar results. Fig. 6.12 shows the discussed scenario. In this work, dynamic aspects of SVC are not discussed.

\section{IEEE 30 Bus System}

The single line diagram of the IEEE 30 bus system is depicted in Fig. 6.13. For the IEEE 30 bus system the number of SVC's required depends on factors such as system operating conditions, load demand, etc. 


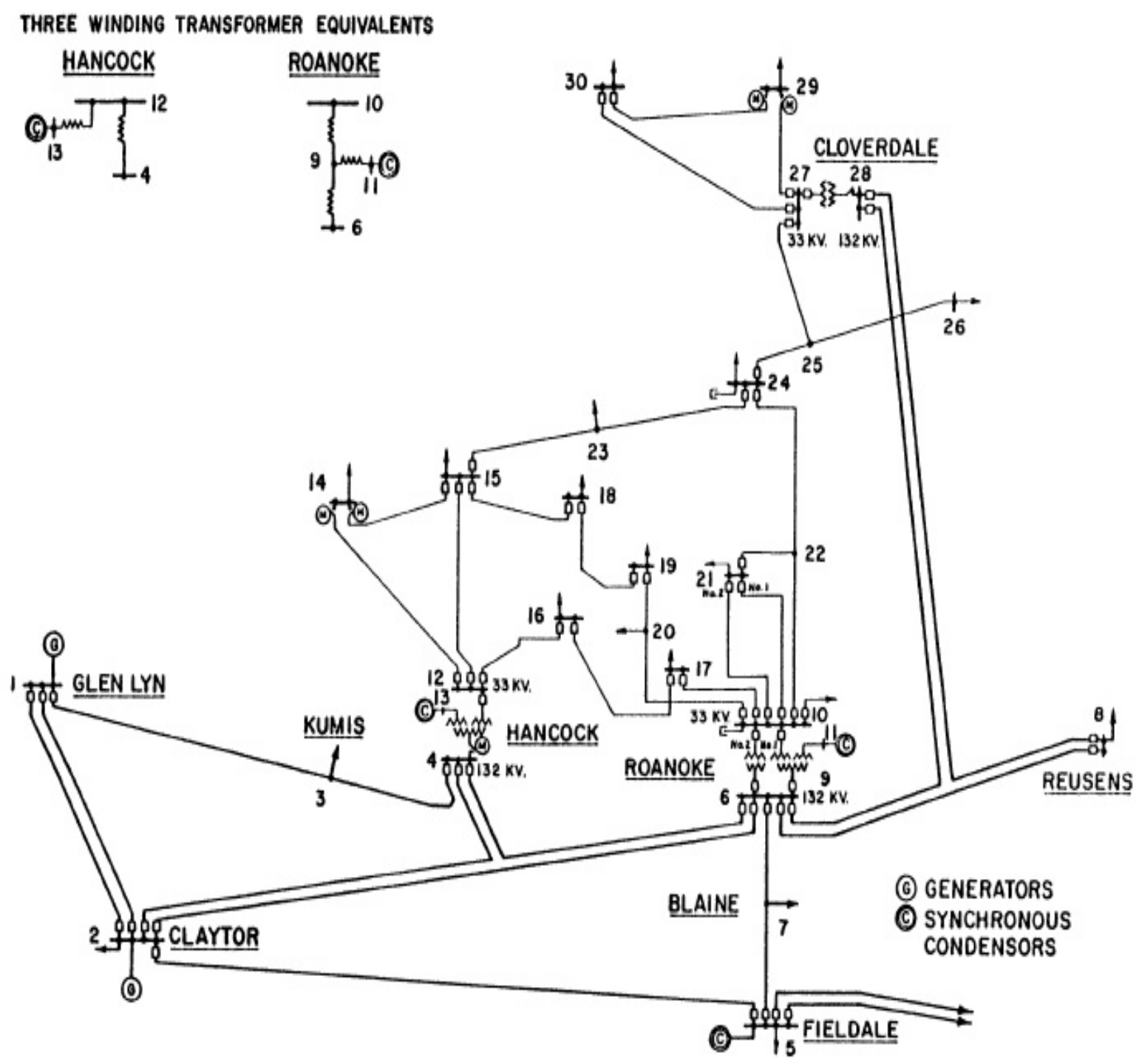

Figure 6.13: Single line diagram of the IEEE 30 Bus Test System [42] . 


\begin{tabular}{|c|c|}
\hline Proposed & Modal \\
\hline \hline 6 & 30 \\
\hline 3 & 29 \\
\hline 15 & 26 \\
\hline 7 & 25 \\
\hline 25 & 27 \\
\hline
\end{tabular}

Table 6.4: Ranking of buses for VAR support for IEEE 30 bus system using proposed and modal analysis

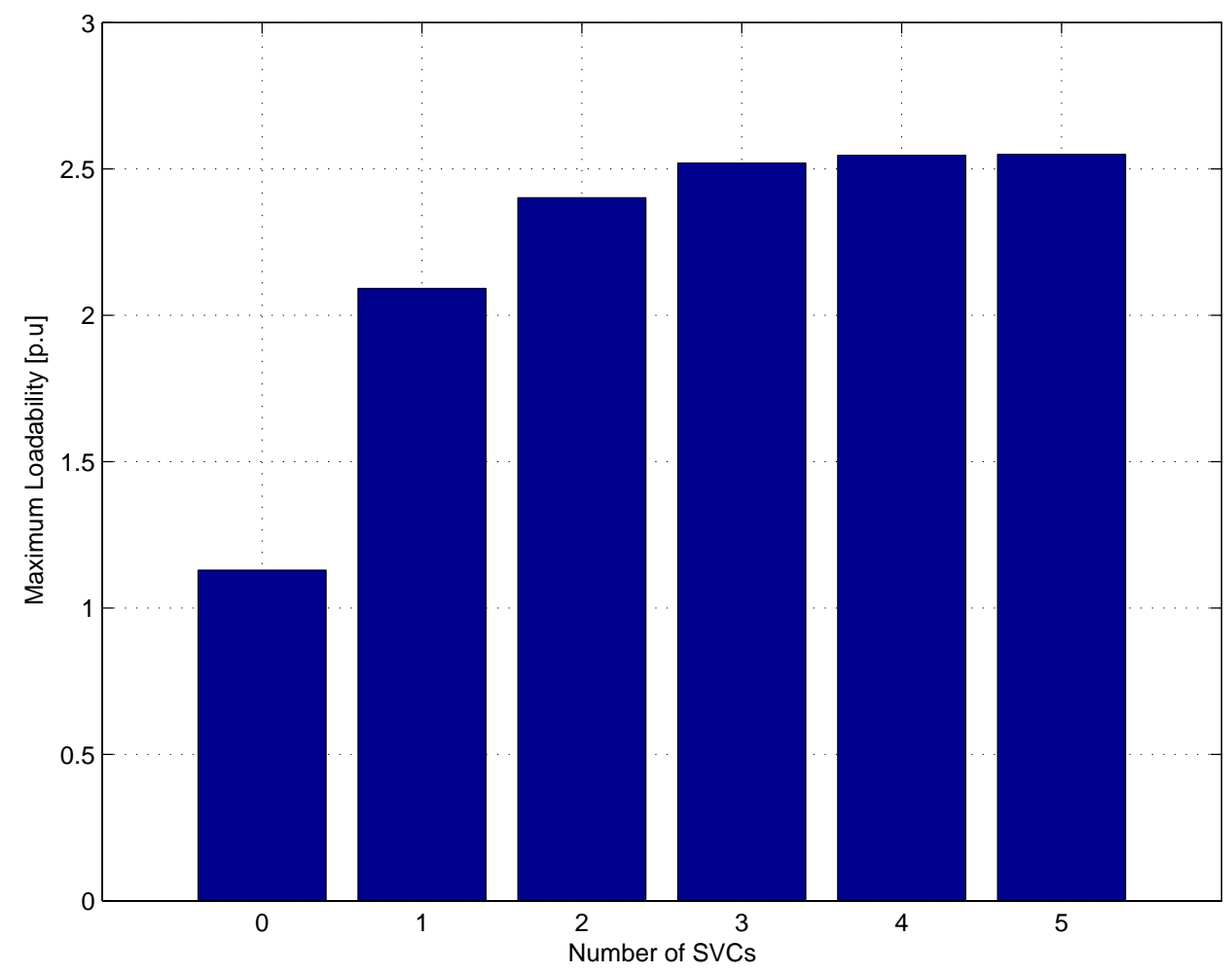

Figure 6.14: Plot of Maximum Loadability vs Number of SVCs 


\begin{tabular}{|l||c|c|}
\hline Approach & SVC locations & Maximum Loadability \\
\hline \hline Modal Analysis & Bus \# 30 (400 MVA) & 1.1557 \\
& Bus \# 29 (200 MVA) & \\
\hline Proposed & Bus \# 6 (400 MVA) & 2.4014 \\
& Bus \# 3 (200 MVA) & \\
\hline
\end{tabular}

Table 6.5: Comparison of SVC Vs Maximum Loadability for Proposed approach and Modal Analysis

The proposed algorithm can be used to locate multiple locations for the SVC placement in the system. Once the best location for one SVC has been chosen by the algorithm, the search for the next best choice is determined by repeating the algorithm with the first SVC included in the system. The MVar capacity of the SVC is chosen based on its affect on the loading margin of the system. This approach would automatically make sure that the optimal location and size is guaranteed. Based on the above approach, the best locations for the placement of SVC according to the priority is listed in the Table 6.4. Fig. 6.14 shows the effect of SVCs in the system against the system's maximum loadability. As the number of SVCs increases improvements in loadability reduces. To evaluate the difference between the proposed approach and modal analysis, two SVCs are placed in this system according to the ranking given in Table 6.4. The top two buses are selected as the locations and the loading margins are evaluated. The results in Table 6.5 show that the proposed approach gives a better result in terms of margin to voltage collapse.

\subsection{PART II : Voltage Stability Risk Analysis}

An analysis of the system with and without an SVC and the risk of a voltage collapse in the system as discussed in Chapter 5 and demonstrated next. The IEEE 24-bus Reliability Test System [43] is depicted in Fig. 6.15 and used here to illustrate a more realistic application of the concepts above. The IEEE Single Area Reliability Test System is a relatively large system with 24 buses including 10 generators, 17 load buses and 38 lines. The base load is 2850 MW and peak load is 3135 MW. The appendix A and [43] provide more information on the data of the system.

In this study only the selected contingencies are considered. The contingency ranking is based on maximum power flow in the lines at collapse point. Table 6.6 lists the set of 


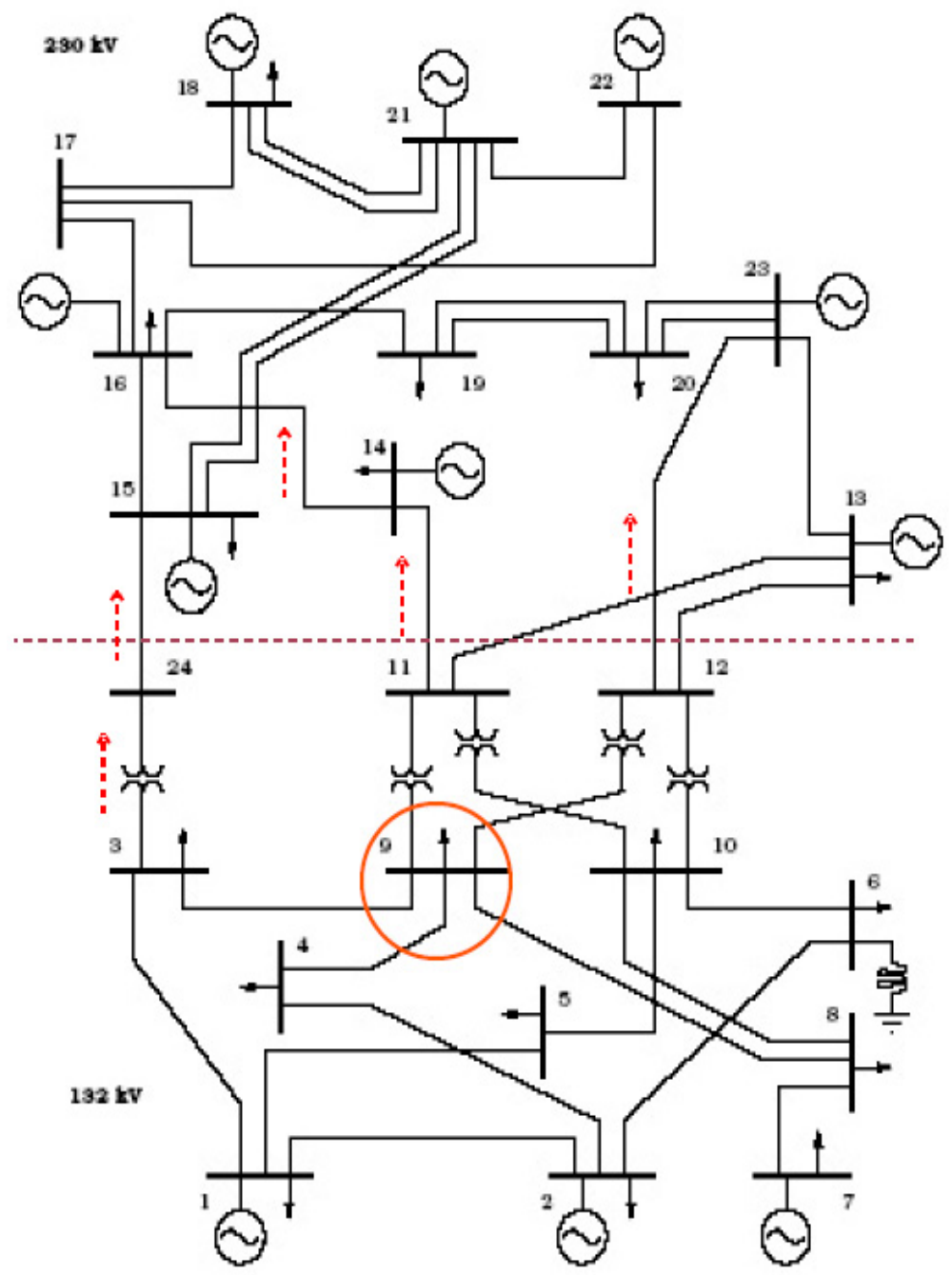

Figure 6.15: IEEE Single Area 24 Bus Reliability Test System - 96 [42]

\begin{tabular}{|c|c|}
\hline Line \# & From-To \\
\hline \hline 7 & $24-3$ \\
\hline 23 & $16-14$ \\
\hline 27 & $15-24$ \\
\hline 19 & $14-11$ \\
\hline 21 & $23-124$ \\
\hline
\end{tabular}

Table 6.6: Critical Contingencies for IEEE 24 bus system 


\begin{tabular}{|l|c|c|}
\hline $\begin{array}{l}\text { Contingency } \\
\text { Line Outages }\end{array}$ & $\begin{array}{c}\text { Occurrence } \\
\text { Probability per hour }\end{array}$ & $\begin{array}{c}\text { Loadability } \\
\text { w/o SVC (MW) }\end{array}$ \\
\hline \hline No outage & 0.97455 & 4390 \\
\hline outage $24-3$ & 0.00175 & 3530 \\
\hline outage $14-11$ & 0.00049 & 3860 \\
\hline outage $23-12$ & 0.00065 & 3890 \\
\hline outage $16-14$ & 0.00048 & 3500 \\
\hline outage $15-24$ & 0.00051 & 3520 \\
\hline
\end{tabular}

Table 6.7: Loadability under various contingency conditions with their respective occurrence probabilities

contingencies. The lines analyzed are primarily those which connect the high-voltage side $(230 \mathrm{kV})$ if the network to the low-voltage side $(132 \mathrm{kV})$ of the network.

\subsubsection{Without SVC}

\section{A. Assumptions}

It is assumed that the forecast expectation of the future system load will be same with and without the SVC in the system. The time frame analyzed is one hour assuming a one hour ahead market structure and for LMP computation. The standard deviation of the future load level is assumed is to be $5 \%$ [26]. The occurences of the contigencies are estimated from the annual outage rates for the corresponding transmission lines. The probability of each contingency for the corresponding outage and no outage is listed in Table 6.7. These probabilities are evaluated based on the outage rates specified for the test system. The expected financial impacts of collapse and no collapse is evaluated using the equations (5.10) and (5.11). As stated in Chapter 5, it is assumed that voltage collapse results in total system blackout. As assumed in [5], [60], [46], the security cost for voltage collapse is $10,000 \$ / \mathrm{MWh}$, and the security cost for voltage limit violation and associated service interruption of load when voltage does not collapse is assumed to be $2,000 \$ / \mathrm{MWh}$. At the loading level of $3870 \mathrm{MW}$, the total impact is expected to be $\$ 0.65$ Million/h based on these values. 


\begin{tabular}{|c|c|}
\hline Expected Load & Standard Deviation \\
\hline $3870 M W$ & $193 \mathrm{MW}$ \\
\hline
\end{tabular}

Table 6.8: Expected Load and standard deviation

\begin{tabular}{|l|c|c|}
\hline Contingency & $\begin{array}{c}\text { Expected } \\
\text { Margin (MW) }\end{array}$ & $\begin{array}{c}\text { Probability of Collapse } \\
\text { w/ Contingency }\end{array}$ \\
\hline \hline No outage & 426 & 0.014 \\
\hline outage $24-3$ & -342 & 0.961 \\
\hline outage $14-11$ & -11 & 0.523 \\
\hline outage $23-12$ & 19 & 0.469 \\
\hline outage $16-14$ & -365 & 0.970 \\
\hline outage $15-24$ & -342 & 0.961 \\
\hline
\end{tabular}

Table 6.9: Loading Margin Randomness and Probability of Collapse Given a Contingency

\section{B. Evaluation of Voltage Stability Risk and Expected Impact}

The base case with a load level of $3870 \mathrm{MW}$ is assumed for calculation of the parameters as discussed in the Chapter 5. First, our aim is to calculate the probability of collapse under current loading conditions without any SVC in the network. Table 6.9 lists the probability of collapse given a contingency.

Using equation (5.9), the probability of collapse for the next hour and the load forecasted is only $1.66 \times 10^{-2}$. It is calculated by summing up all the products of collapse probability under contingency and the probability of corresponding contingency. Figure 6.16 provides a plot of total collapse probability against different loading levels.

\subsubsection{With SVC}

Using the proposed algorithm for the optimal location of reactive support, bus \#9 was found to be best for the SVC placement. The capacity is determined using the relationship between the loading margin and MVar capacity as shown in Fig. 6.17. The capacity of the device is found to be 450 MVar. Note that unlike previous cases, here loading margin is taken on the y-axis. . 


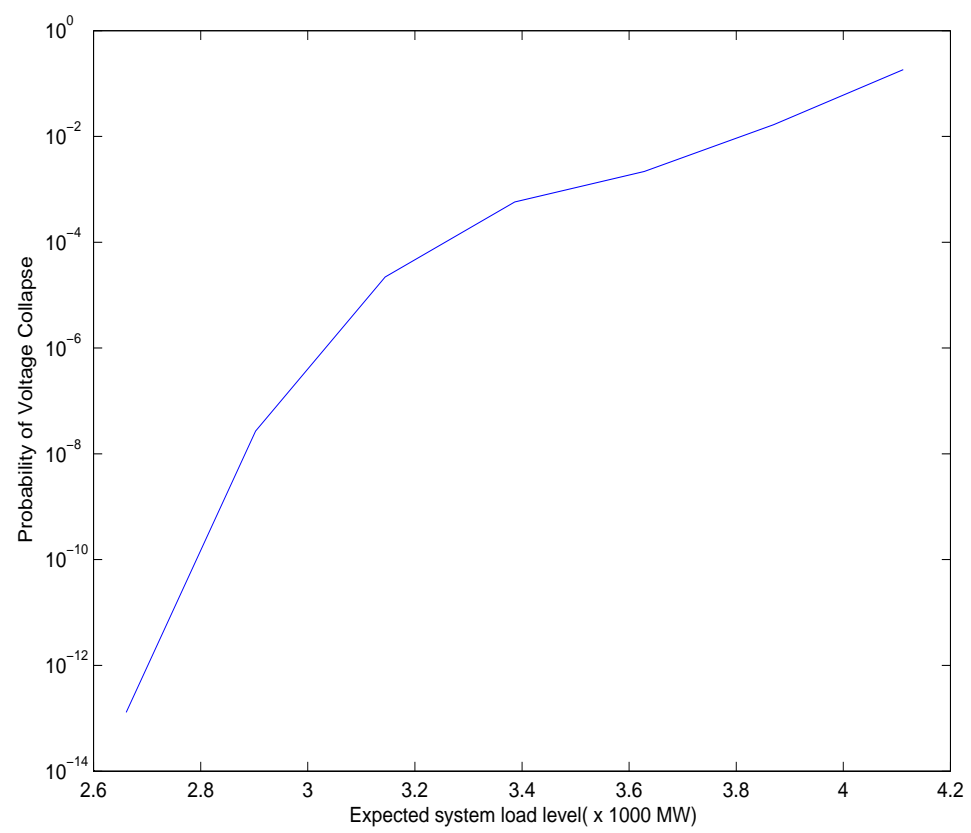

Figure 6.16: Probability of Voltage Collapse without SVC

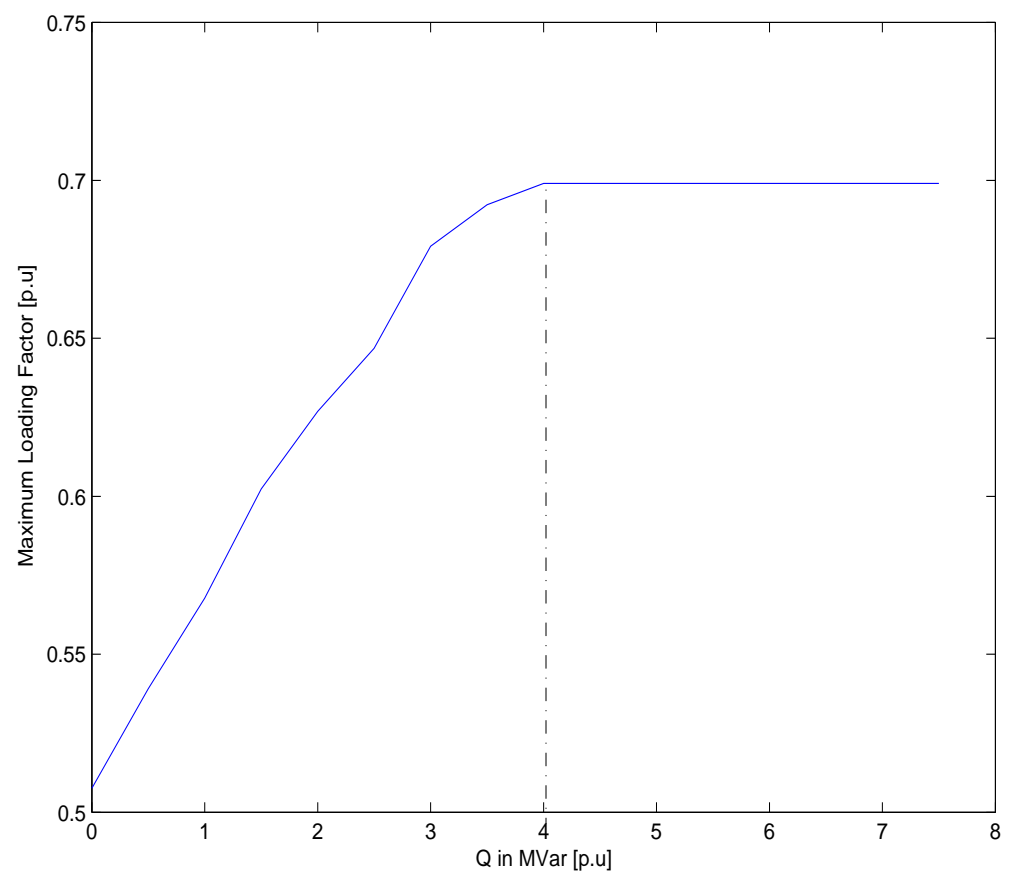

Figure 6.17: Determining the Rating of SVC at Bus\# 9 for IEEE 24 bus Reliability Test System 


\begin{tabular}{|c|c|}
\hline $\begin{array}{c}\text { Contingency } \\
\text { Line Outage }\end{array}$ & $\begin{array}{c}\text { Loadability } \\
\text { with SVC (MW) }\end{array}$ \\
\hline \hline No outage & 4840 \\
\hline outage $24-34$ & 4270 \\
\hline outage $14-11$ & 4650 \\
\hline outage $23-12$ & 4410 \\
\hline outage $16-14$ & 3940 \\
\hline outage $15-24$ & 4260 \\
\hline
\end{tabular}

Table 6.10: Loadability under various contingency conditions

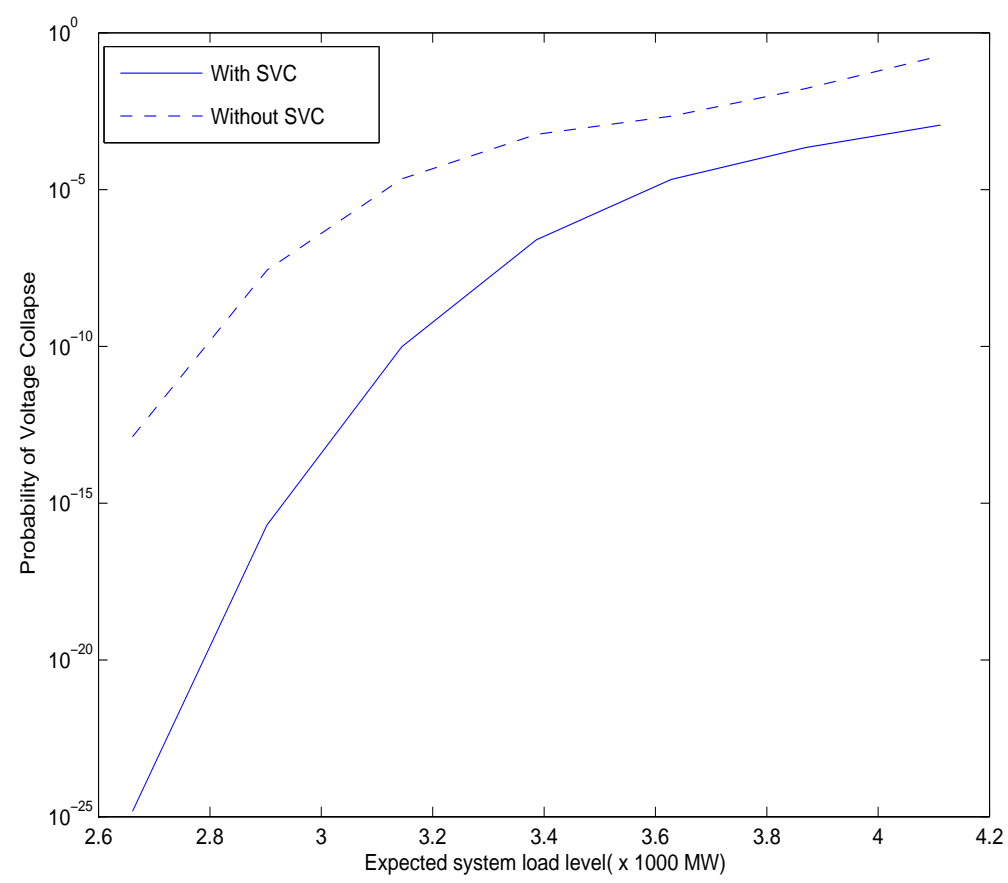

Figure 6.18: Comparison of Probability of Collapse with and without SVC for IEEE 24 bus Reliability Test System

Table 6.11 lists the probability of collapse at the loading level of $3870 \mathrm{MW}$ with SVC in the system. Comparing Table 6.11 with Table 6.9 shows the affect of placing an SVC in the system. Also, Figure 6.18 shows the probability of collapse with and without SVC in the system. 


\begin{tabular}{|l|c|c|}
\hline Contingency & $\begin{array}{c}\text { Expected } \\
\text { Margin (MW) }\end{array}$ & $\begin{array}{c}\text { Probability of Collapse } \\
\text { for next hour with SVC }\end{array}$ \\
\hline \hline No outage & 972 & $2.584 \times 10^{-7}$ \\
\hline outage $24-3$ & 398 & $2.012 \times 10^{-2}$ \\
\hline outage $14-11$ & 781 & $2.705 \times 10^{-5}$ \\
\hline outage $23-12$ & 537 & $2.857 \times 10^{-3}$ \\
\hline outage $16-14$ & 714 & $3.558 \times 10^{-1}$ \\
\hline outage $15-24$ & 390 & $2.220 \times 10^{-2}$ \\
\hline
\end{tabular}

Table 6.11: Loading Margin Randomness and Probability of Collapse with SVC

\section{Cost Evaluation of SVC using Payment Function}

The SVC investment cost is annualized assuming a uniform interest rate of $15 \%$ and life expectancy of 15 years. This is calculated as follows

$$
P M T=\left[F V+\frac{P V \cdot r \cdot\left((1+r)^{N}\right)}{\left((1+r)^{N}-1\right) \cdot(1+r \cdot X)}\right]
$$

where

- $\operatorname{Rate}(\mathbf{r})$ is the interest rate for the investment loan $=15 \%$.

- $\mathbf{N}$ is the total number of payments for the loan $=15$.

- $\mathbf{P V}$ is the present value, also known as principal $=3,912,143.34 \$$.

- $\mathbf{F V}$ is the future value $=0$.

- Type(X) is 0 for end of period payments, and 1 for beginning of period payments. Here, $\mathrm{X}=0$.

The cost for an investment into an 450 MVar SVC was found to be $447 \$ / \mathrm{h}$.

\section{E. Expected Impact with SVC}

The financial risk is evaluated using the equation (5.16)and as before it is assumed that voltage collapse results in total system blackout. Table 6.10 gives the loadability with SVC in the system. Furthermore, the outage occurrence probability is assumed to be the same as before. For the evaluation of the security costs, it is assumed that the security costs decrease by the same percentage value the loading margin increases. This assumption is justified 


\begin{tabular}{|c|c|c|}
\hline $\begin{array}{c}\text { Loading } \\
\text { Level(MW) }\end{array}$ & $\begin{array}{c}\text { Total Cost without } \\
\text { SVC }(\$ / \mathrm{h})\end{array}$ & $\begin{array}{c}\text { Total Cost with } \\
\text { SVC }(\$ / \mathrm{h})\end{array}$ \\
\hline \hline 2660 & 0 & 447 \\
\hline 2900 & 23 & 447 \\
\hline 3140 & 714 & 447 \\
\hline 3390 & 20200 & 457 \\
\hline 3640 & 81200 & 975 \\
\hline 3870 & 651000 & 5600 \\
\hline 4110 & 7560000 & 27970 \\
\hline
\end{tabular}

Table 6.12: Value at risk with and without $S V C$

because additional loading margin automatically guarantees increased security. Based on the loadability values it is found that loading margin with SVC for different contingencies increases by $43 \%$. Therefore, security costs for both voltage collapse and service interruption decrease by same amount. For the loading level of $3870 \mathrm{MW}$, an SVC can reduce the value at risk by an amount $645,400 \$ / \mathrm{h}$.

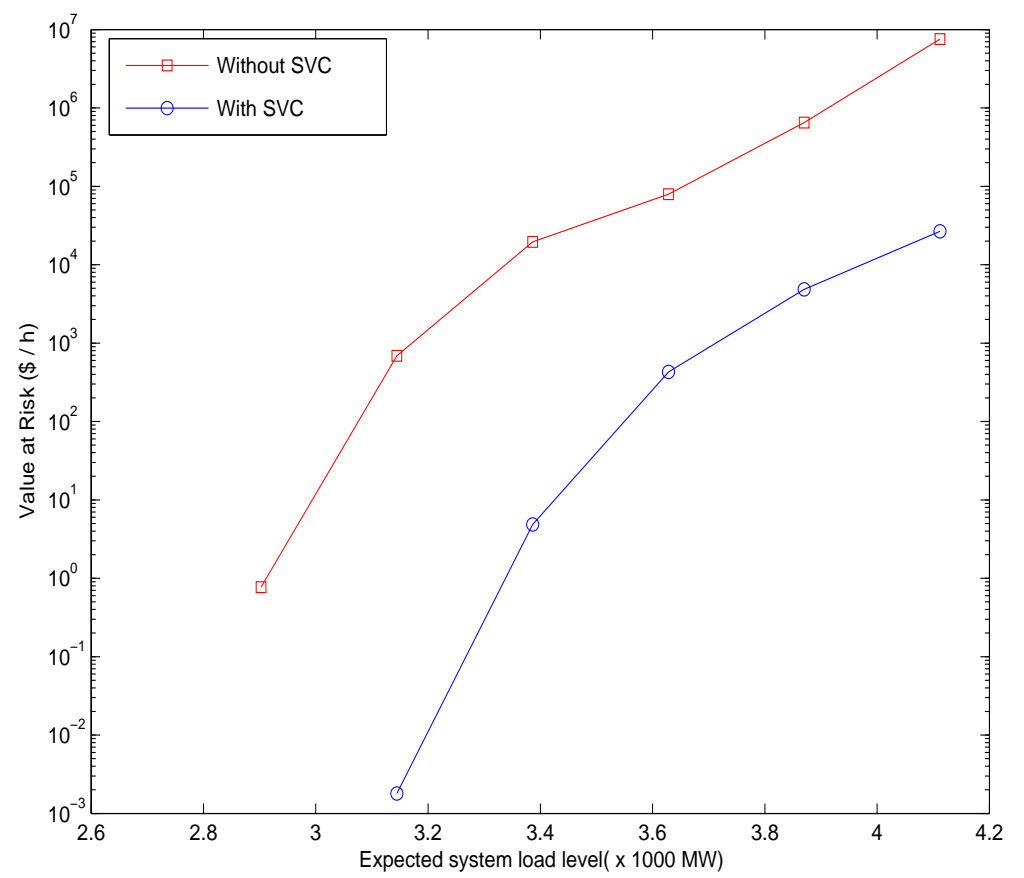

Figure 6.19: Impact of voltage collapse with and without SVC for IEEE 24 bus RTS. 


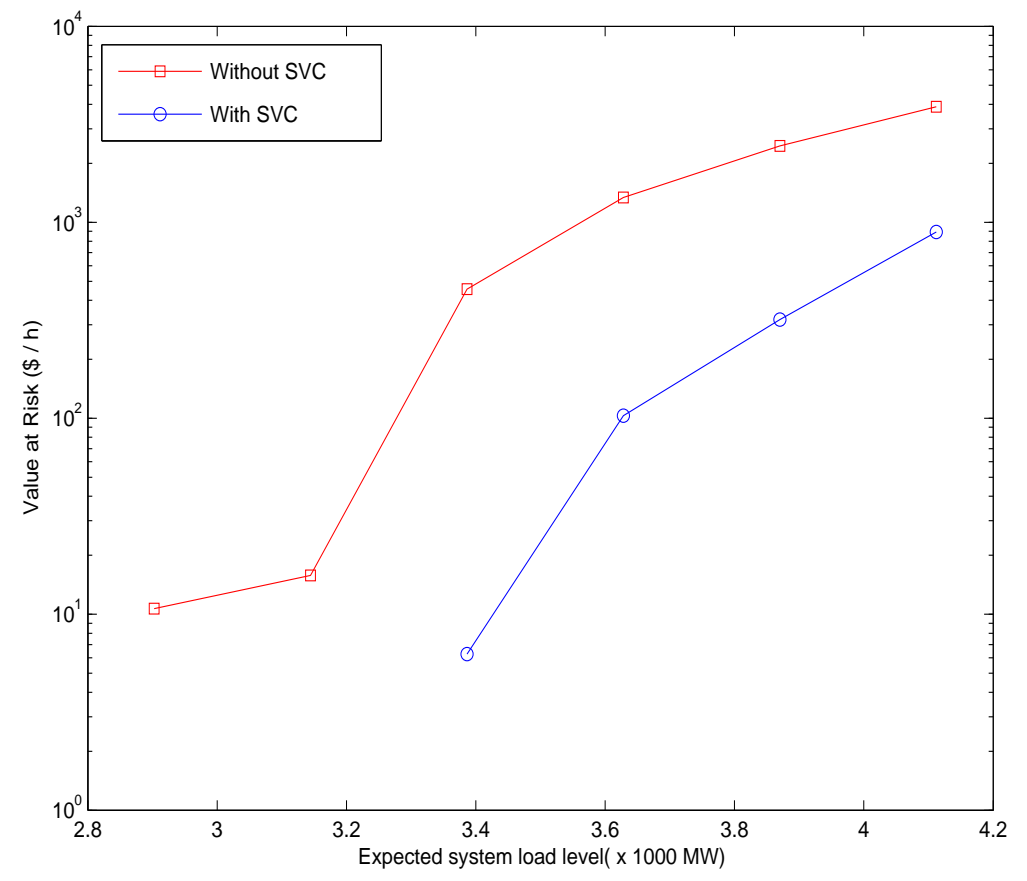

Figure 6.20: Impact of No voltage collapse with and without SVC for IEEE 24 bus RTS.

\begin{tabular}{|c|c|c|}
\hline $\begin{array}{c}\text { Loading } \\
\text { Level(MW) }\end{array}$ & $\begin{array}{c}\text { Total Cost without } \\
\text { SVC }(\$ / \mathrm{h})\end{array}$ & $\begin{array}{c}\text { Total Cost with } \\
\text { SVC }(\$ / \mathrm{h})\end{array}$ \\
\hline \hline 2660 & 0 & 447 \\
\hline 2900 & 23 & 447 \\
\hline 3140 & 714 & 447 \\
\hline 3390 & 20200 & 466 \\
\hline 3620 & 81200 & 1375 \\
\hline 3870 & 651000 & 9500 \\
\hline 4110 & 7560000 & 48800 \\
\hline
\end{tabular}

Table 6.13: Value at Risk with and without SVC with no decrease in Security Costs

Figures 6.19 and 6.20 show the comparision of risk of voltage collapse case and no voltage collapse case, both with and without SVC. Figure 6.21 shows the value at risk associated with and without SVC in the network. Table 6.12 shows the value at risk with and without SVC. Table 6.13 shows the risk at value with security cost assumption removed (i.e., No $43 \%$ decrease in security costs). It is evident that having an SVC in the system can minimize the 


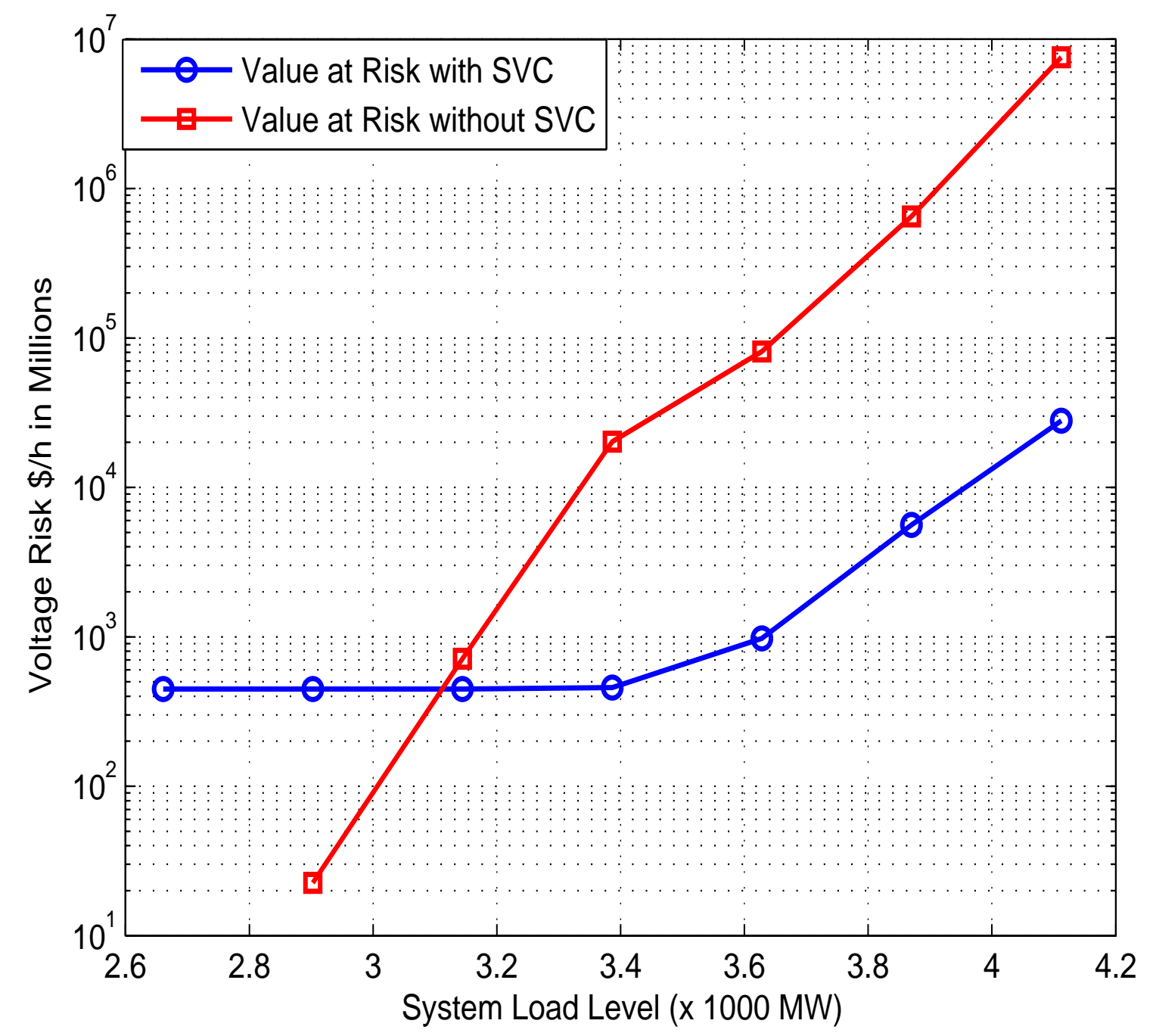

Figure 6.21: Value at Risk with and without SVC

potential of financial loss considerably. Here, the value at risk in the plot gives a quantitative measure (in terms of dollars) of reliability for operating the system with and without a SVC for voltage stability and voltage level improvement. The expected impact computed here, provides an expectation of insecurity cost but does not guarantee future outcome to be exact same as the expected value. 


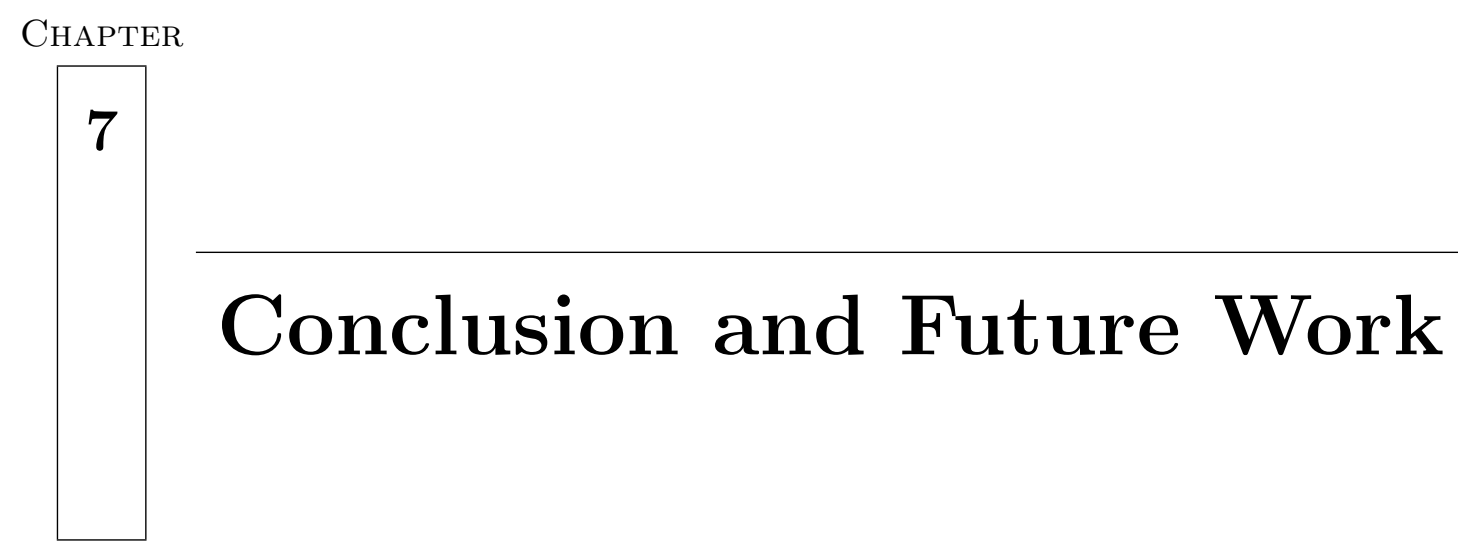

\subsection{Conclusion}

In this work the problem of pilot bus selection for reactive power support has been addressed. Additionally, a probabilistic risk analysis is performed as an aid into decision making for the installation of SVC. The following can be concluded:

1. An approach for selecting critical buses for reactive power support based on continuation power flow and N-1 contingency analysis that thoroughly takes into consideration important factors like contingencies and system loading has been introduced The objective was to minimize the worst case voltage deviations and at the same time increase the loading margin for all selected contingencies.

2. The approach was found to improve over existing approaches like modal analysis and singular values which only use linear approximations to determine indices. The current work shows the selection of pilot buses results in better voltage profile and increased loading margin.

3. For static analysis the SVC performance is quite similar to the shunt capacitors, but the 
main advantage of SVC would be its dynamic performance and voltage control at the installed bus.

4. A probabilistic risk analysis was performed to assess the value at risk associated with decision making of installing SVC in the power system. A decision tree was developed and used to take into account uncertainties such as unreliable load forecasts and line outage probabilites. The probability of collapse and expected service interruption costs were determined and allow a quantitative measure for the value at risk in terms of dollars per hour.

5. The results found through the risk analysis show us that installing an SVC in the system can be useful in terms of reliability and financial risk reduction. Also, because of its dynamic advantages SVC could possibly lessen the congestion costs and thus aid in improving reliability of the system.

\subsection{Future Work}

The research work leads to various promising topics for future investigations. The following topics are recommendations for possible future research:

1. Modeling the effect of different loads in continuation power flow method and into selection of critical buses for VAR support. The present work considers only constant P and Q loads for continuation power flow.

2. A detail model for evaluation of outage costs to evaluate the security costs for limit violations and voltage collapse.

3. Extending the current concept of risk in assessing other security problems like transient instability with Static Var Compensator. 


\section{APPENDIX}

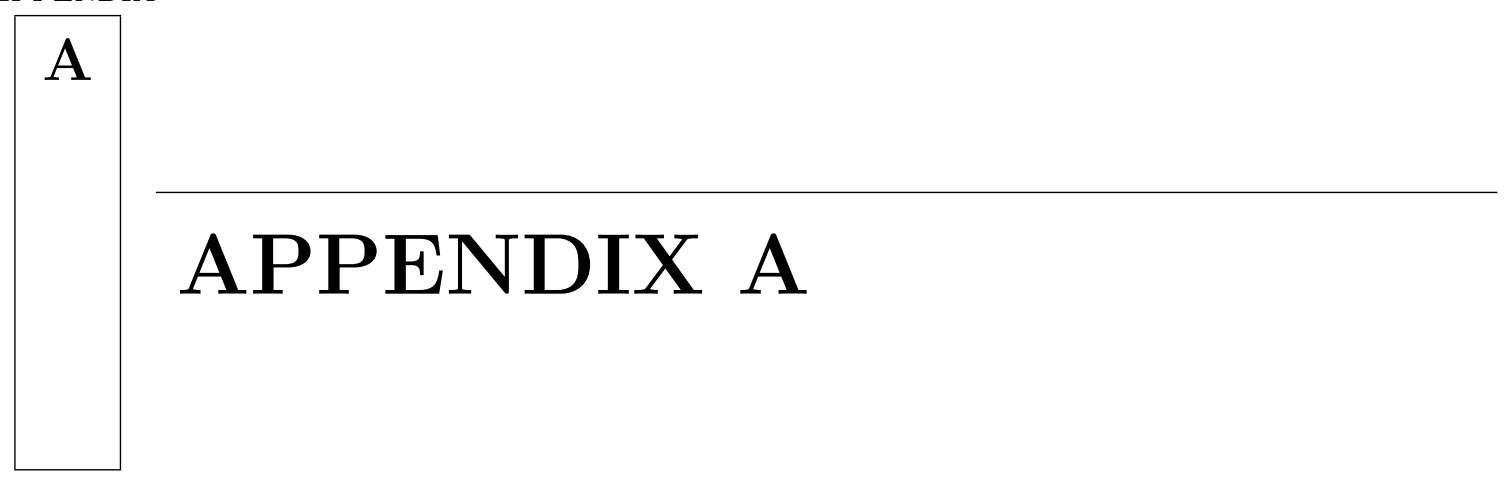

\section{A.1 Test System Data}

\section{A.1.1 PSAT Data Format}

The following tables ${ }^{1}$ illustrate the PSAT data structure.

Table A.1: Bus Data Format (Bus.con)

\begin{tabular}{c|l|c}
\hline Column & Description & Unit \\
\hline \hline 1 & Bus number & int \\
2 & Voltage base & $\mathrm{kV}$ \\
$\dagger 3$ & Voltage amplitude initial guess & $\mathrm{p.u.}$ \\
$\dagger 4$ & Voltage phase initial guess & $\mathrm{rad}$ \\
$\dagger 5$ & Area number (not used yet...) & int \\
$\dagger 6$ & Region number (not used yet...) & int \\
\hline
\end{tabular}

\footnotetext{
${ }^{1}$ In this table and remaining tables in this chapter, fields marked with $\dagger$ are optional
} 
Table A.2: $P Q$ Data Format (PQ.con)

\begin{tabular}{c|l|c}
\hline Column & Description & Unit \\
\hline \hline 1 & Bus number & int \\
2 & Power rating & MVA \\
3 & Voltage rating & $\mathrm{kV}$ \\
4 & Active power & p.u. \\
5 & Reactive power & p.u. \\
$\dagger 6$ & Maximum voltage & p.u. \\
$\dagger 7$ & Minimum voltage & p.u. \\
$\dagger 8$ & Allow conversion to impedance & boolean. \\
\hline
\end{tabular}

Table A.3: PV Data Format (PV.con)

\begin{tabular}{c|l|c}
\hline Column & Description & Unit \\
\hline \hline 1 & Bus number & int \\
2 & Power rating & MVA \\
3 & Voltage rating & $\mathrm{kV}$ \\
4 & Active power & $\mathrm{p} . \mathrm{u}$. \\
5 & Voltage magnitude & $\mathrm{p} . \mathrm{u}$. \\
$\dagger 6$ & Maximum reactive power & $\mathrm{p} . \mathrm{u}$. \\
$\dagger 7$ & Minimum reactive power & $\mathrm{p} . \mathrm{u}$. \\
$\dagger 8$ & Maximum voltage & $\mathrm{p} . \mathrm{u}$. \\
$\dagger 9$ & Minimum voltage & $\mathrm{p} . \mathrm{u}$. \\
$\dagger 10$ & Loss participation coefficient & - \\
\hline
\end{tabular}

Table A.4: Shunt Data Format (Shunt.con)

\begin{tabular}{c|l|c}
\hline Column & Description & Unit \\
\hline \hline 1 & Bus number & int \\
2 & Power rating & $\mathrm{MVA}$ \\
3 & Voltage rating & $\mathrm{kV}$ \\
4 & Frequency rating & $\mathrm{Hz}$ \\
5 & Conductance & p.u. \\
6 & Susceptance & p.u. \\
\hline
\end{tabular}


Table A.5: $S W$ Data Format (SW.con)

\begin{tabular}{c|l|c}
\hline Column & Description & Unit \\
\hline \hline 1 & Bus number & int \\
2 & Power rating & MVA \\
3 & Voltage rating & $\mathrm{kV}$ \\
4 & Voltage magnitude & p.u. \\
5 & Reference angle & p.u. \\
$\dagger 6$ & Maximum reactive power & p.u. \\
$\dagger 7$ & Minimum reactive power & p.u. \\
$\dagger 8$ & Maximum voltage & p.u. \\
$\dagger 9$ & Minimum voltage & p.u. \\
$\dagger 10$ & Active power guess & p.u. \\
$\dagger 11$ & Loss participation coefficient & - \\
\hline
\end{tabular}

Table A.6: Line Data Format (Line.con)

\begin{tabular}{c|l|c}
\hline Column & Description & Unit \\
\hline \hline 1 & From Bus & int \\
2 & To Bus & int \\
3 & Power Rating & MVA \\
4 & Voltage Rating & $\mathrm{kV}$ \\
5 & Frequency Rating & $\mathrm{Hz}$ \\
6 & Line Length & $\mathrm{km}$ \\
7 & (not used yet...) & - \\
8 & Resistance & p.u. $(\Omega / \mathrm{km})$ \\
9 & Reactance & p.u. $(\mathrm{H} / \mathrm{km})$ \\
10 & Susceptance & p.u. $(\mathrm{F} / \mathrm{km})$ \\
$\dagger 11$ & (not used yet...) & - \\
$\dagger 12$ & (not used yet...) & - \\
$\dagger 13$ & Current limit & p.u. \\
$\dagger 14$ & Active power limit & p.u. \\
$\dagger 15$ & Apparent power limit & p.u. \\
\hline
\end{tabular}


Table A.7: Demand Data Format (Demand.con)

\begin{tabular}{c|l|c}
\hline Column & Description & Unit \\
\hline \hline 1 & Bus number & int \\
2 & Power Rating & MVA \\
3 & Forecasted active power & p.u. \\
4 & Forecasted reactive power & p.u. \\
5 & Maximum power bid & p.u. \\
6 & Minimum power bid & p.u. \\
7 & Actual power bid & p.u. $(\$ / h)$ \\
8 & Fixed cost(active power) & p.u. $(\$ / M W h)$ \\
9 & Proportional cost(active power) & p.u. $\left(\$ / M W^{2} h\right)$ \\
10 & Quadratic cost(active power) & p.u. $(\$ / h)$ \\
11 & Fixed cost(reactive power) & p.u. $(\$ / M V a r h)$ \\
12 & Proportional cost(reactive power) & p.u. $\left(\$ / M W^{2} h\right)$ \\
13 & Quadratic cost(active power) & \\
& \multicolumn{2}{|}{} \\
\hline
\end{tabular}

Table A.8: Supply Data Format (Supply.con)

\begin{tabular}{c|l|c}
\hline Column & Description & Unit \\
\hline \hline 1 & Bus number & int \\
2 & Power Rating & MVA \\
3 & Forecasted active power & p.u. \\
4 & Forecasted reactive power & p.u. \\
5 & Maximum power bid & p.u. \\
6 & Minimum power bid & p.u. \\
7 & Actual power bid & p.u. $(\$ / h)$ \\
8 & Fixed cost(active power) & p.u. $(\$ / M W h)$ \\
9 & Proportional cost(active power) & p.u. $\left(\$ / M W^{2} h\right)$ \\
10 & Quadratic cost(active power) & p.u. $(\$ / h)$ \\
11 & Fixed cost(reactive power) & p.u. $(\$ / M V a r h)$ \\
12 & Proportional cost(reactive power) & p.u. $\left(\$ / M W^{2} h\right)$ \\
13 & Quadratic cost(active power) & \\
\multicolumn{2}{|l}{} \\
\hline
\end{tabular}




\section{A.1.2 WSCC 3-Machine 9 Bus System}

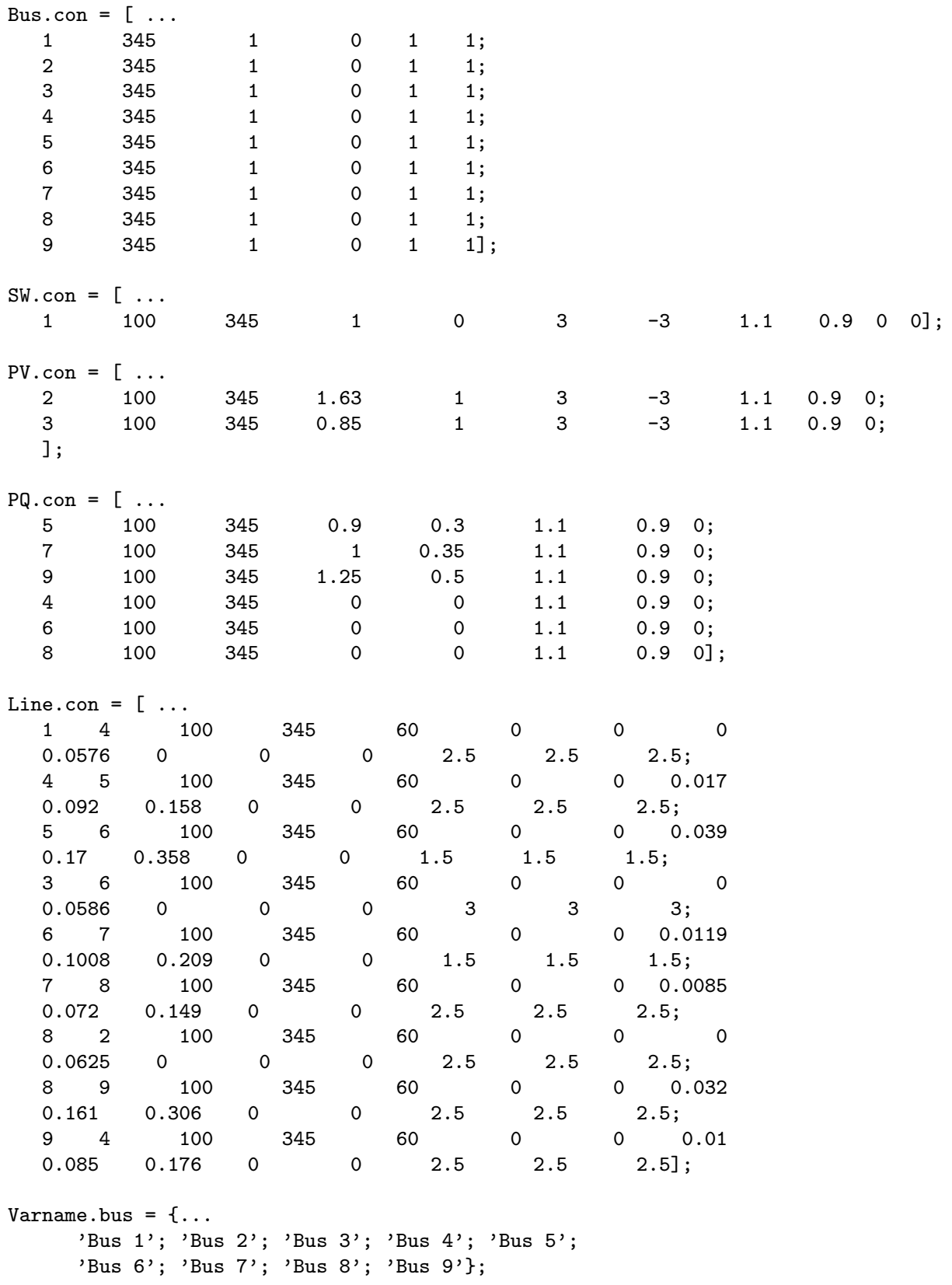

\section{A.1.3 IEEE 14 Bus System}

\begin{tabular}{|c|c|c|c|c|}
\hline 1 & 69 & 1 & 0 & 4 \\
\hline 2 & 69 & 1 & 0 & 4 \\
\hline 3 & 69 & 1 & 0 & 4 \\
\hline 4 & 69 & 1 & 0 & 4 \\
\hline
\end{tabular}




$\begin{array}{llllll}5 & 69 & 1 & 0 & 4 & 1 ; \\ 6 & 13.8 & 1 & 0 & 2 & 1 ; \\ 7 & 13.8 & 1 & 0 & 2 & 1 ; \\ 8 & 18 & 1 & 0 & 3 & 1 ; \\ 9 & 13.8 & 1 & 0 & 2 & 1 ; \\ 10 & 13.8 & 1 & 0 & 2 & 1 ; \\ 11 & 13.8 & 1 & 0 & 2 & 1 ; \\ 12 & 13.8 & 1 & 0 & 2 & 1 ; \\ 13 & 13.8 & 1 & 0 & 2 & 1 ; \\ 14 & 13.8 & 1 & 0 & 2 & 1] ;\end{array}$

\begin{tabular}{|c|c|c|c|c|c|c|c|c|}
\hline 2 & 5 & 100 & 69 & 60 & & 0 & 0 & 0.05695 \\
\hline 0.17388 & & 034 & 0 & 0 & 0 & & 0 & 0 \\
\hline 6 & 12 & 100 & 13.8 & 60 & & 0 & 0 & 0.12291 \\
\hline 0.25581 & & 0 & 0 & 0 & 0 & & 0 & 0 \\
\hline 12 & 13 & 100 & 13.8 & 60 & & 0 & 0 & 0.22092 \\
\hline 0.19988 & & 0 & 0 & 0 & 0 & & 0 & 0 \\
\hline 6 & 13 & 100 & 13.8 & 60 & & 0 & 0 & 0.06615 \\
\hline 0.13027 & & 0 & 0 & 0 & 0 & & 0 & 0 \\
\hline 6 & 11 & 100 & 13.8 & 60 & & 0 & 0 & 0.09498 \\
\hline 0.1989 & & 0 & 0 & 0 & 0 & & 0 & 0 \\
\hline 11 & 10 & 100 & 13.8 & 60 & & 0 & 0 & 0.08205 \\
\hline 0.19207 & & 0 & 0 & 0 & 0 & & 0 & 0 \\
\hline 9 & 10 & 100 & 13.8 & 60 & & 0 & 0 & 0.03181 \\
\hline 0.0845 & & 0 & 0 & 0 & 0 & & 0 & 0 \\
\hline 9 & 14 & 100 & 13.8 & 60 & & 0 & 0 & 0.12711 \\
\hline 0.27038 & & 0 & 0 & 0 & 0 & & 0 & 0 \\
\hline 14 & 13 & 100 & 13.8 & 60 & & 0 & 0 & 0.17093 \\
\hline 0.34802 & & 0 & 0 & 0 & 0 & & 0 & 0 \\
\hline 7 & 9 & 100 & 13.8 & 60 & & 0 & 0 & 0 \\
\hline 0.11001 & & 0 & 0 & 0 & 0 & & 0 & 0 \\
\hline 1 & 2 & 100 & 69 & 60 & & 0 & 0 & 0.01938 \\
\hline 0.05917 & & 528 & 0 & 0 & 0 & & 0 & 0 \\
\hline 3 & 2 & 100 & 69 & 60 & & 0 & 0 & 0.04699 \\
\hline 0.19797 & & 438 & 0 & 0 & 0 & & 0 & 0 \\
\hline 3 & 4 & 100 & 69 & 60 & & 0 & 0 & 0.06701 \\
\hline 0.17103 & & 346 & 0 & 0 & 0 & & 0 & 0 \\
\hline 1 & 5 & 100 & 69 & 60 & & 0 & 0 & 0.05403 \\
\hline 0.22304 & & 492 & 0 & 0 & 0 & & 0 & 0 \\
\hline 5 & 4 & 100 & 69 & 60 & & 0 & 0 & 0.01335 \\
\hline 0.04211 & & 128 & 0 & 0 & 0 & & 0 & 0 \\
\hline 2 & 4 & 100 & 69 & 60 & & 0 & 0 & 0.05811 \\
\hline 0.17632 & & 374 & 0 & 0 & 0 & & 0 & 0 \\
\hline 5 & 6 & 100 & 69 & 60 & & 0 & 5 & 0 \\
\hline 0.25202 & & 0 & 0.932 & 0 & 0 & & 0 & 0 \\
\hline 4 & 9 & 100 & 69 & 60 & & 0 & 5 & 0 \\
\hline 0.55618 & & 0 & 0.969 & 0 & 0 & & 0 & 0 \\
\hline 4 & 7 & 100 & 69 & 60 & & 0 & 5 & 0 \\
\hline 0.20912 & & 0 & 0.978 & 0 & 0 & & 0 & 0 \\
\hline 8 & 7 & 100 & 18 & 60 & & 0 & .304348 & 0 \\
\hline 0.17615 & & 0 & 0 & 0 & 0 & & 0 & 0 ]; \\
\hline
\end{tabular}

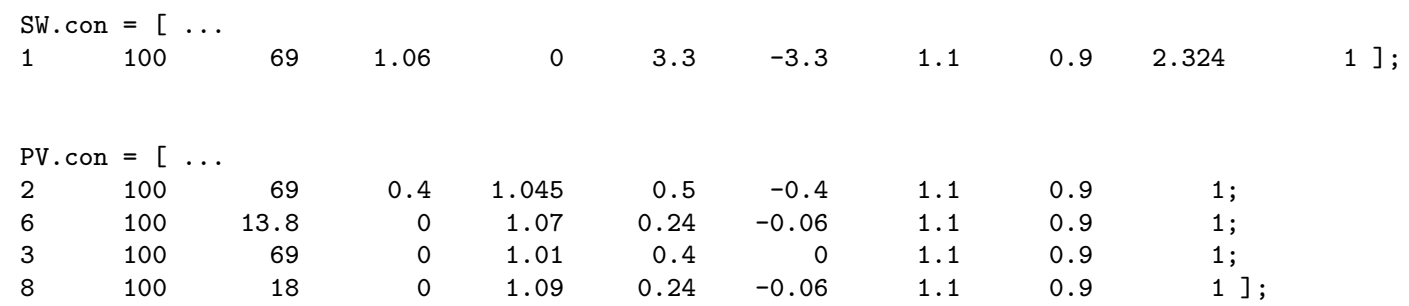




\begin{tabular}{|c|c|c|c|c|c|c|c|}
\hline \multicolumn{8}{|c|}{$P Q \cdot \operatorname{con}=[\ldots$} \\
\hline 11 & 100 & 13.8 & 0.035 & 0.018 & 1.1 & 0.9 & 0 \\
\hline 13 & 100 & 13.8 & 0.135 & 0.058 & 1.1 & 0.9 & 0 \\
\hline 3 & 100 & 69 & 0.942 & 0.19 & 1.1 & 0.9 & 0 ; \\
\hline 5 & 100 & 69 & 0.076 & 0.016 & 1.1 & 0.9 & 0 \\
\hline 2 & 100 & 69 & 0.217 & 0.127 & 1.1 & 0.9 & 0 ; \\
\hline 6 & 100 & 13.8 & 0.112 & 0.075 & 1.1 & 0.9 & 0 \\
\hline 4 & 100 & 69 & 0.478 & 0.04 & 1.1 & 0.9 & 0 ; \\
\hline 14 & 100 & 13.8 & 0.149 & 0.05 & 1.1 & 0.9 & 0 \\
\hline 12 & 100 & 13.8 & 0.061 & 0.016 & 1.1 & 0.9 & 0 \\
\hline 10 & 100 & 13.8 & 0.09 & 0.058 & 1.1 & 0.9 & 0 ; \\
\hline 9 & 100 & 13.8 & 0.295 & 0.166 & 1.1 & 0.9 & $0]$; \\
\hline
\end{tabular}

Varname. bus $=\{\ldots$

'Bus 01'; 'Bus 02'; 'Bus 03'; 'Bus 04'; 'Bus 05';

'Bus 06'; 'Bus 07'; 'Bus 08'; 'Bus 09'; 'Bus 10';

'Bus 11'; 'Bus 12'; 'Bus 13'; 'Bus 14'\};

\section{A.1.4 IEEE 30 Bus System}

$\begin{array}{rrrrrr}\text { Bus.con }=[\ldots & \ldots & & & \\ 1 & 132.00 & 1.06000 & 0.00000 & 1 & 1 ; \\ 2 & 132.00 & 1.04300 & -0.09564 & 1 & 1 ; \\ 3 & 132.00 & 1.02100 & -0.13893 & 1 & 1 ; \\ 4 & 132.00 & 1.01200 & -0.16790 & 1 & 1 ; \\ 5 & 132.00 & 1.01000 & -0.25080 & 1 & 1 ; \\ 6 & 132.00 & 1.01000 & -0.19792 & 1 & 1 ; \\ 7 & 132.00 & 1.00200 & -0.22899 & 1 & 1 ; \\ 8 & 132.00 & 1.01000 & -0.21118 & 1 & 1 ; \\ 9 & 1.00 & 1.05100 & -0.25098 & 1 & 1 ; \\ 10 & 33.00 & 1.04500 & -0.27873 & 1 & 1 ; \\ 11 & 11.00 & 1.08200 & -0.25115 & 1 & 1 ; \\ 12 & 33.00 & 1.05700 & -0.26599 & 1 & 1 ; \\ 13 & 11.00 & 1.07100 & -0.26599 & 1 & 1 ; \\ 14 & 33.00 & 1.04200 & -0.28152 & 4 & 1 ; \\ 15 & 33.00 & 1.03800 & -0.28309 & 5 & 1 ; \\ 16 & 33.00 & 1.04500 & -0.27629 & 6 & 1 ; \\ 17 & 33.00 & 1.04000 & -0.28170 & 7 & 1 ; \\ 18 & 33.00 & 1.02800 & -0.29356 & 8 & 1 ; \\ 19 & 33.00 & 1.02600 & -0.29671 & 9 & 1 ; \\ 20 & 33.00 & 1.03000 & -0.29322 & 1 & 1 ; \\ 21 & 33.00 & 1.03300 & -0.28658 & 1 & 1 ; \\ 22 & 33.00 & 1.03300 & -0.28641 & 2 & 1 ; \\ 23 & 33.00 & 1.02700 & -0.28990 & 3 & 1 ; \\ 24 & 33.00 & 1.02100 & -0.29287 & 4 & 1 ; \\ 25 & 33.00 & 1.01700 & -0.28536 & 5 & 1 ; \\ 26 & 33.00 & 1.00000 & -0.29269 & 6 & 1 ; ; \\ 27 & 33.00 & 1.02300 & -0.27611 & 1 & 1 ; \\ 28 & 132.00 & 1.00700 & -0.20892 & 1 & 1 ; \\ 29 & 33.00 & 1.00300 & -0.29775 & 9 & 1 ; \\ 30 & 33.00 & 0.99200 & -0.31311 & 1 & 1] ; \\ & & & & \end{array}$

SW. con $=[\ldots$

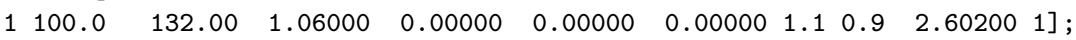

PV.con $=[\ldots$ 


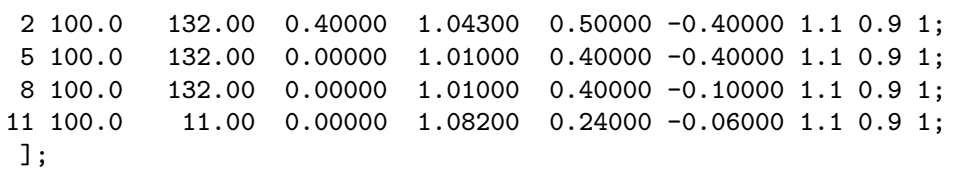



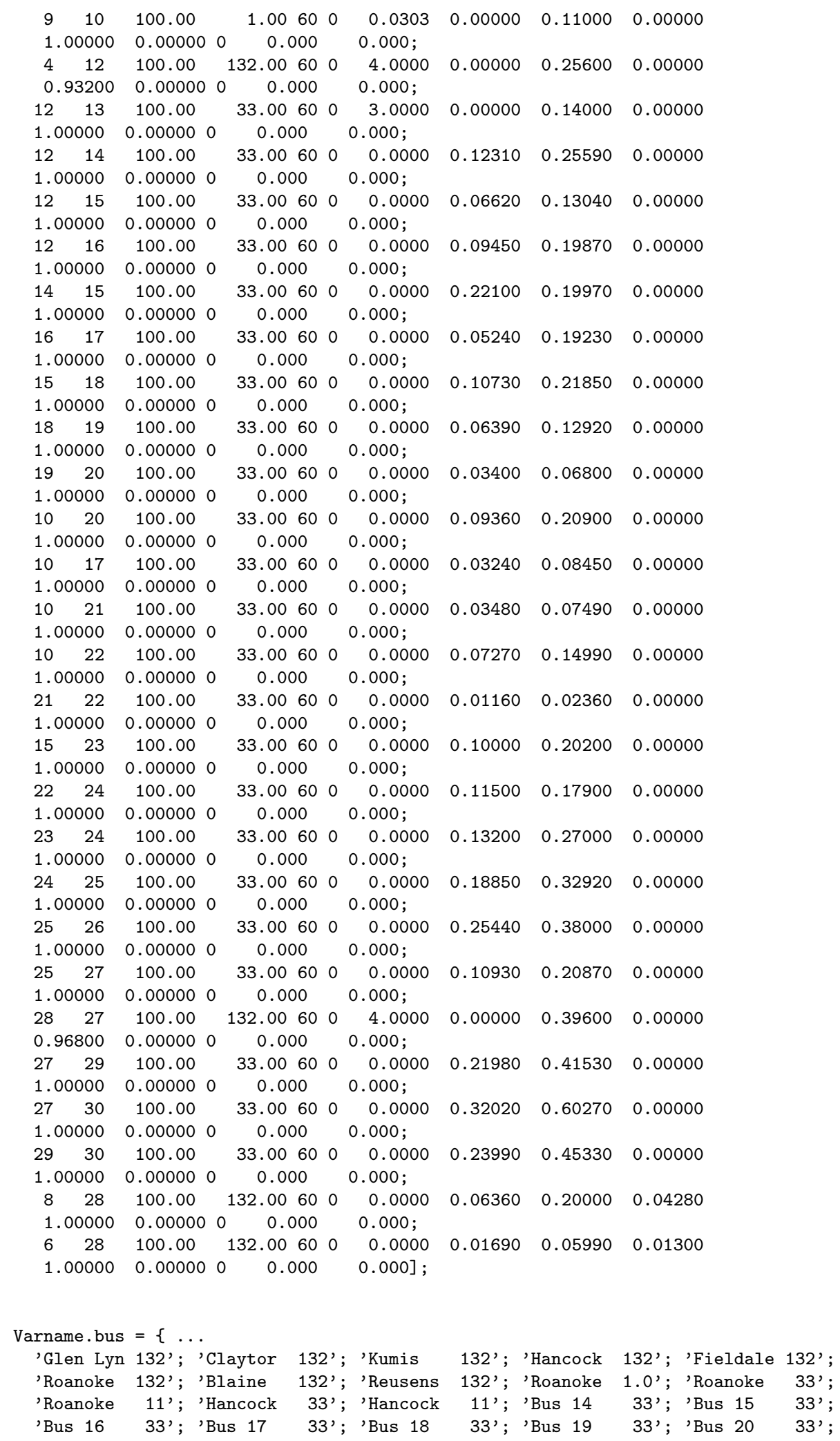
'Bus $21 \quad 33^{\prime}$; 'Bus 22 33'; 'Bus $23 \quad 33^{\prime}$; 'Bus $24 \quad 33^{\prime}$; 'Bus 25 33';

'Bus 26 33'; 'Cloverdle 33'; 'Cloverdle132'; 'Bus 29 33'; 'Bus 30 33'\};

\section{A.1.5 IEEE 24 Bus Reliability Test System}

\begin{tabular}{|c|c|c|c|c|c|c|c|c|c|c|c|}
\hline \multicolumn{12}{|c|}{ Bus. $\operatorname{con}=[\ldots$} \\
\hline 1 & 138 & 1 & 0 & 2 & $1 ;$ & & & & & & \\
\hline 2 & 138 & 1 & 0 & 2 & $1 ;$ & & & & & & \\
\hline 3 & 138 & 1 & 0 & 2 & $1 ;$ & & & & & & \\
\hline 4 & 138 & 1 & 0 & 2 & $1 ;$ & & & & & & \\
\hline 5 & 138 & 1 & 0 & 2 & $1 ;$ & & & & & & \\
\hline 6 & 138 & 1 & 0 & 2 & $1 ;$ & & & & & & \\
\hline 7 & 138 & 1 & 0 & 2 & $1 ;$ & & & & & & \\
\hline 8 & 138 & 1 & 0 & 2 & $1 ;$ & & & & & & \\
\hline 9 & 138 & 1 & 0 & 2 & $1 ;$ & & & & & & \\
\hline 10 & 138 & 1 & 0 & 2 & $1 ;$ & & & & & & \\
\hline 11 & 230 & 1 & 0 & 3 & $1 ;$ & & & & & & \\
\hline 12 & 230 & 1 & 0 & 3 & $1 ;$ & & & & & & \\
\hline 13 & 230 & 1 & 0 & 3 & $1 ;$ & & & & & & \\
\hline 14 & 230 & 1 & 0 & 3 & $1 ;$ & & & & & & \\
\hline 15 & 230 & 1 & 0 & 3 & $1 ;$ & & & & & & \\
\hline 16 & 230 & 1 & 0 & 3 & $1 ;$ & & & & & & \\
\hline 17 & 230 & 1 & 0 & 3 & $1 ;$ & & & & & & \\
\hline 18 & 230 & 1 & 0 & 3 & $1 ;$ & & & & & & \\
\hline 19 & 230 & 1 & 0 & 3 & $1 ;$ & & & & & & \\
\hline 20 & 230 & 1 & 0 & 3 & $1 ;$ & & & & & & \\
\hline 21 & 230 & 1 & 0 & 3 & $1 ;$ & & & & & & \\
\hline 22 & 230 & 1 & 0 & 3 & $1 ;$ & & & & & & \\
\hline 23 & 230 & 1 & 0 & 3 & $1 ;$ & & & & & & \\
\hline 24 & 230 & 1 & 0 & 3 & 1] ; & & & & & & \\
\hline \multicolumn{12}{|c|}{ Line. con $=[\ldots$} \\
\hline \multicolumn{2}{|c|}{1} & 2 & 100 & & 138 & 60 & & 0 & 0 & 0.0026 & 0.0139 \\
\hline \multicolumn{2}{|c|}{0.4611} & 0 & & 0 & 1.93 & & 0 & & $2 ;$ & & \\
\hline \multicolumn{2}{|c|}{1} & 3 & 100 & & 138 & 60 & & 0 & 0 & 0.0546 & 0.2112 \\
\hline \multicolumn{2}{|c|}{0.0572} & 0 & & 0 & 2.08 & & 0 & & 2.2 & & \\
\hline \multicolumn{2}{|c|}{1} & 5 & 100 & & 138 & 60 & & 0 & 0 & 0.0218 & 0.0845 \\
\hline \multicolumn{2}{|c|}{0.0229} & 0 & & 0 & 2.08 & & 0 & & 2.2 & & \\
\hline \multicolumn{2}{|c|}{2} & 4 & 100 & & 138 & 60 & & 0 & 0 & 0.0328 & 0.1267 \\
\hline \multicolumn{2}{|c|}{0.0343} & 0 & & 0 & 2.08 & & 0 & & 2.2 & & \\
\hline \multicolumn{2}{|c|}{2} & 6 & 100 & & 138 & 60 & & 0 & 0 & 0.0497 & 0.192 \\
\hline \multicolumn{2}{|c|}{0.052} & 0 & & 0 & 2.08 & & 0 & & 2.2 & & \\
\hline \multicolumn{2}{|c|}{9} & 3 & 100 & & 138 & 60 & & 0 & 0 & 0.0308 & 0.119 \\
\hline \multicolumn{2}{|c|}{0.0322} & 0 & & 0 & 2.08 & & 0 & & 2.2 & & \\
\hline \multicolumn{2}{|c|}{24} & 3 & 100 & & 230 & 60 & & 0 & 1.666667 & 0.0023 & 0.0839 \\
\hline 0 & \multicolumn{2}{|c|}{0.9852217} & & 0 & 5.1 & & 0 & & 6 & & \\
\hline 9 & & 4 & 100 & & 138 & 60 & & 0 & 0 & 0.0268 & 0.1037 \\
\hline 0. & 281 & 0 & & 0 & 2.08 & & 0 & & 2.2 & & \\
\hline 10 & & 5 & 100 & & 138 & 60 & & 0 & 0 & 0.0228 & 0.0883 \\
\hline & 239 & 0 & & 0 & 2.08 & & 0 & & 2.2 & & \\
\hline 10 & & 6 & 100 & & 138 & 60 & & 0 & 0 & 0.0139 & 0.0605 \\
\hline 2.4 & & 0 & & 0 & 1.93 & & 0 & & $2 ;$ & & \\
\hline 7 & & 8 & 100 & & 138 & 60 & & 0 & 0 & 0.0159 & 0.0614 \\
\hline 0. & 166 & 0 & & 0 & 2.08 & & 0 & & 2.2 & & \\
\hline 9 & & 8 & 100 & & 138 & 60 & & 0 & 0 & 0.0427 & 0.1651 \\
\hline 0. & & 0 & & 0 & 2.08 & & 0 & & 2.2 & & \\
\hline 10 & & 8 & 100 & & 138 & 60 & & 0 & 0 & 0.0427 & 0.1651 \\
\hline 0. & & 0 & & 0 & 2.08 & & 0 & & 2.2 & & \\
\hline 11 & & 9 & 100 & & 230 & 60 & & 0 & 1.666667 & 0.0023 & 0.0839 \\
\hline 0 & & .9708738 & & 0 & 5.1 & & 0 & & 6 & & \\
\hline
\end{tabular}




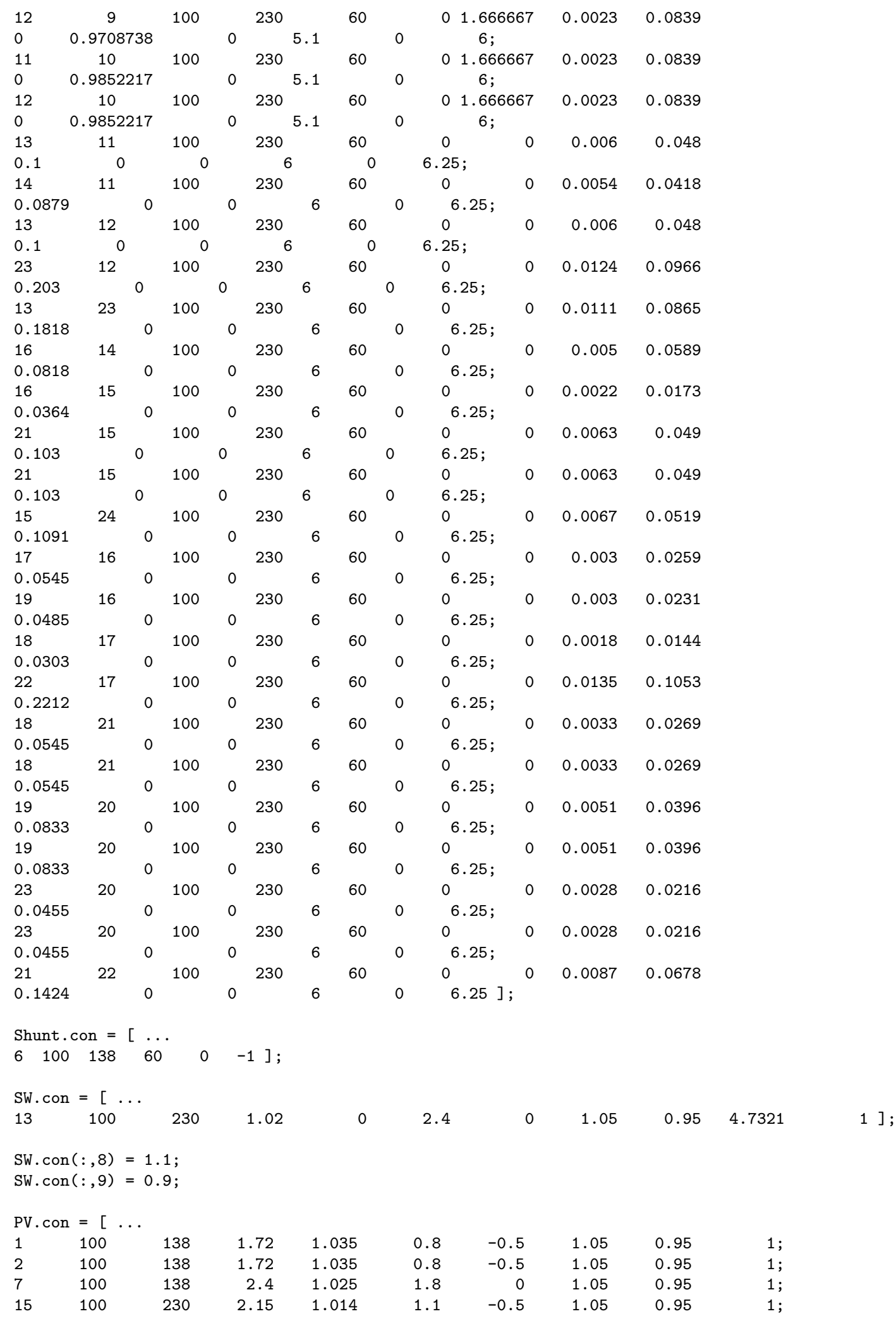




\begin{tabular}{|c|c|c|c|c|c|c|c|}
\hline 16 & 100 & 230 & 1.55 & 1.017 & 0.8 & -0.5 & 1.05 \\
\hline 18 & 100 & 230 & 4 & 1.05 & 2 & -0.5 & 1.05 \\
\hline 21 & 100 & 230 & 4 & 1.05 & 2 & -0.5 & 1.05 \\
\hline 22 & 100 & 230 & 3 & 1.05 & 0.96 & -0.6 & 1.05 \\
\hline $\begin{array}{r}23 \\
]\end{array}$ & 100 & 230 & 6.6 & 1.05 & 3.1 & -1.25 & 1.05 \\
\hline \multicolumn{8}{|c|}{ PV. $\operatorname{con}(:, 8)=1.1 ;$} \\
\hline$P Q$ & $=[$ & $\ldots$ & & & & & \\
\hline 1 & 100 & 138 & 1.188 & 0.242 & 1.05 & 0.95 & 1 ; \\
\hline 2 & 100 & 138 & 1.067 & 0.22 & 1.05 & 0.95 & 1 ; \\
\hline 3 & 100 & 138 & 1.98 & 0.407 & 1.05 & 0.95 & 1 ; \\
\hline 4 & 100 & 138 & 0.814 & 0.165 & 1.05 & 0.95 & $1 ;$ \\
\hline 5 & 100 & 138 & 0.781 & 0.154 & 1.05 & 0.95 & $1 ;$ \\
\hline 6 & 100 & 138 & 1.496 & 0.308 & 1.05 & 0.95 & $1 ;$ \\
\hline 7 & 100 & 138 & 1.375 & 0.275 & 1.05 & 0.95 & $1 ;$ \\
\hline 8 & 100 & 138 & 1.881 & 0.385 & 1.05 & 0.95 & $1 ;$ \\
\hline 9 & 100 & 138 & 1.925 & 0.396 & 1.05 & 0.95 & $1 ;$ \\
\hline 10 & 100 & 138 & 2.145 & 0.44 & 1.05 & 0.95 & $1 ;$ \\
\hline 13 & 100 & 230 & 2.915 & 0.594 & 1.05 & 0.95 & $1 ;$ \\
\hline 14 & 100 & 230 & 2.134 & 0.429 & 1.05 & 0.95 & $1 ;$ \\
\hline 15 & 100 & 230 & 3.487 & 0.704 & 1.05 & 0.95 & $1 ;$ \\
\hline 16 & 100 & 230 & 1.1 & 0.22 & 1.05 & 0.95 & 1 ; \\
\hline 18 & 100 & 230 & 3.663 & 0.748 & 1.05 & 0.95 & $1 ;$ \\
\hline 19 & 100 & 230 & 1.991 & 0.407 & 1.05 & 0.95 & $1 ;$ \\
\hline 20 & 100 & 230 & 1.408 & 0.286 & 1.05 & 0.95 & 1] \\
\hline
\end{tabular}

$\mathrm{PQ} \cdot \operatorname{con}(:, 4)=\mathrm{PQ} \cdot \operatorname{con}(:, 4) / 1 \cdot 1$;

$P Q \cdot \operatorname{con}(:, 5)=P Q \cdot \operatorname{con}(:, 5) / 1 \cdot 1$;

$\mathrm{PQ} \cdot \operatorname{con}(:, 6)=1 \cdot 1$;

$P Q \cdot \operatorname{con}(:, 7)=0.9$;

Demand. con $=[\ldots$

\begin{tabular}{|c|c|c|c|c|c|c|c|c|}
\hline 1 & 100 & 1.188 & 0.242 & 1.4256 & 0.9504 & 0 & 0 & 18 \\
\hline 0 & 0 & 0 & 0 & 0 & 0 & & & \\
\hline 2 & 100 & 1.067 & 0.22 & 1.2804 & 0.8536 & 0 & 0 & 25 \\
\hline 0 & 0 & 0 & 0 & 0 & 0 & & & \\
\hline 3 & 100 & 1.98 & 0.407 & 2.376 & 1.584 & 0 & 0 & 19 \\
\hline 0 & 0 & 0 & 0 & 0 & 0 & & & \\
\hline 4 & 100 & 0.814 & 0.165 & 0.9768 & 0.6512 & 0 & 0 & 24 \\
\hline 0 & 0 & 0 & 0 & 0 & 0 & & & \\
\hline 5 & 100 & 0.781 & 0.154 & 0.9372 & 0.6248 & 0 & 0 & 22 \\
\hline 0 & 0 & 0 & 0 & 0 & $0 ;$ & & & \\
\hline 6 & 100 & 1.496 & 0.308 & 1.7952 & 1.1968 & 0 & 0 & 19 \\
\hline 0 & 0 & 0 & 0 & 0 & 0 & & & \\
\hline 7 & 100 & 1.375 & 0.275 & 1.65 & 1.1 & 0 & 0 & 22 \\
\hline 0 & 0 & 0 & 0 & 0 & 0 & & & \\
\hline 8 & 100 & 1.881 & 0.385 & 2.2572 & 1.5048 & 0 & 0 & 20 \\
\hline 0 & 0 & 0 & 0 & 0 & $0 ;$ & & & \\
\hline 9 & 100 & 1.925 & 0.396 & 2.31 & 1.54 & 0 & 0 & 20 \\
\hline 0 & 0 & 0 & 0 & 0 & 0 & & & \\
\hline 10 & 100 & 2.145 & 0.44 & 2.574 & 1.716 & 0 & 0 & 19 \\
\hline 0 & 0 & 0 & 0 & 0 & 0 & & & \\
\hline 13 & 100 & 2.915 & 0.594 & 3.498 & 2.332 & 0 & 0 & 19 \\
\hline 0 & 0 & 0 & 0 & 0 & 0 & & & \\
\hline 14 & 100 & 2.134 & 0.429 & 2.5608 & 1.7072 & 0 & 0 & 25 \\
\hline 0 & 0 & 0 & 0 & 0 & $0 ;$ & & & \\
\hline 15 & 100 & 3.847 & 0.704 & 4.6164 & 3.0776 & 0 & 0 & 25 \\
\hline
\end{tabular}




$\begin{array}{lrrrrcrll}0 & 0 & 0 & 0 & 0 & 0 ; & & & \\ 16 & 100 & 1.1 & 0.22 & 1.32 & 0.88 & 0 & 0 & 23 \\ 0 & 0 & 0 & 0 & 0 & 0 ; & & & \\ 18 & 100 & 3.663 & 0.748 & 4.3956 & 2.9304 & 0 & 0 & 18 \\ 0 & 0 & 0 & 0 & 0 & 0 ; & & & \\ 19 & 100 & 1.991 & 0.407 & 2.3892 & 1.5928 & 0 & 0 & 19 \\ 0 & 0 & 0 & 0 & 0 & 0 ; & & & \\ 20 & 100 & 1.408 & 0.286 & 1.6896 & 1.1264 ; & 0 & 0 & 23 \\ 0 & 0 & 0 & 0 & 0 & 0] ; & & & \end{array}$

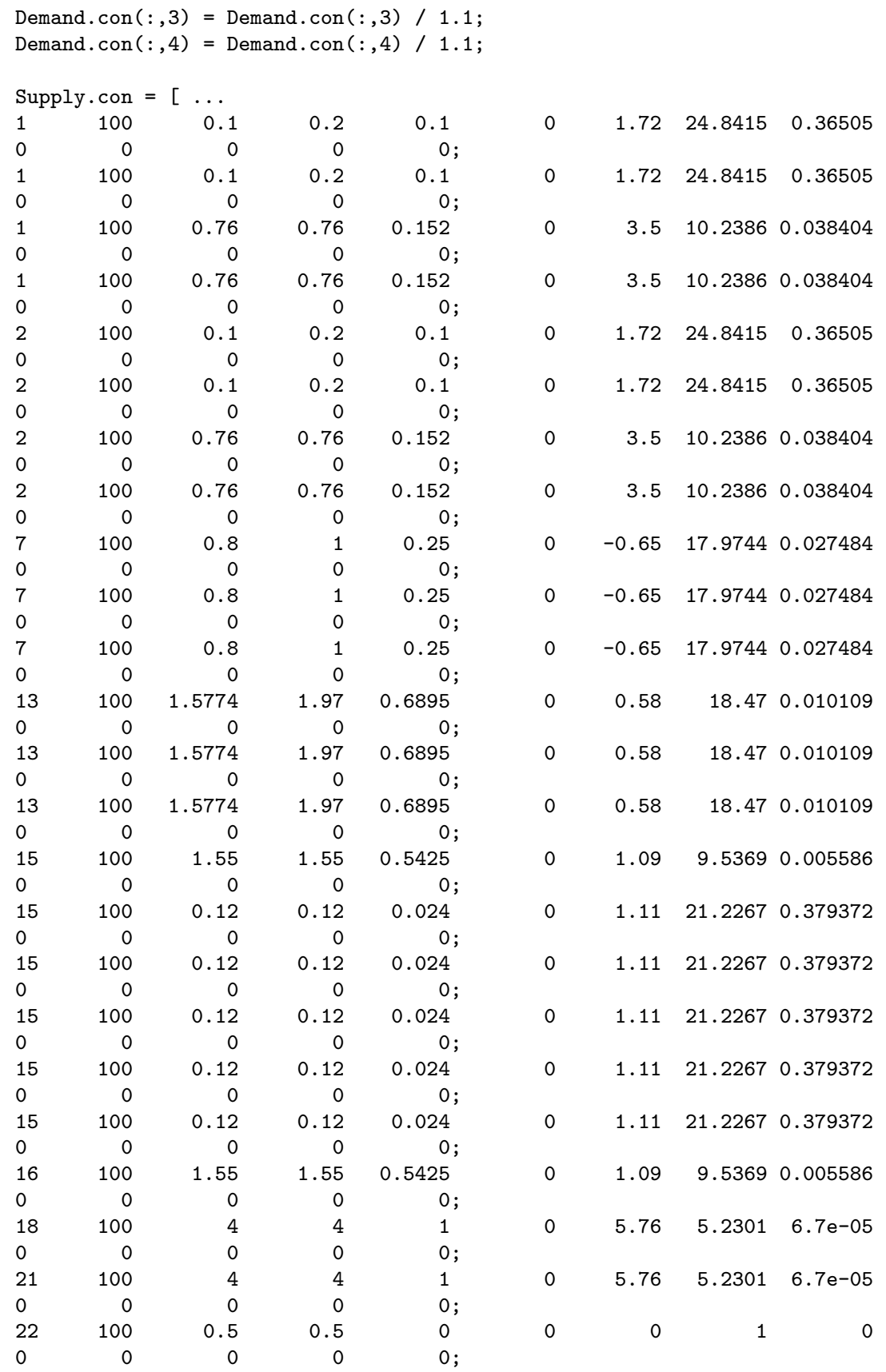




$\begin{array}{lrrrccccr}22 & 100 & 0.5 & 0.5 & 0 & 0 & 0 & 1 & 0 \\ 0 & 0 & 0 & 0 & 0 ; & & & & \\ 22 & 100 & 0.5 & 0.5 & 0 & 0 & 0 & 1 & 0 \\ 0 & 0 & 0 & 0 & 0 ; & & & & \\ 22 & 100 & 0.5 & 0.5 & 0 & 0 & 0 & 1 & 0 \\ 0 & 0 & 0 & 0 & 0 ; & & & & \\ 22 & 100 & 0.5 & 0.5 & 0 & 0 & 0 & 1 & 0 \\ 0 & 0 & 0 & 0 & 0 ; & & & & \\ 22 & 100 & 0.5 & 0.5 & 0 & 0 & 0 & 1 & \\ 0 & 0 & 0 & 0 & 0 ; & & & & \\ 23 & 100 & 1.55 & 1.55 & 0.5425 & 0 & 1.09 & 9.5369 & 0.005586 \\ 0 & 0 & 0 & 0 & 0 ; & & & & \\ 23 & 100 & 1.55 & 1.55 & 0.5425 & 0 & 1.09 & 9.5369 & 0.005586 \\ 0 & 0 & 0 & 0 & 0 ; & & & & \\ 23 & 100 & 3.5 & 3.5 & 1.4 & 0 & 1.64 & 9.5856 & 0.003152 \\ 0 & 0 & 0 & 0 & 0] ; & & & & \end{array}$

Varname.bus $=\{\ldots$

'Bus101'; 'Bus102'; 'Bus103'; 'Bus104'; 'Bus105';

'Bus106'; 'Bus107'; 'Bus108'; 'Bus109'; 'Bus110';

'Bus111'; 'Bus112'; 'Bus113'; 'Bus114'; 'Bus115';

'Bus116'; 'Bus117'; 'Bus118'; 'Bus119'; 'Bus120';

'Bus121'; 'Bus122'; 'Bus123'; 'Bus124'\}; 


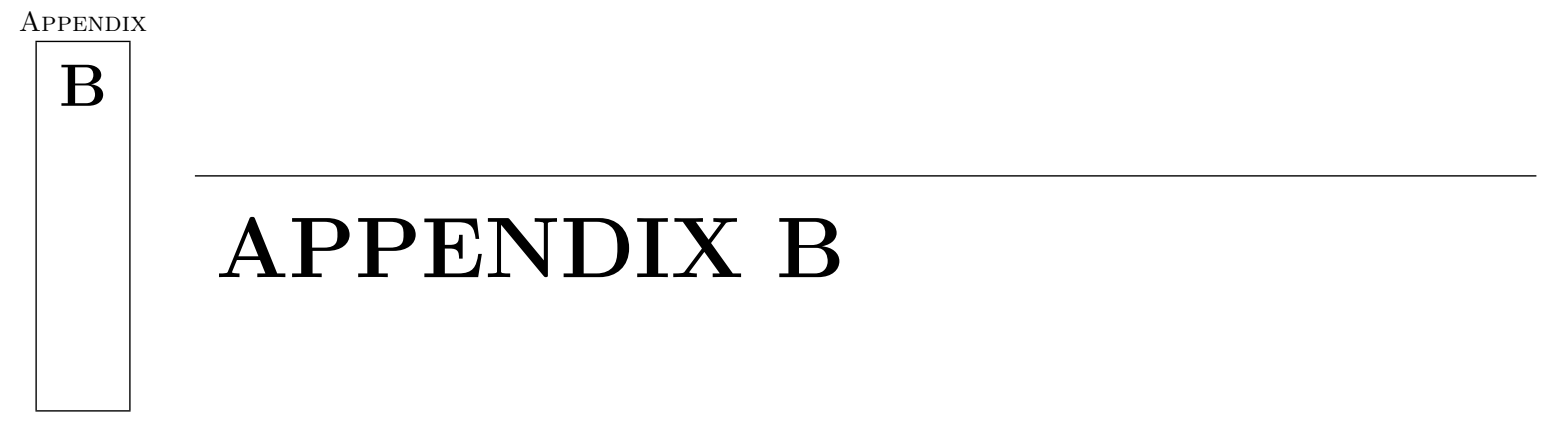

\section{B.1 Locational Marginal Prices}

\begin{tabular}{|c||c|c|}
\hline Load Buses & $\begin{array}{c}\text { Without SVC } \\
\text { LMP's }\end{array}$ & $\begin{array}{c}\text { With SVC } \\
\text { LMP's }\end{array}$ \\
\hline \hline Bus1 & 21.9626 & 22.0358 \\
\hline Bus2 & 21.9678 & 22.0408 \\
\hline Bus3 & 23.1134 & 23.3254 \\
\hline Bus4 & 22.3839 & 22.4983 \\
\hline Bus5 & 22.1066 & 22.1591 \\
\hline Bus6 & 22.2687 & 22.3127 \\
\hline Bus7 & 22 & 22 \\
\hline Bus8 & 22.4098 & 22.4493 \\
\hline Bus9 & 21.7195 & 21.7638 \\
\hline Bus10 & 21.7221 & 21.7411 \\
\hline Bus13 & 21.1604 & 21.1363 \\
\hline Bus14 & 21.2726 & 21.2471 \\
\hline Bus15 & 20.2639 & 20.2204 \\
\hline Bus16 & 20.3832 & 20.3417 \\
\hline Bus18 & 19.83 & 19.787 \\
\hline Bus19 & 20.5206 & 20.4843 \\
\hline Bus20 & 20.4832 & 20.4529 \\
\hline
\end{tabular}

Table B.1: LMPs with and without SVC for IEEE 24 Bus System (Load level : $3870 \mathrm{MW}$ ) 


\section{B.2 Hourly Peak Load in Percent of Daily Peak}

\begin{tabular}{|c|c|c|c|c|c|c|}
\hline Hour & $\begin{array}{c}\text { Winter weeks } \\
\text { Wkdy }\end{array}$ & Wknd & $\begin{array}{c}\text { Summer weeks } \\
\text { Wkdy }\end{array}$ & Wknd & $\begin{array}{l}\text { Spring/fall weeks } \\
\text { Wkdy }\end{array}$ & Wknd \\
\hline $12-1 \mathrm{am}$ & 67 & 78 & 64 & 74 & 63 & 75 \\
\hline $1-2 \mathrm{am}$ & 63 & 72 & 60 & 70 & 62 & 73 \\
\hline $2-3 \mathrm{am}$ & 59 & 66 & 56 & 65 & 58 & 66 \\
\hline $3-4 a m$ & 60 & 65 & 58 & 62 & 65 & 65 \\
\hline 4-5am & 74 & 66 & 64 & 62 & 72 & 68 \\
\hline $5-6 a m$ & 86 & 70 & 76 & 66 & 85 & 74 \\
\hline 6-7am & 95 & 80 & 87 & 81 & 95 & 83 \\
\hline $7-8 \mathrm{am}$ & 96 & 88 & 95 & 86 & 99 & 89 \\
\hline 8-9am & 96 & 90 & 99 & 91 & 100 & 92 \\
\hline 9-10am & 95 & 91 & 100 & 93 & 99 & 94 \\
\hline 10-11am & 95 & 90 & 99 & 93 & 93 & 91 \\
\hline 11am-noon & 95 & 88 & 100 & 92 & 92 & 90 \\
\hline $12-1 \mathrm{pm}$ & 93 & 87 & 100 & 91 & 90 & 90 \\
\hline $1-2 \mathrm{pm}$ & 94 & 87 & 97 & 91 & 88 & 86 \\
\hline $2-3 \mathrm{pm}$ & 99 & 91 & 96 & 92 & 90 & 85 \\
\hline $3-4 \mathrm{pm}$ & 100 & 100 & 96 & 94 & 92 & 88 \\
\hline $4-5 \mathrm{pm}$ & 100 & 99 & 93 & 95 & 96 & 92 \\
\hline $5-6 \mathrm{pm}$ & 96 & 97 & 92 & 95 & 98 & 100 \\
\hline $6-7 \mathrm{pm}$ & 91 & 94 & 92 & 100 & 96 & 97 \\
\hline $7-8 \mathrm{pm}$ & 83 & 92 & 93 & 93 & 90 & 95 \\
\hline 8-9pm & 73 & 87 & 87 & 88 & 80 & 90 \\
\hline $9-10 \mathrm{pm}$ & 63 & 81 & 72 & 80 & 70 & 85 \\
\hline
\end{tabular}

Table B.2: Hourly Peak Load in Percent of Daily Peak ([43] ) 


\section{References}

[1] Ajjarappu, V., Lee, B., "Bibliography on voltage stability," IEEE Transactions on Power Systems, Vol. 12, No. 1, February 1997.

[2] Ajjarappu, V., Christy, C., "The Continuation Power flow: A tool for steady state voltage stability analysis." IEEE Transactions on Power Systems, Vol. 7, No. 1, pp. 416-423, February 1992.

[3] Al-Hinai, Amer., "Voltage Collapse Prediction for Interconnected Power System," Master Thesis, West Virginia University, 2000.

[4] Arthit, S.Y., Mithulanathan, N., "Static voltage stability margin enhancement using STATCOM, TCSC and SSSC," IEEE/PES Transmission and Distribution Conference and Exhibition, pp. 1-6, August 2005.

[5] Billinton, R., Ghajar, R., "Evaluation of the marginal outage costs of generating systems for the purposes of spot pricing," IEEE Transaction on Power Systems, Vol. 9, pp. 68-75, February 1994.

[6] Cai, L.J., Erlich, I., "Optimal choice and allocation of FACTS devices in deregulated electricity market using genetic algorithms," IEEE/PES Power Systems Conference and Exposition, Vol. 1, pp. 201-207, October 2004.

[7] Cañizares, C.A., "Voltage Stability Assesment : Concepts Practices and Tools," IEEEPES Power System Stability Subcommittee Special Publication, SP101PSS, Technical Report,2002.

[8] Cañizares, C.A., Alvarado F.L., "Point of Collapse and Continuation Methods for Large AC/DC systems," IEEE Transactions on Power Systems, Vol. 8, No. 1, pp. 1-8, February 1993. 
[9] Cañizares, C.A., De Souza, A.Z.,Quintana, V.H., "Comparison of performance indices for detection of proximity of voltage collapse," IEEE Transactions on Power Systems, Vol. 11, No. 3, pp. 1441-1450, August 1996.

[10] Cañizares, C.A., Cavallo, C., Pozzi, M., Corsi, S., "Comparing Secondary Voltage Regulation and Shunt Compensation for Improving Voltage Stability and Transfer Capability in the Italian Power System," Electric Power Systems Research, Vol. 73, No. 1, pp. 67-76, January 2005.

[11] De Souza, A. C. Z., Cañizares, C.A., Quintana, V. H., "New techniques to speed up voltage collapse computations using tangent vectors," IEEE Transactions on Power Systems, Vol. 12, No. 3, pp. 1380-1387, August 1997.

[12] Cañizares, C.A., Faur Z.T., "Analysis of SVC and TCSC Controllers in Voltage Collapse Point of Collapse and Continuation Methods for Large AC/DC systems," IEEE Transactions on Power Systems, Vol. 8, No. 1, pp. 1-8, February 1993.

[13] Chang, C.S., Huang, J.S., "Optimal multi objective SVC planning for voltage stability enhancement," IEE Generation, Transmission and Distribution, Vol. 145, March 1998.

[14] Chow, J., "Power System Toolbox Version 2.0: Load Flow Tutorial and Functions ", Cherry Tree Scientific Software, RR-5 Colborne, Ontario K0K 1S0, 1991-1999.

[15] Chen, A. H. L., Nwankpa, C. O., Kawatny, H. G. and ming Yu, X., "Voltage Stability Toolbox: An Introduction and Implementation" , Proceedings of North American Power Symposium, MIT, 1996

[16] Chen, Y.L., "Weak Bus-Oriented optimal Multi-objective VAR Planning," IEEE Transactions on Power Systems, Vol. 11, No. 4, pp. 1885-1890, November 1996.

[17] Conejo, A., Gomez, T., De La Fuente, I.J., "Pilot bus selection for secondary votlage control," ETEP, Vol. 3, No. 5, pp. 359-366, September-October 1993.

[18] Conejo, A., Aguilar, M., "A Nonlinear approach to the selection of pilot buses for secondary votlage control," Power System Control and Management Conference, No. 421, pp. 16-18, April 1996.

[19] Conejo, A., De La Fuente, I.J., Goransson, S., "Comparison of alternative algorithms to select pilot buses for secondary voltage control in electric power network," IEEE Transactions on Power Systems, Vol.3 , pp. 940-943, April 1994.

[20] De Souza, A. C. Z., Cañizares, C.A., Quintana, V. H., 'Critical bus and point of collapse determination using tangent vectors," Proceedings of NAPS, M.I.T, pp. 329-333, Novemeber 1996.

[21] Gao, B., Morison, G., Kundur, P., "Voltage Stability Evaluation Using Modal Analysis," IEEE Transactions on Power Systems, Vol. 7, No. 4, pp. 1423-1543, November 1992.

[22] Greene, S., Dobson, I., Alvarado, F. L., "Sensitivity of the loading margin to votlage collapse with respect to arbitrary parameters," IEEE Transactions on Power Systems, Vol. 12, No. 1, pp. 262-272, February 1997

[23] Guo, C., Crow, M. L., Chowdhury, B. H., Acar, L., "A New approach to secondary voltage control," IEEE PES Summer Meeting, Chicago, IL, July 2002.

[24] Habur, K., and Oleary, D., "A FACTS - flexiable AC transmission systems, For cost effective and reliable transmission of electrical energy," Available Online : http://www.siemenstd.com/TransSys/pdf/CostEffectiveReliabTrans.pdf 
[25] IEEE, " The New IEEE Standard Dictionary of Electrical and Electronic Terms, 5th Edition ", 1993

[26] James, H.W., McCalley, D., Vittal, Vijay., "Risk based Voltage Security Assessment," IEEE Transactions on Power Systems, Vol. 15, No. 4, November 2000.

[27] Kessel. P., Glavitsch, H., "Estimating the voltage stability of a power system," IEEE Transactions on Power Systems, Vol. 3, pp. 346 - 354, 1986

[28] Kristina, H., Eto, J.H., "Understanding the cost of power interruptions to US electricity customers," Ernest Orlando Lawrence Berkeley National Laboratory, Environmental Energy Technologies Division, September 2004

[29] Kundur, P., Power System Stability and Control, New York : McGraw-Hill, 1994.

[30] Kundur, P., Paserba, J., Ajjarappu, V., et.al, "Definition and classification of power system stability IEEE/CIGRE joint task force on stability terms and definitions," IEEE Transactions on Power Systems, Vol. 19, No. 3, pp. 1387-1401, August 2004.

[31] Lind, Douglas., Marchal, William., Mason., "Statistical Techniques in Business and Economics " , Eleventh Edition, McGraw-Hill College, October 2001.

[32] Lagonotte, P., Sabonnadiere, J.C., Leost, J.Y., Paul, J.P., "Structural analysis of the electrical system : application to the secondary voltage control in France," IEEE Transactions on Power Systems, Vol. 2, pp. 479-484, 1989.

[33] Lassete, H Robert., Wang, Ronghai., "The Impact of Generation Mix on Placement of Static Var Compensators," IEEE Transactions on Power Systems, Vol. 11, No. 4, pp. 1885-1890, November 1996.

[34] Lof, P. A., Smed, T., Andersson, G., Hill, D. J., "Fast calculation of voltage stability index," IEEE Transactions on Power Systems, Vol. 7, No. 1, pp. 54-64, Februaray 1992

[35] Lof, P. A., Anderson, G., Hill, D. J., "Voltage Stability Indices For Stressed Power System," IEEE Transactions on Power Systems, Vol. 8, pp. 326-335, Februaray 1993

[36] Mahseredjian, J. and Alvarado, F., "Creating an Electromagnetic Transient Program in Matlab: MatEMTP ", IEEE Transactions on Power Delivery, 12(1), pp. 380 - 388, 1997

[37] Mansour, Y., Xu, W., Alverado, F., Rinzin, C., "SVC Placement Using Critical Modes of Voltage Instability," IEEE Transactions on Power Systems, Vol. 9, No. 2, pp. 757-763, May 1994.

[38] Milano, Federico., PSAT : A Matlab based Power System Analysis Toolbox[Online] Available : http://www.power.uwaterloo.ca/ fmilano.

[39] Ming, Ni., McCalley, D., Vittal, Vijay., "On line Risk- Based Security Assessment," IEEE Transactions on Power Systems, Vol. 18, No. 1, February 2003.

[40] Morrison, G. K., Gao, B., Kundur, P, "Voltage stability analysis using static and dynamic approaches," IEEE Transactions on Power Systems, Vol. 8, No. 3, pp. 1159-1171, August 1993

[41] NERC., "Examples of major bulk electric system power outages," Online: www.nerc.com/ filez/blackout.html

[42] UWEE., " Power system test case archive ", Online: http://www.ee.washington.edu/research/pstca/ 
[43] Reliability Test System Task Force of the Application of Probability Methods subcommittee, "The IEEE Reliability Test System - 1996," IEEE Transactions on Power Systems, Vol. 14, No.3, pp. 1010-1020, August 1999

[44] @RISK., "Advanced Risk Analysis for spreadsheets, "Online : www.palisade.com

[45] Sancha, J.L., Fernandez, J.L., Cortes, A., "Secondary Voltage Control : Analysis Solutions and Simulation results for the spanish transmission system," IEEE Transactions on Power Systems, Vol. 11, No. 2, pp. 630-638, May 1996.

[46] Chen, H., Cañizares, C.A., Singh, A., "Transaction security cost analysis by takerisk strategy," Proceedings of Power Systems Computation Conference (PSCC), Sevilla, Spain, June 2002. [Online] Available: http://www.pscc02.org/

[47] Seydel, R., Practical Bifurcation and Stability Analysis - From Equilibrium to Chaos, Springer-Verlag, Newyork, second edition, 1994.

[48] Schoder, K., Feliachi, A. and Hasanovic, A., "PAT: A Power Analysis Toolbox for Matlab/Simulink", IEEE Transactions on Power Systems, 18(1), 2003.

[49] Stancovic, A., Ilic-Spong, M., Maratukulam, D., "Recent results in secondary voltage control of power systems, "IEEE Transaction on Power Systems, Vol. 6, No. 1, pp. 94-101, February 1991

[50] Strogatz, H. Steven., "Nonlinear dynamics and chaos: With applications to physics, biology, chemistry, and engineering ", Reading, MA: Perseus Books, Cambridge MA, 1994.

[51] Sybille, G., "SimPowerSystems User's Guide, Version 4, published under sublicense from Hydro-Quebec, and The MathWorks, Inc.", Available at http://www.mathworks.com.

[52] Taylor, C.W., Power System Voltage Stability, New York : McGraw-Hill, 1994.

[53] Thukaram, D., Lomi, A., "Selection of Static Var Compensator location and dsize for system voltage stability improvement," Journal of Electric Power Systems Research, Vol. 54, pp. 139-150, 2000.

[54] Tiranuchit. A., Thomas, R. J., "A posturing strategy against voltage instability in electric power systems," IEEE Transactions on Power Systems, Vol. 3, No. 1, pp. 87-93, February 1988

[55] Tung, Au., Thomas, Au., Engineering Economics for capital investment analysis, $2^{\text {nd }}$ Ed., Prentice - Hall, NJ.

[56] Van Cutsem, T., Vournas, C., Voltage Stability of Electric Power Systems, Norwell, MA : Kluwer, 1994.

[57] Van Cutsem, T., "Voltage instability : Phenomenon, counter measures and analysis methods," IEEE Proceedings, Vol. 88, pp. 208-227, 2000.

[58] Van Cutsem, T., "A method to compute reactive power margins with respect to voltage collapse," IEEE Transactions on Power Systems, Vol. 6, No. 1, pp. 145-156, February 1991

[59] Vournas, C. D., Potamianakis, E. G., Moors, C. and Cutsem, T. V., " An Educational Simulation Tool for Power System Control and Stability," IEEE Transactions on Power Systems 19(1), 48-55, 2004. 
[60] Warren, King., Cañizares, Claudio., Chen, Hong., "A Probabilistic approach to evaluate security costs and levels in competitive electricity markets," Bulk Power System Dynamics and Control VI,, Cortina DAmpezzo, Italy, August 22- 27, 2004.

[61] Wenyuan, Li., Risk assessment of power systems, models, methods and applications, Wiley-Interscience, 2005.

[62] Yuan-Lin, Chen., Chi-Wei, Chang., Chun-Chang Liu., "Efficient methods for identifying weak nodes in electric power networks," IEE Proceedings Generation Transmission and Distribution, Vol. 142, No. 3, May 1995.

[63] Zimmerman, R. D. and Gan, D., " Matpower, Documentation for version 2 ", Power system engineering research center, Cornell University, 1997. Available at http://www.pserc.cornell.edu/matpower/matpower.html 